\title{
Ground-Based Smoke Sampling Techniques Training Course and Collaborative Local Smoke Sampling in Saudi Arabia
}

Nelson Bryner

Building and Fire Research Laboratory

and

Bruce A. Benner, Jr.

Chemical Science and Technology Laboratory National Institute of Standards and Technology

Gaithersburg, MD 20899

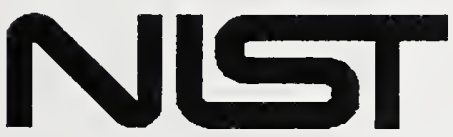

United States Department of Commerce

-echnology Administration 'ational Institute of Standards and Technology 



\section{Ground-Based Smoke Sampling Techniques Training Course and Collaborative Local Smoke Sampling in Saudi Arabia}

Nelson Bryner

Building and Fire Research Laboratory

and

Bruce A. Benner, Jr.

Chemical Science and Technology Laboratory

National Institute of Standards and Technology

Gaithersburg, MD 20899

August 1993

Issued January 1994

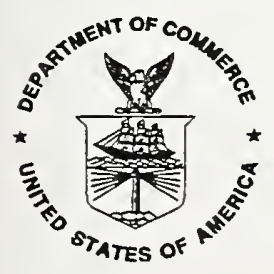

\section{U.S. Department of Commerce}

Ronald H. Brown, Secretary

Technology Administration

Mary L. Good, Under Secretary for Technology

National Institute of Standards and Technology

Arati Prabhakar, Director 


\begin{abstract}
Smoke and gaseous emissions such as those generated by multiple oil-well fires can significantly impact the health of the local population. To assess the immediate risk to public health, the chemical and physical properties of the smoke and gaseous emissions must be quickly characterized. Local sampling via portable gas analyzers, filters and pumps, and particle sizing instrumentation provides real-time characterization of pollutant levels.

The Ground-Based Smoke Sampling Techniques Training Course and Collaborative Local Smoke Sampling project was initiated between the Ministry of Defence and Aviation (Kingdom of Saudi Arabia) and the National Institute of Standards and Technology (USA) to train Saudi medical personnel. A team of Saudi and NIST researchers assembled in December 1992 to collect smoke and gas samples in Saudi Arabia for analysis. Sample analysis included determination of polycyclic aromatic hydrocarbons (PAHs), $\mathrm{CO}, \mathrm{CO}_{2}$ and total particulate concentrations. Split-sample analysis was conducted with some samples being analyzed in Saudi Arabia and other samples being returned to NIST for more specialized analysis, including micro-Raman, laser micro-probe, and environmental scanning electron microscopy.

These analyses provide a snapshot of the physical and chemical properties of the aerosols sampled in Saudi Arabia, but due to the very limited number of samples, they do not provide a reasonable basis for estimating the short- or long-term health risk due to exposure to smoke and gaseous emissions. Concentrations of PAHs measured in the samples were about the same order of magnitude as samples collected in Roanoke, Virginia, but 3 to 10 times lower than samples from Boise, Idaho. While these results do suggest significant levels of PAH and dust particulates, the data set-is very limited and a program involving the collection and analysis of air samples in or around Saudi Arabian urban areas would provide valuable data for determining current airborne $\mathrm{PAH}$ concentrations as well as for devising air pollution control strategies for the future. The appearance of significant concentrations of PAHs in what was expected to provide background levels indicates that a more comprehensive sampling program should be implemented to characterize the levels and the distribution of PAHs throughout the Kingdom.
\end{abstract}




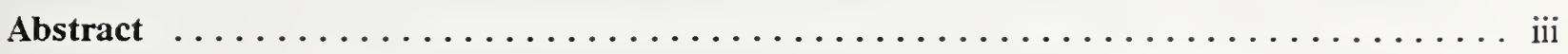

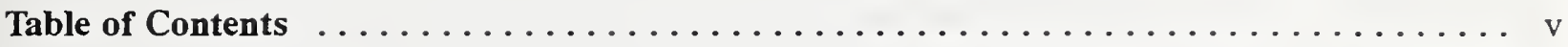

List of Figures $\ldots \ldots \ldots \ldots \ldots \ldots \ldots \ldots \ldots \ldots \ldots \ldots \ldots \ldots \ldots \ldots \ldots \ldots \ldots \ldots \ldots \ldots$

List of Tables $\ldots \ldots \ldots \ldots \ldots \ldots \ldots \ldots \ldots \ldots \ldots \ldots \ldots \ldots \ldots \ldots$ viii

1.0 Introduction $\ldots \ldots \ldots \ldots \ldots \ldots \ldots \ldots \ldots \ldots \ldots \ldots \ldots \ldots \ldots \ldots \ldots \ldots \ldots \ldots$

2.0 Ground-Based Smoke Sampling Training Course $\ldots \ldots \ldots \ldots \ldots \ldots \ldots \ldots \ldots$

2.1 Total Mass Concentration and Inhalable Fraction of Particulates ......... 2

2.2 Gas Analyzers and Gas Sampling ...................... 3

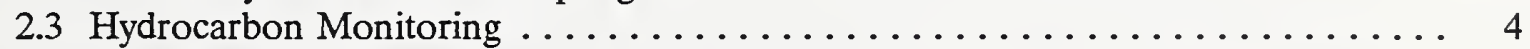

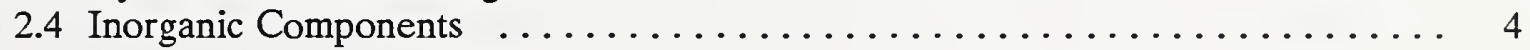

3.0 Collaborative Local Smoke Sampling in Saudi Arabia $\ldots \ldots \ldots \ldots \ldots \ldots \ldots \ldots$

3.1 Riyadh Armed Forces Military Hospital .................. 5

3.2 Collaborative Sampling - Field Work .................... 6

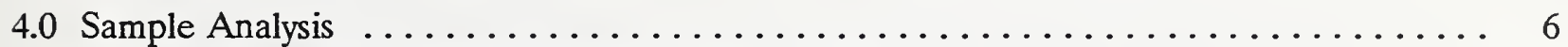

4.1 Polycyclic Aromatic Hydrocarbons Analysis $\ldots \ldots \ldots \ldots \ldots \ldots \ldots \ldots \ldots$ Bruce A. Benner, Jr.

4.2 Laser Microprobe Mass Spectrometry .................. 20 Robert A. Fletcher

4.3 Micro-Raman Analysis . . . . . . . . . . . . . . . . . . . 24 Edgar S. Etz

4.4 Environmental Scanning Electron Microscopy $\ldots \ldots \ldots \ldots \ldots \ldots \ldots \ldots$ Scott A. Wight

4.5 Thermal-Optical Analysis For Organic/Elemental Carbon $\ldots \ldots \ldots \ldots \ldots 2$ Robert A. Cary

4.6 Gas Chromatographic Analysis of Grab-Bag Samples .............. 57 James E. Brown

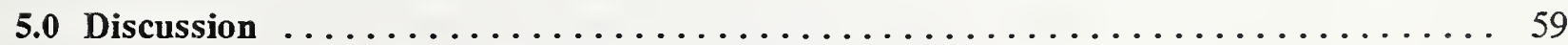

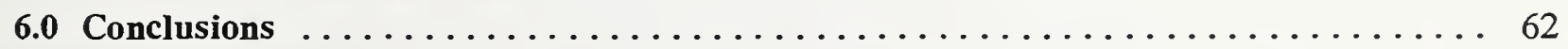

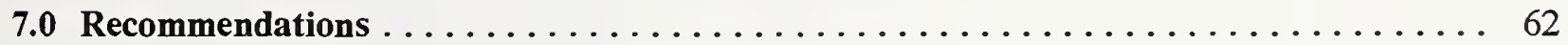

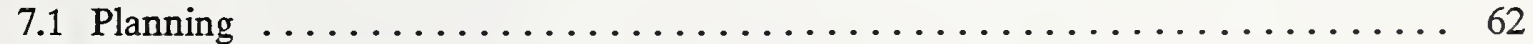

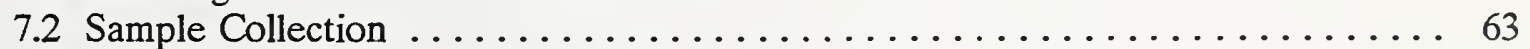

7.3 Sample Analysis . . . . . . . . . . . . . . . . . . . 63 


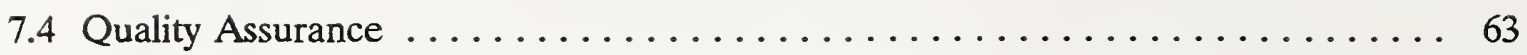

7.5 Split Sample Analysis . . . . . . . . . . . . . . . . . . . . 63

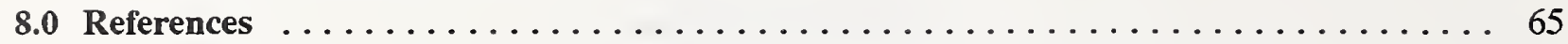

APPENDIX A. Ground-Based Smoke Sampling Course Program ............. 67

APPENDIX B. Reconstructed Selected-Ion Chromatograms of Sorbent Tube Sample XAD $-01 \ldots \ldots \ldots \ldots \ldots \ldots \ldots \ldots \ldots \ldots \ldots \ldots$

APPENDIX C. Reconstructed Selected-Ion Chromatograms of HiVol Filter Sample PM10-01 ................... 75

APPENDIX D. Reconstructed Selected-Ion Chromatograms of Teflon Filter PAH-01 


\section{List of Figures}

Figure 1. Optical micrograph of fine particulate material taken from stage MA-02-8 viewed

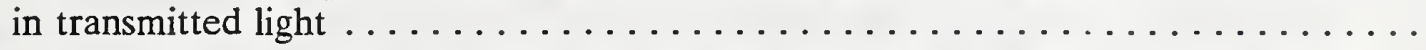

Figure 2. Positive ion mass spectrum that results from averaging 9 spectra of particulate

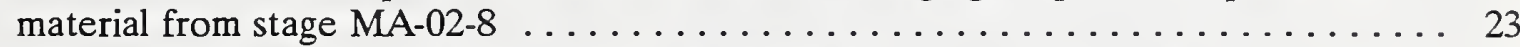

Figure 3. Expanded version of spectrum shown in Figure $2 \ldots \ldots \ldots \ldots \ldots \ldots \ldots \ldots$

Figure 4. Single typical negative ion mass spectrum of MA-02-8 material . . . . . . . . . 27

Figure 5. Expanded section of a positive ion spectrum that is the average of 8 spectra of MA-

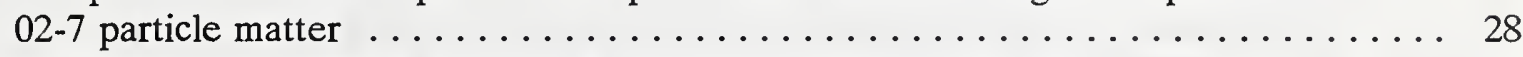

Figure 6. Single typical negative ion mass spectrum of MA-02-7 material. . . . . . . . . . . . 29

Figure 7. Positive ion mass spectrum that results from averaging 8 spectra produced from particles attached to quartz fiber filter material . . . . . . . . . . . . . .

Figure 8. Single positive ion mass spectrum of a particle attached to the quartz fiber illustrating the isotopic pattern found for lead $\ldots \ldots \ldots \ldots \ldots \ldots \ldots \ldots \ldots$

Figure 9. Single positive ion mass spectrum of a particle in Figure 8 shown with expanded scale illustrating the isotopic pattern found for lead $\ldots \ldots \ldots \ldots \ldots \ldots \ldots$

Figure 10. Raman microprobe spectrum of a single particle (size $\approx 8 \mu \mathrm{m}$ ) of the mineral

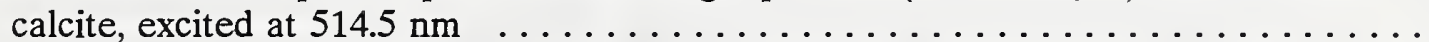

Figure 11. Raman microprobe spectrum of a particle (size $\approx 13 \mu \mathrm{m}$ ) of natural quartz,

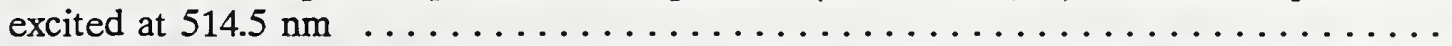

Figure 12. Micro-Raman spectrum of a microcrystal (size $\approx 10 \mu \mathrm{m}$ ) of the high explosive

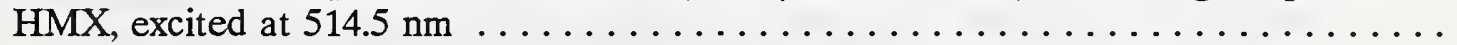

Figure 13. Representative micro-Raman spectrum of a particle agglomerate typical of the material collected on Stage MA-01-6. Analyzed on the stainless-steel substrate, with

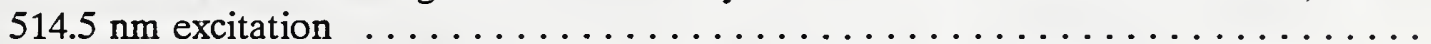

Figure 14. Representative micro-Raman spectrum of a particle agglomerate typical of the material collected on Stage MA-01-8. Analyzed on the stainless-steel substrate, with $514.5 \mathrm{~nm}$ excitation.

Figure 15. Representative micro-Raman spectrum of a typical particle agglomerate on Stage MA-01-6. Analyzed on the stainless-steel substrate with $647.1 \mathrm{~nm}$ excitation .....

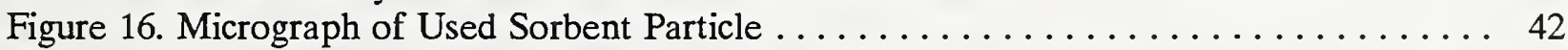

Figure 17. Micrograph of Unused Sorbent Particle . . . . . . . . . . . . . . . 43

Figure 18. Micrograph Showing Exterior Detail of Used Sorbent Particle . . . . . . . . . . . 44

Figure 19. Micrograph Showing Exterior Detail of Unused Sorbent Particle . . . . . . . . . 45

Figure 20. Loading of Particles on Glass Fiber Filter . . . . . . . . . . . . . . 46

Figure 21. EDS Background of a Quartz Fiber Filter . . . . . . . . . . . . . . . . 47

Figure 22. Typical Lead/Bromine Containing Particle EDS Spectrum . . . . . . . . . . . . 48

Figure 23. Typical Barium Containing Particle EDS Spectrum . . . . . . . . . . . . . . 49

Figure 24. Backscattered Mode Search of Fiber Mat to Identify Particles . . . . . . . . . . 50

Figure 25. Low Magnification of Stainless Steel Substrate . . . . . . . . . . . . . . 51

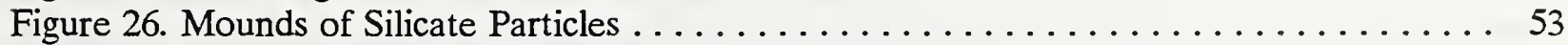

Figure 27. Titanium Containing Particle $\ldots \ldots \ldots \ldots \ldots \ldots \ldots \ldots \ldots \ldots \ldots \ldots \ldots \ldots$

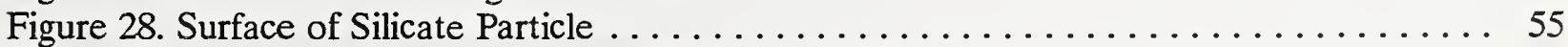

Figure 29. EDS of Stainless Steel Substrate $\ldots \ldots \ldots \ldots \ldots \ldots \ldots \ldots \ldots \ldots \ldots \ldots$ 


\section{List of Tables}

Table 1. PAH Teflon Filter Samples $\ldots \ldots \ldots \ldots \ldots \ldots \ldots \ldots \ldots \ldots \ldots \ldots \ldots \ldots \ldots \ldots \ldots \ldots$

Table 2. PAH Sorbent (XAD-2) Tube Samples $\ldots \ldots \ldots \ldots \ldots \ldots \ldots \ldots \ldots \ldots \ldots \ldots \ldots$

Table 3. Total Particulate (TP) Filter Samples $\ldots \ldots \ldots \ldots \ldots \ldots \ldots \ldots \ldots \ldots \ldots . . \ldots \ldots \ldots \ldots$

Table 4. Inhalable Particulate (IP) Filter Samples ...................... 10

Table 5. Grab-Bag, Electron Microscopy, and Cascade Impactor Samples ............. 11

Table 6. Mass Spectrometric Selected Ion-Monitoring Program for Determining PAHs in

Extracts of Saudi Air Samples ........................ 14

Table 7. Measurement of PAHs in Standard Reference Material 1649 ............. 15

Table 8. PAH Contamination in XAD Laboratory and Field Blanks ............. 16

Table 9. Concentration of PAHs Measured in XAD Samples ................ 17

Table 10. Concentrations and Detection Limits of PAHs Measured in Teflon Filter

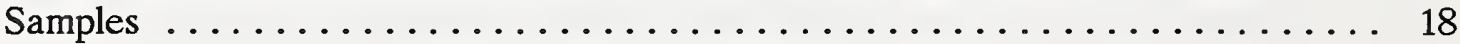

Table 11. Concentrations and Detection Limits of PAHs Measured in PM-10 Filter

Samples ................................. 19

Table 12. Particles Analyzed from Mylar Substrate of Marple Cascade Impactor ........ 26

Table 13. Organic/Elemental Carbon Analysis ....................... 58

Table 14. Gas Chromatographic Analysis of Grab-Bag Samples ................ 60

Table B-1. Peak Identifications for Reconstructed Selected-Ion Chromatograms of Sorbent Tube XAD-01.......................... 74

Table C-1. Peak Identifications for Reconstructed Selected-Ion Chromatograms of

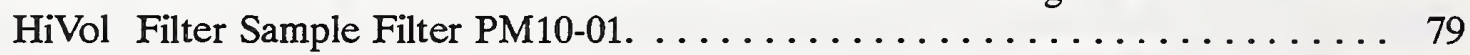

Table D-1. Peak Identifications for Reconstructed Selected-Ion Chromatograms of Teflon Filter PAH $-01 . \ldots \ldots \ldots \ldots \ldots \ldots \ldots \ldots \ldots \ldots \ldots \ldots \ldots \ldots \ldots \ldots \ldots$ 


\subsection{Introduction}

Large quantities of smoke and gaseous emissions such as those generated by multiple oil-well fires can significantly impact the health of the local population. In order to assess the immediate risk to public health, it is important to characterize quickly the chemical and physical properties of the smoke or gas plume. Local sampling via portable gas analyzers, filters and pumps, and particle sizing instrumentation can provide real-time characterization of pollutant levels which are affecting a small and localized population. Short-term exposure to high levels of smoke and gaseous emissions often exacerbate certain medical conditions, such as asthma or emphysema. Exposure to high levels of smoke and other airborne particulates can cause pneumoconiosis which reduces the lungs' efficiency [1]. Other combustion products, such as sulfur dioxide and nitrogen dioxide, are lung irritants; and pulmonary edema can result from exposure to high concentrations [2]. Relatively short-term exposure, 1 to 5 minutes, to carbon monoxide [3,4] or carbon dioxide [5,6] at $1.5 \%$ and $15 \%$ levels, respectively, can lead to unconsciousness and death via asphyxiation. Portable gas analyzers and other particulate sampling instrumentation allow the concentration of aerosol particulates and gases to be quickly determined. Once the smoke or gaseous emissions have been characterized, knowledgeable medical specialists can recommend appropriate action, such as remaining indoors, wearing filter masks, and/or evacuating the affected area.

Local monitoring of smoke and gas concentrations is critical to the real-time assessment of acute exposure of local population groups, but meteorological modelling and source characterization are usually necessary to provide health warnings over longer time frames for larger areas. Routine sampling and monitoring programs are necessary for evaluating longer term exposures. Both acute and chronic exposures need to be quantified to assess completely the health impact of the smoke and combustion gases.

In 1991, during the oil-well fires in Kuwait, the Ministry of Defence and Aviation (Kingdom of Saudi Arabia) decided to start training some of their medical personnel in the operation of portable gas analyzers and particulate sampling instrumentation. This training would allow the Saudi medical personnel to begin local sampling of smoke and gases in Saudi Arabia as the oil wells burned in Kuwait. Local monitoring of smoke and gas concentrations was the just the first step in collecting some of the data necessary for qualified medical specialists to assess the risk to the local population. Since the National Institute of Standards and Technology (NIST) had an ongoing program to study the smoke and gaseous emissions from crude oil fires [7 - 13], the Ministry of Defence and Aviation (MODA) proposed that NIST provide the training for Saudi personnel via a Ground-Based Smoke Sampling Techniques Training Course and Collaborative Local Smoke Sampling in Saudi Arabia project. The two week training course occurred at NIST in August 1992 and involved lectures and demonstrations of gravimetric measurements, light scattering cells, portable size classifiers, battery-powered gas analyzers, and filter sampling trains. NIST's Organic Analytical Research Division demonstrated sample preparation and illustrated the use of gas and liquid chromatographic instrumentation.

A team of MODA and NIST researchers assembled in December 1992 to collect smoke, and gas samples in Saudi Arabia for analysis. Analysis of smoke and gas samples included determination of polycyclic aromatic hydrocarbons (PAHs), $\mathrm{CO}, \mathrm{CO}_{2}$ and total particulate concentrations. Splitsample analysis was conducted with some samples being analyzed locally and other samples being returned to NIST for more specialized analysis, including micro-Raman, laser micro-probe, and environmental scanning electron microscopy. The performance of the portable analyzers in the field was verified by comparing the concentrations measured in the field with the samples analyzed in the laboratory. 


\subsection{Ground-Based Smoke Sampling Training Course}

This course was designed to introduce MODA medical personnel to techniques for groundbased monitoring of acute episodes of smoke and gaseous emissions. Topics presented included total particulate concentrations, inhalable particulates, gas analyzers, gas sampling, hydrocarbon monitoring, metals and inorganic compound detection, and analytical chemistry. A more detailed list of topics is presented in Appendix A.

\subsection{Total Mass Concentration and Inhalable Fraction of Particulates}

In estimating the impact of smoke on a local area, it is important to determine the total mass concentration of particulates suspended in the air. In the field, total mass concentration of aerosols can be measured using light-scattering instruments or gravimetric techniques. Real-time concentrations of total particulate material are quickly obtained using portable light-scattering cells. Light-scattering cells, such as the Mini-Ram*, are battery powered and provide digital or analog output of real-time total aerosol concentrations. The smoke passes through a light cell where the intensity of scattered light is monitored. The scattering intensity increases as the concentration of the particulates increases. Scattering cells can be calibrated for specific concentration ranges, although the cells are unable to differentiate between smoke particulates and sand or soil particles. While the light-scattering cells can provide immediate measurements of particle concentrations, the somewhat slower gravimetric method can yield more accurate data and also provides a filter sample for additional analyses.

The gravimetric method of determining the total particulate concentration involves using a portable battery-powered pump to pull a known volume of smoke through a pre-weighed filter. The filter sample is typically returned to a laboratory and re-weighed to determine the total particulate mass. Dividing the particulate mass by the total volume sampled provides the total particulate concentration. The gravimetric filter method collects aerosol particulates over a wide range of particle sizes and concentration while the light scattering cells typically are typically optimized for a specific (usually relatively narrow) size and concentration range. Thus the gravimetric techniques can provide more accurate total particulate concentrations, but can not provide them in real-time. Gravimetric techniques can not differentiate between background soil aerosols and fire generated smoke so other more specialized analyses are needed to determine whether the particulates originated in the soil or from fuel combustion.

If the total mass concentration of particulates suggests that there might be enough particulates to be a significant hazard to the population, then it becomes more important to determine the inhalable fraction of the particulates. The particulate size is important because the smaller the particle the further the particle typically penetrates into the human respiratory system. Relatively large particles, approximately 7 to $10 \mu \mathrm{m}$ in diameter, may be filtered out by the nose or throat, while

\footnotetext{
* Certain commercial equipment, instruments, or materials are identified in this report to specify adequately the experimental procedure. Such identification does not imply recommendation or endorsement by the National Institute of Standards and Technology, nor does it imply that the materials or equipment identified are necessarily the best available for the purpose.
} 
smaller particles, about 0.4 to $1.1 \mu \mathrm{m}$ in diameter, may travel through the bronchi and reach the alveolar spaces of the lung. The inhalable particulates, usually less than $10 \mu \mathrm{m}$ in diameter, can be monitored by cascade impactors or ambient samplers equipped with a size selective sampling head.

Cascade impactors are available in either completely portable models, such as the Marple Personal Sampler or less portable versions, including the Andersen 2000 Impactor. The less portable versions usually require larger pumps which are more difficult to power with batteries. A cascade impactor aerodynamically classifies the smoke aerosol as the particulates are pulled through a series of stages. As the aerosol cascades through the stages the larger particulates are inertially impacted onto the early stages while smaller particles continue to be drawn through additional stages. As the carrier gas is accelerated between each stage, the largest of the remaining particles are impacted on subsequent stages, gradually distributing the aerosol particles on the stages as a function of aerodynamic particle size. Typically, each impactor stage simulates how far an aerosol particle could travel into the respiratory system. For instance, particulates captured on the first stage may be filtered out by the mouth or nose while particles collected on the eighth stage may penetrate deep into the lung. As with the gravimetric filter measurements, the individual stages of a cascade impactor must be weighed before and after sample collection. Since weighing the individual stages in the field is difficult, the stages are usually weighed before going into the field and after returning from the field. After weighing each stage, it is placed into a sample carriers which can be sealed. Once in the field, the stages are unpacked, loaded into the impactor, and the samples collected. The impactors are then unloaded, resealed, and placed on dry ice for transport to the laboratory.

Ambient samplers, such as the PM-10 HiVol, are equipped with a sampling head which allows only inhalable particles to be collected on the filter. Since ambient samplers are designed to monitor relatively low concentrations of aerosol particles, the equipment must sample very large volumes of air. While the personal cascade impactor samples 1 to 2 liters per minute, the PM-10 HiVol collects 1000 to 1500 liters per minute. The PM-10 HiVol sampler is relatively large and not very portable, but it does allow routine monitoring of inhalable aerosol mass concentrations. PM-10s are often used to establish background or ambient aerosol levels. The PM-10s are also used to monitor emission sources to help insure compliance with aerosol emission regulations.

\subsection{Gas Analyzers and Gas Sampling}

In estimating the impact of gaseous emissions on a local area, it is also important to determine the chemical composition of the smoke plume or gas cloud. A limited number of gas species can be identified in real-time via portable battery-powered analyzers utilizing electrochemical sensors. The species which can be monitored include sulfur dioxide $\left(\mathrm{SO}_{2}\right)$, nitrogen dioxide $\left(\mathrm{NO}_{2}\right)$, hydrogen sulfide $\left(\mathrm{H}_{2} \mathrm{~S}\right)$, carbon monoxide $(\mathrm{CO})$ and carbon dioxide $\left(\mathrm{CO}_{2}\right)$. Multi-gas analyzers incorporate small sample pumps while single-gas instruments typically use diffusion cells.

Additional gases can be identified by collecting a sample in a container and returning the sample to a laboratory for analysis by gas chromatography. The container may be simply an evacuated cylinder or may be a small glass tube filled with sorbent material designed to select specific species. Evacuated sample containers range from electro-passivated stainless steel cylinders with calibrated flow controllers to Tedlar plastic bags with off/on valves. Sorbent materials such as XAD-2, silica gel, Tenax, or coconut charcoal will preferentially adsorb or absorb specific species. A portable pump can be used to collect or "grab" samples to fill Tedlar bags with 3 - 5 liters of smoke and/or combustion gases. Evacuated stainless steel containers, such as Summa cylinders, can collect samples with or without a pump. The portable pump is also used to pull a known volume of aerosol through 
the sorbent tubes. Sample bags, Summa cylinders, or sorbent tubes are returned to a laboratory for subsequent analysis with gas chromatography. These "grab" samples, where a sample is collected in the field but returned to the laboratory, offer more accurate measurements, but do not provide the real-time data of a portable gas analyzer.

\subsection{Hydrocarbon Monitoring}

Another component of the smoke emissions from many combustion sources is the hydrocarbon fraction. This portion of the emissions can range from unburned fuel, usually lighter hydrocarbons, volatile organic compounds (VOCs), to polycyclic aromatic hydrocarbons (PAHs). Since some of the PAHs are thought to be mutagenic, it is especially important to identify and quantify these compounds. Unfortunately, portable hydrocarbon analyzers can not detect or discriminate these compounds rapidly enough to provide real-time concentrations. A limited number of the lighter hydrocarbons, such as methane or propane, can be detected in real-time using portable analyzers. Hydrocarbon samples can be collected by using small portable pumps to fill evacuated stainless steel cylinders or Tedlar plastic bags, but the higher molecular weight compounds may condense on the walls of the container. Careful warming of the containers during the analysis procedure can re-volatilize some of the compounds. Unfortunately, the condensation of the heavier hydrocarbons introduces additional uncertainty into the concentration measurements.

An alternative analytical technique for both the light and heavy hydrocarbons is to use a portable pump to pull a known volume of smoke through a pre-weighed filter and/or sorbent tube which is returned to a specialized laboratory for the measurement of PAHs and VOCs. For either grab samples or sorbent tubes, the specialized techniques which are often used to determine hydrocarbon concentrations include gas chromatography and liquid chromatography. Operators with the background and training necessary for these specialized analysis techniques can usually be found at large hospitals, universities, or private and government research centers.

\subsection{Inorganic Components}

Another component of a smoke plume can be various inorganic elements and compounds including metals, sulfates, and nitrates. The metals and sulfates are often produced by the combustion of fuels containing trace metals and/or sulfur. Nitrates and sulfates can result from the reaction of oxides of sulfur or nitrogen with other compounds in the high temperature fire environment. However, the combustion process is not the only path that inorganic compounds may take to become part of the smoke plume. The convective flow patterns associated with the fire plume can entrain the surrounding air into the fire. Fine dust or soil can be swept into the fire and emerge in the smoke plume. In order to identify and determine the concentrations of these chemical species, a known volume is pulled through a filter and returned to the lab for analysis. Specialized analysis techniques include laser microprobe mass spectrometry, micro-Raman analysis, environmental scanning electron microscopy, neutron activation, and ion chromatography. 


\subsection{Collaborative Local Smoke Sampling in Saudi Arabia}

Mr. Nelson P. Bryner and Dr. Bruce A. Benner, Jr. of NIST visited Saudi Arabia to tour research facilities at the Riyadh Armed Forces Military Hospital (RAFMH) and collect smoke and gas samples. RAFMH is the largest military hospital in Saudi Arabia and has extensive research facilities. Like all military hospitals in Saudi Arabia, RAFMH is administered by the Ministry of Defence and Aviation. Lt. Colonel Ibrahim Al-Nasser hosted the visit and arranged for the sampling trips to Dhahran and Al-Jubail.

\subsection{Riyadh Armed Forces Military Hospital}

The tours of the Riyadh Armed Forces Military Hospital (RAFMH) were presented by Mr. Abdulrahman Al-Asmari, Captain Suleimun Al-Hedaithy and Lt. Colonel Al-Nasser. The Saudi hosts provided a tour of the Toxicology, Biochemistry, Clinical Pathology, Endocrinology and Environmental Aerosol Laboratories. The NIST researchers were quite impressed by the size and the sophistication of the RAFMH laboratory facilities. The tour of the Toxicology Laboratory was particularly valuable, since this department has some of the equipment necessary for measurement of organic and inorganic air pollutants. The gas chromatograph (GC), the gas chromatograph with mass spectrometric detector (GC-MS) and the atomic absorption spectrophotometers in the Toxicology Laboratory could be used for future measurement of organic and inorganic constituents of air particulate matter collected in Saudi Arabia. The polycyclic aromatic hydrocarbons (PAHs) are of interest in the atmosphere since they are used as indicators of combustion processes and a number of PAHs are considered to be mutagenic. Some additional equipment, including specific GC capillary columns, and time for method development would be necessary before actual sample analysis (for PAHs) could be accomplished. In addition, NIST has available a large number of Standard Reference Materials (SRMs) that should be used for quality control and quality assurance of the analyses. Procurement of a new gas chromatograph with combined Fourier Transform Infra-Red and Mass Spectrometric Detection capability would be desirable since the two detection techniques compliment one another and aid in analyte confirmation. The enthusiasm and interest expressed by the RAFMH hosts suggested that they are prepared to put forth the effort necessary in establishing a high quality program for monitoring health-related compounds in the atmosphere.

Mr. Bryner and Dr. Benner were pleased to discuss the purpose of their visit with Brigadier General Ahmed Moaz, Director of Laboratory Services, Major General Dr. Ketab Al-Otaibi, Director of Riyadh Armed Forces Military Hospital and with Major General Dr. Abdulhameed Al-Fraidie, Director of Medical Services Department (MSD), Ministry of Defence and Aviation. All of the discussions, especially with Dr. Al-Fraidie, indicated a need and desire for the MSD to continue development of the technical expertise and facilities necessary to assess the impact of environmental aerosols and particulates on the health of the Saudi people. Lt. Colonel Al-Nasser, Captain AlHedaithy, Lieutenant Abdullah Kholaify and Mr. Al-Asmari already form the core of an environmental aerosol assessment center. Additional personnel will be required as more comprehensive sampling and analysis are implemented. While the present Toxicology Laboratory can, with minor additions, provide the facilities necessary for initial analysis, the laboratory will have to be expanded to support a comprehensive environmental aerosol monitoring program. 


\subsection{Collaborative Sampling - Field Work}

On Saturday, December 5, 1992, the four hosts from RAFMH and the two NIST guests travelled to Dhahran to collect air samples for subsequent analyses by NIST and RAFMH. Samples were collected at the King Fahad Military Medical Center (KFMMC) near Dhahran and at the Royal Saudi Naval Base (RSNB) near Al-Jubail (Tables 1 to 5). Samples collected at KFMMC were expected to represent background air samples while those collected at the RSNB were expected to be highly concentrated in organic pollutants from the heavy industrial sites near the city of Al-Jubail. A number of inhalable particulate matter samples (PM-10), particle size distribution samples (Marple Cascade Impactor), $\mathrm{PAH}$ sampling trains (Teflon filter and $\mathrm{XAD}$ sorbent tube), organic/inorganic carbon analysis samples (Quartz filter) and microscopy samples were collected at both sites (Table 1 - 5). One PM-10 sample was collected at each of three sites, including the roof of the main hospital at KFMMC, the roof of apartment building 74 at KFMMC, and the roof of the hospital at RSNB. Two sets of PAH sampling trains including a $35 \mathrm{~mm}$ Teflon filter in line with a XAD-2 air sorbent tube were collected at the KFMMC apartment building and the RSNB. The KFMMC apartment building sample was collected during a dust storm, and the associated filter had an easily observable amount of "reddish-tan" sandy material on its surface. A field blank was also generated by sampling indoor apartment air through a sampling train for two minutes. A sealed XAD-2 cartridge from the same lot as those used for the outdoor sampling was employed as the laboratory blank for that media. This was necessary because unlike the filter material, which is pre-cleaned by either heating $\left(>500^{\circ} \mathrm{C}\right.$ ) or extracting with dichloromethane, the XAD-2 sorbent tubes were used as received from the vendor, and it was of interest to distinguish contamination inherent in the XAD sorbent from any obtained in the field.

During the field work, instrument hardware assembly, operation, and calibration as well as site selection considerations, were discussed with the RAFMH personnel. They successfully demonstrated their ability to assemble and calibrate PAH sampling trains, personal cascade impactors, PM-10 HiVol Samplers, and single- and multiple-gas analyzers. All the sampling equipment performed satisfactorily and a number of the samples were noticeably high in collected particulate matter. The group returned to Riyadh on December 9.

\subsection{Sample Analysis}

The samples were divided between RAFMH and NIST to allow for split-sample analysis. Samples left in Riyadh for analysis included PAH-02, PAH-03, XAD-02, XAD-03, Q-02, Q-06, and B-07. Each of the PM-10 samples was divided in half with each laboratory receiving a filter half for analysis. The electron microscopy samples, and personal cascade impactor samples were all returned to NIST for analysis.

At NIST, the PAH samples (Teflon filter and XAD-2 sorbent tube), quartz filters, and PM-10 samples were analyzed for polycyclic aromatic hydrocarbon content. Quartz fibers from the PM-10 samples and particles from the cascade impactor stages were examined by Laser Microprobe Mass Spectrometry. Other particles selected from cascade impactor stages were investigated using MicroRaman Analysis. Environmental Scanning Electron Microscopy was employed to study XAD adsorbent, PM-10 filters, and impactor stages. Thermal-optical analysis techniques were used on PM10 filters to determine organic and elemental carbon content. Gas chromatography was used to measure carbon dioxide and carbon monoxide concentrations of the grab bag samples. 


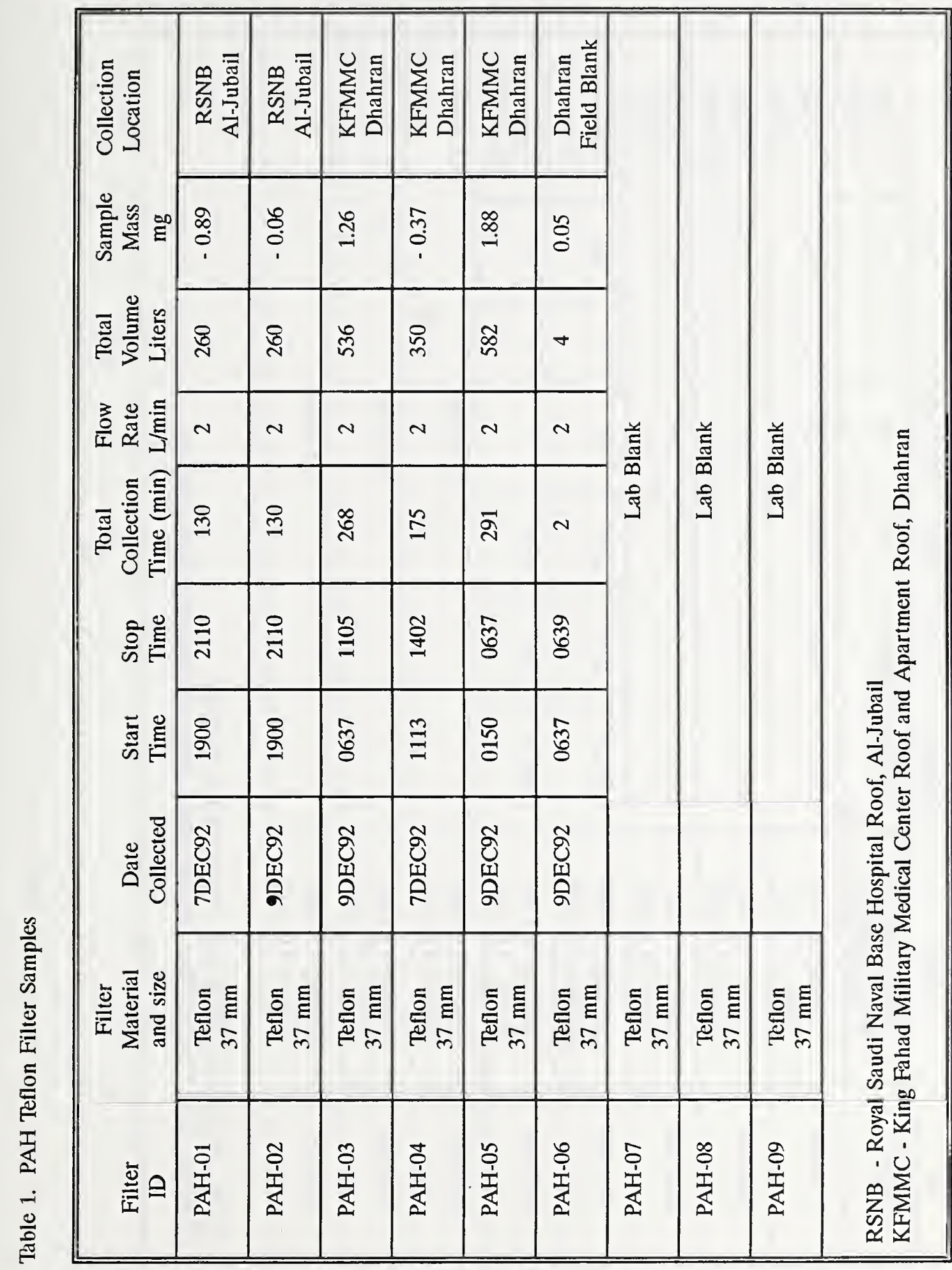




\begin{tabular}{|c|c|c|c|c|c|c|c|c|c|c|}
\hline 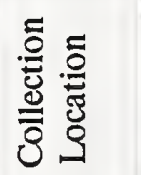 & 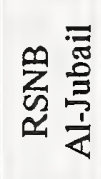 & 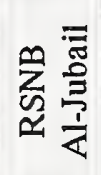 & 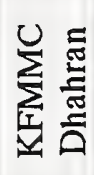 & 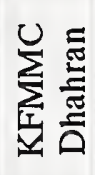 & 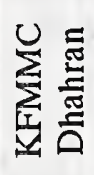 & 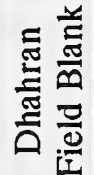 & \multirow{7}{*}{ 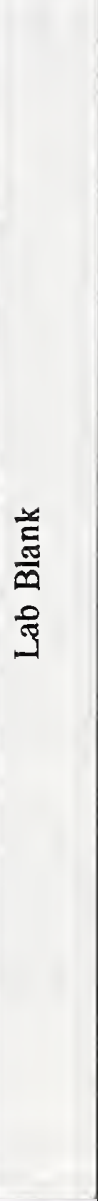 } & \multirow{7}{*}{$\begin{array}{l}\text { 兰 } \\
\text { 矛 } \\
\text { ज़ }\end{array}$} & \multirow{7}{*}{ 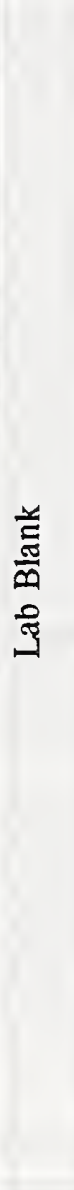 } & \multirow{9}{*}{ 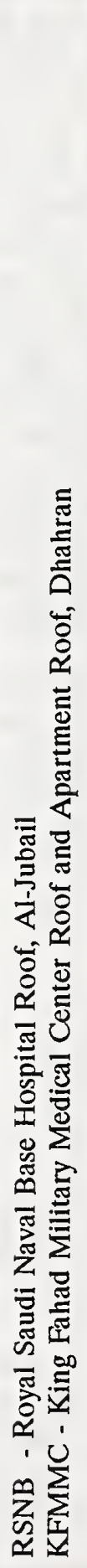 } \\
\hline 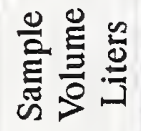 & 류 & 류 & in & ஜ్లి & $\underset{\infty}{\infty}$ & $\nabla$ & & & & \\
\hline 总急 & $N$ & $N$ & $N$ & $N$ & $N$ & $\sim$ & & & & \\
\hline 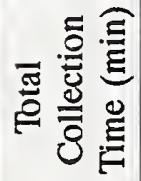 & 욤 & 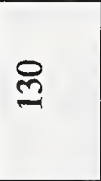 & ㄱ. & $\stackrel{2}{\simeq}$ & ন & $N$ & & & & \\
\hline 을 & $\stackrel{ }{ㄱ}$ & $\stackrel{ }{ }$ & 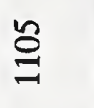 & Q & $\hat{\sigma}$ & શ્छ & & & & \\
\hline 莺导 & 융 & ફ) & $\widehat{\hat{8}}$ & $\stackrel{\varrho}{\exists}$ & $\stackrel{\circ}{0}$ & $\hat{8}$ & & & & \\
\hline 总 & 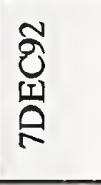 & 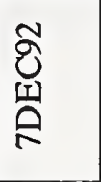 & 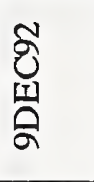 & 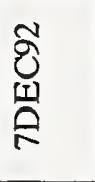 & 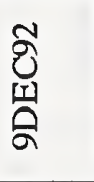 & 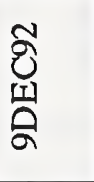 & & & & \\
\hline 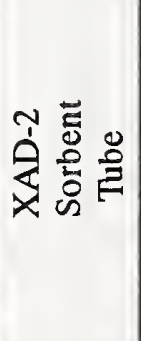 & 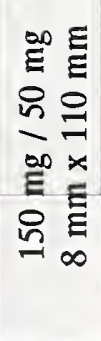 & 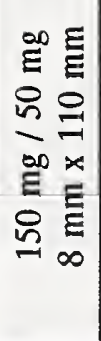 & 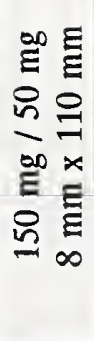 & 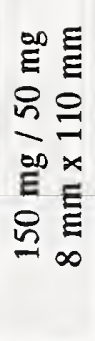 & 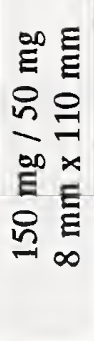 & 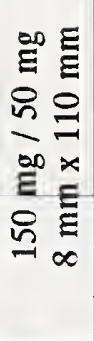 & 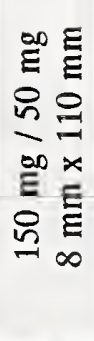 & 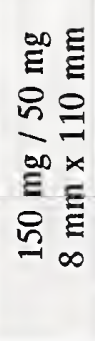 & 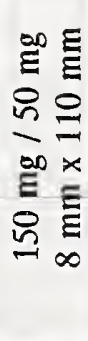 & \\
\hline$\stackrel{\rightleftarrows}{E} \Xi$ & 官 & 일 & 官 & 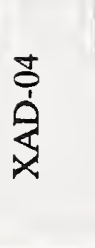 & 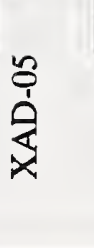 & $\begin{array}{l}\stackrel{8}{8} \\
\dot{1}\end{array}$ & 占 & $\stackrel{\infty}{0}$ & $\begin{array}{l}8 \\
\dot{1} \\
\text { 芠 }\end{array}$ & \\
\hline
\end{tabular}




\begin{tabular}{|c|c|c|c|c|c|c|c|c|}
\hline 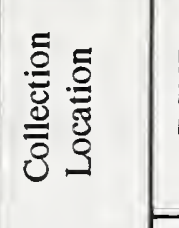 & 器言高 & & 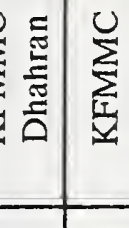 & & 墨讋 & & & \\
\hline 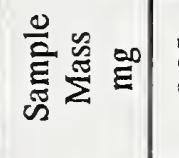 & 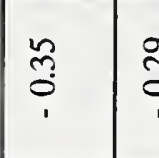 & 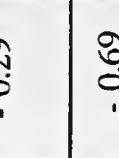 & 8 & $\mathscr{g}$ & : & & & \\
\hline 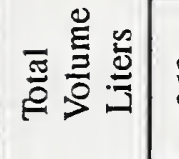 & 8 & 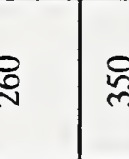 & 吸 & 品 & - & & & \\
\hline 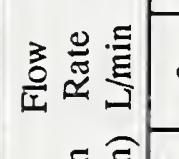 & \begin{tabular}{l|l} 
& - \\
\end{tabular} & 5. & $1 \sim$ & $\sim$ & $\sim$ & 茞 & & 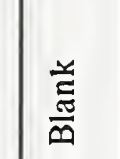 \\
\hline 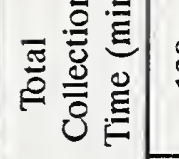 & 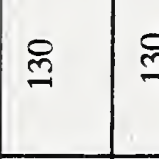 & 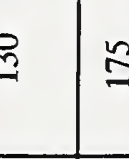 & : & क्ष & $\sim$ & & & \\
\hline 言影 & ڤI & 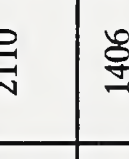 & $\frac{5}{8}$ & $\stackrel{\text { }}{\underline{\underline{g}}}$ & 胥 & & & \\
\hline 言员 & g & 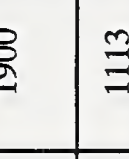 & $\frac{8}{0}$ & 8 & 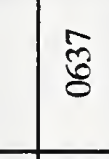 & & & \\
\hline 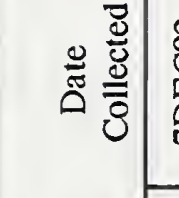 & 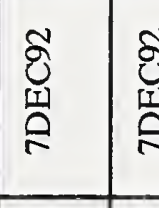 & $\begin{array}{l}8 \\
\vdots\end{array}$ & $\begin{array}{l}\text { 8ू } \\
\text { 罗 }\end{array}$ & 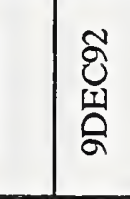 & 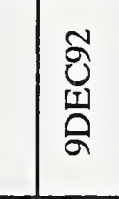 & & & \\
\hline 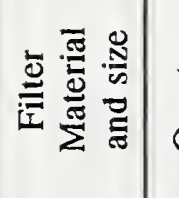 & 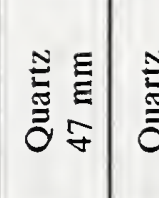 & 害言言言 & (⿸\zh14) & 童言 & $=$ & 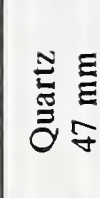 & \multicolumn{2}{|c|}{ 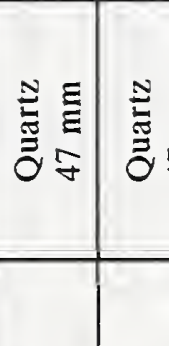 } \\
\hline$\frac{\underline{\underline{\underline{m}}} \mathrm{z}}{\mathrm{z}}$ & $\overline{\dot{\partial}}$ & $\begin{array}{c}c \\
0\end{array}$ & 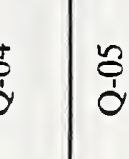 & $\check{\delta}$ & T & & & $\bar{\alpha}$ \\
\hline
\end{tabular}




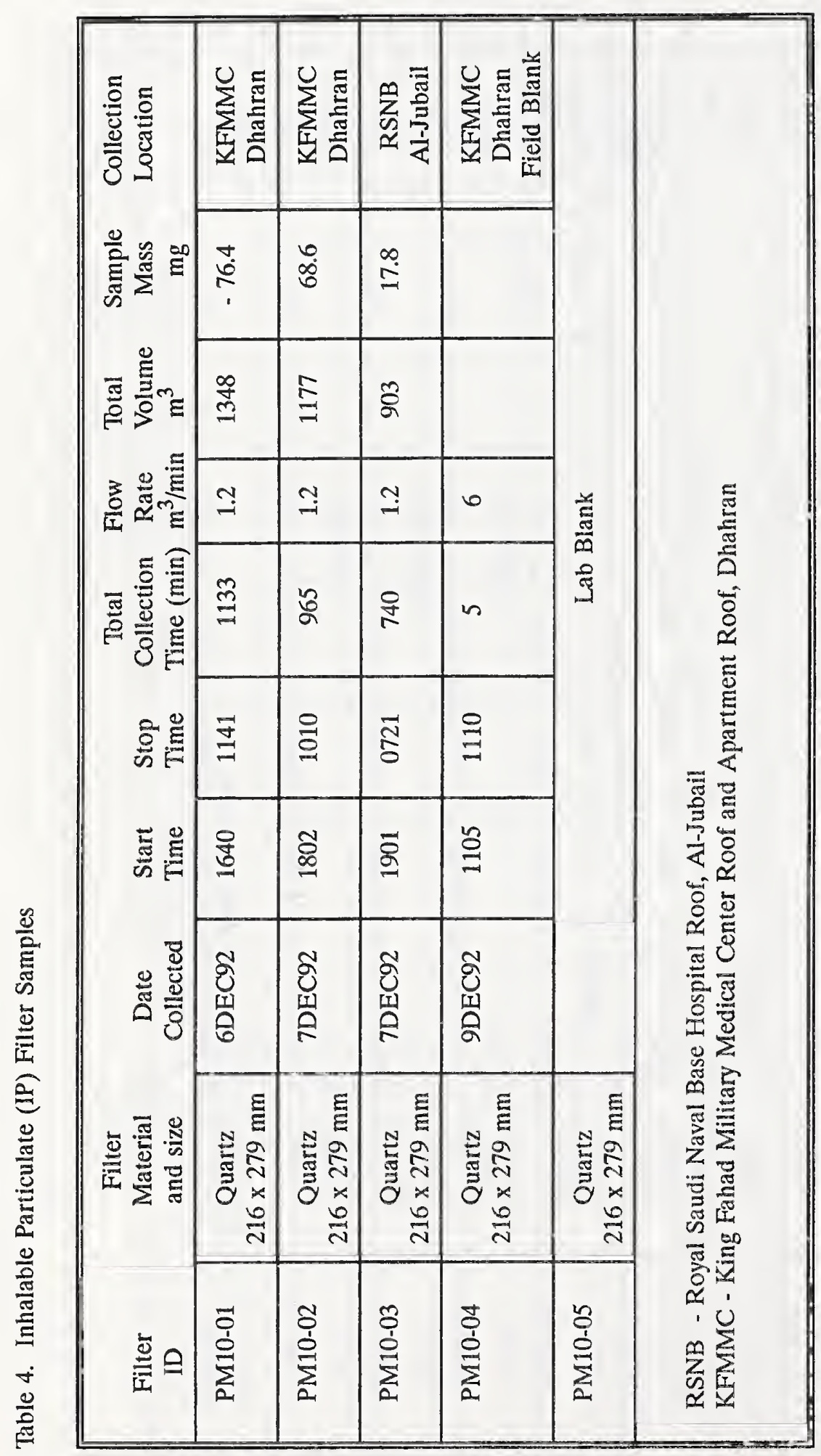




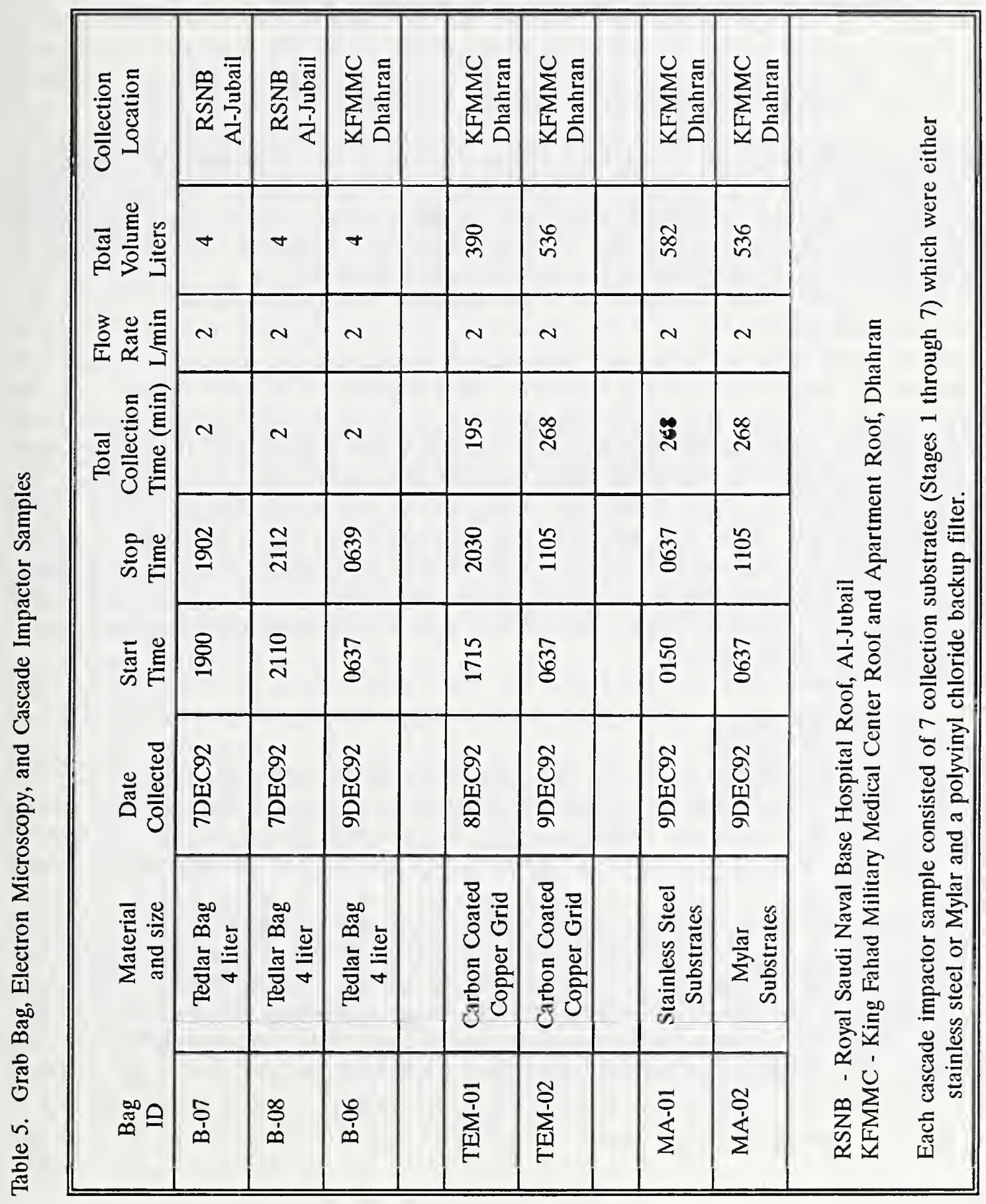




\title{
4.1 Polycyclic Aromatic Hydrocarbons Analysis
}

\author{
Contributed by - \\ Dr. Bruce A. Benner, Jr. \\ Organic Analytical Research Division \\ Chemical Science and Technology Laboratory, NIST
}

\subsubsection{Sample Preparation and Analysis}

The PM-10 filter samples and the PAH sampling trains, Teflon filter and XAD-2 sorbent tube, were analyzed for PAHs. Each type of sample, such as PM-10 or Teflon filter, was extracted and analyzed using techniques specifically developed for each sample media. Each sample was "spiked" with internal standards and several Standard Reference Materials with certified PAH concentrations were simultaneously analyzed to provide quality assurance.

Each PAH sampling train consisted of a $37 \mathrm{~mm}$ diameter Teflon filter followed by an XAD-2 sorbent tube. The sorbent tube was an $8 \mathrm{~mm}$ diameter by $110 \mathrm{~mm}$ long glass tube with $200 \mathrm{mg}$ of $\mathrm{XAD}-2$ collections media. The XAD-2 sorbent material was divided into two segments, the upstream (150 mg material) and downstream (50 mg material). Each segment of an XAD cartridge and the associated glass wool was treated as individual samples (two per XAD cartridge sample). Any PAHs detected above blank levels in the downstream XAD segment would indicate that the analytes were not quantitatively collected by the upstream XAD cartridge and experienced "breakthrough." The $\mathrm{XAD}$ samples were placed in $15 \mathrm{~mL}$ centrifuge tubes, spiked with a solution containing known amounts of perdeuterated PAHs and extracted by ultrasonication for $5 \mathrm{~min}$ with $5 \mathrm{~mL}$ of dichloromethane (DCM). The extracts were then transferred to clean $15 \mathrm{~mL}$ centrifuge tubes, leaving most of the sorbent and glass wool behind, concentrated under $\mathrm{N}_{2}$ to $\leq 1 \mathrm{~mL}$ and filtered through pre-cleaned $0.2 \mu \mathrm{m}$ syringe filters. The extracts were further concentrated under $\mathrm{N}_{2}$ to $\leq 50 \mu \mathrm{L}$ prior to instrumental analysis.

The $37 \mathrm{~mm}$ Teflon filters associated with the XAD samples were processed by the same procedure as that described above for the XAD samples except that the filters required $20 \mathrm{~mL}$ of DCM for the ultrasonic extraction.

The PM-10 filter samples were cut into two equal pieces (one-half left with MODA personnel) and one-half of each filter was spiked with the same perdeuterated PAH standard as were the XAD and Teflon filter samples and soxhlet extracted for $18 \mathrm{~h}$ with $300 \mathrm{~mL}$ DCM. The extracts were then concentrated to $0.5 \mathrm{~mL}$ under $\mathrm{N}_{2}$ (Turbovap), and filtered through pre-cleaned $0.2 \mu \mathrm{m}$ syringe filters.

Standard Reference Material 1491 (Aromatic Hydrocarbons in Hexane/Toluene) was fortified with known amounts of perdeuterated PAHs and processed through the identical extraction procedures as the samples. Response factors generated by running these standards corrected for differences in the recoveries and detector responses between the analytes and the perdeuterated standards. Two samples of Standard Reference Material (SRM) 1649 (Urban Dust/Organics) were processed through the ultrasonic and soxhlet extraction procedures, serving as quality assurance samples. 


\subsubsection{GC-MS PAH Analysis}

The PAHs were detected by mass spectrometry (MS) using a Hewlett-Packard 5970 Mass Selective Detector interfaced with an HP 5890 gas chromatograph (GC). The GC-MS was tuned daily prior to beginning analyses of the samples. From 1 to $2 \mu \mathrm{L}$ volumes of the prepared extracts and standards were injected onto a $1.5 \mathrm{~m}$ retention gap connected to the analytical column used in quantifying the PAH. Each extract was analyzed once. The 5\% phenylmethyl-substituted polysiloxane gas chromatographic column (DB- $5 \mathrm{~ms}, 60 \mathrm{~m} \mathrm{x} 0.25 \mathrm{~mm}, 0.25 \mu \mathrm{m}$ phase) was used at a head pressure of 276 kilopascals (40 psi) helium (linear velocity of $43 \mathrm{~cm} / \mathrm{s}$ ) with a temperature program beginning with a $1 \mathrm{~min}$ hold at $100^{\circ} \mathrm{C}$ followed by a rapid ramp $\left(60^{\circ} \mathrm{C} / \mathrm{min}\right)$ to $150^{\circ} \mathrm{C}$, then a gradual increase $\left(2{ }^{\circ} \mathrm{C} / \mathrm{min}\right)$ to $325^{\circ} \mathrm{C}$. The MSD was operated in the selected ionmonitoring mode at an electron multiplier voltage of $1400 \mathrm{~V}$. Specifics of the selected ion-monitoring program are listed in Table 6 . The PAHs present in the sample extracts were quantified by peak area comparisons with perdeuterated PAHs spiked into the samples prior to extraction. Response/recovery factors generated as described above, corrected for differences in the recoveries and detector responses between the analytes and the standards. Reconstructed selected-ion chromatograms for one of the XAD, the PM-10 and the Teflon filter samples can be found as Appendices B, C, and D.

\subsubsection{Results and Discussion}

For quality assurance purposes, Standard Reference Material (SRM) 1649 (Urban Dust/Organics) was processed through both the ultrasonic and the soxhlet extraction procedures described above. Results generated by the two methods, as well as certified concentrations reported in the SRM's Certificate of Analysis, are listed in Table 7. Good agreement was observed between results generated by soxhlet extraction and the certified concentrations. Results for half of the PAHs from the ultrasonic extraction procedure were significantly higher (by $\geq 30 \%$ ) than from the soxhlet technique, perhaps due to problems in the spiking of the internal standard ( $5 \mu \mathrm{L}$ volume) and/or inhomogeneity of the SRM at the $5 \mathrm{mg}$ level. The XAD and the Teflon filter samples were spiked at the same $5 \mu \mathrm{L}$ level as the SRM and the results for those samples may be biased toward higher concentrations.

Table 8 lists the amounts of those PAHs detected in the extracts of the XAD laboratory and field blanks. Naphthalene and benzo[a]pyrene were the only PAHs significantly enriched $(\geq 3 \mathrm{x})$ in the field blank over the laboratory blank. Results for the upstream and downstream segments of each of two XAD samples collected at KFMMC and RSNB are shown in Table 9. When appropriate, the results were corrected for field blank concentrations. With the exception of fluorene and dibenzothiophene, the downstream segments of the XAD samples showed little indication of significant breakthrough of PAHs during sample collection. The XAD cartridges would collect both vapor phase PAHs as well as those desorbed from the retained particles. Except in situations of extreme temperatures, such as those experienced during combustion source sampling, one would not expect to observe larger molecular weight PAHs ( $\geq 228$ atomic mass units) on the XAD cartridges. Results for the associated Teflon filter samples and field blank are listed in Table 10. The vast majority of the PAHs were either not detectable or indistinguishable from the field blank contamination levels. As mentioned above, PAH sample train \#5 (PAH-05 and XAD-05) collected at KFMMC during a dust storm had observable amounts of reddish-tan dust on the filter. The PAH05 results displayed in Table 10 suggest that the dust is not a significant source or carrier for airborne PAHs. 


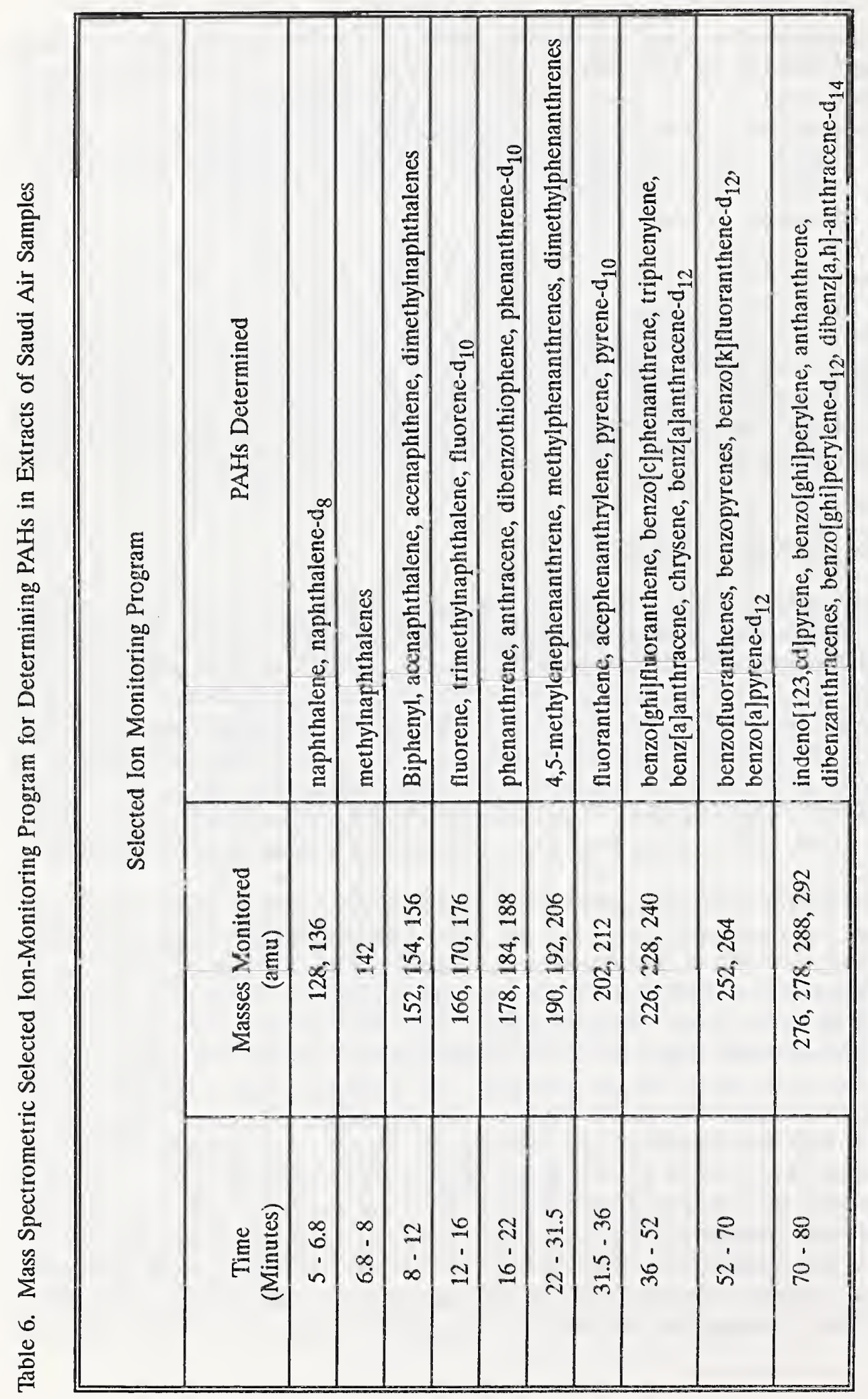


Table 7. Measurement of PAHs in Standard Reference Material 1649 (Urban Dust/Organics) ( $\mu \mathrm{g} / \mathrm{g}$ )

\begin{tabular}{|c|c|c|c|}
\hline PAH & $\begin{array}{l}\text { Ultrasonic } \\
\text { Extraction }\end{array}$ & $\begin{array}{l}\text { Soxhlet } \\
\text { Extraction }^{\mathrm{b}}\end{array}$ & $\begin{array}{c}\text { Certified } \\
\text { Concentration }^{c}\end{array}$ \\
\hline phenanthrene & 7.48 & 5.30 & \\
\hline anthracene & 1.01 & 1.32 & \\
\hline 4,5-methylenephenanthrene & 0.68 & 0.35 & \\
\hline 3-methylphenanthrene & 1.12 & 0.74 & \\
\hline 2-methylphenanthrene & 0.68 & 0.89 & \\
\hline \multicolumn{4}{|l|}{ 4- and 9-methylphenanthrene } \\
\hline 1-methylphenanthrene & 0.98 & 1.73 & \\
\hline fluoranthrene & 0.68 & 6.53 & $7.1 \pm 0.5$ \\
\hline \multicolumn{4}{|l|}{ acephenanthrylene } \\
\hline pyrene & 8.59 & 5.75 & 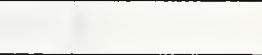 \\
\hline benz[a]anthracene & 3.91 & 2.19 & $2.6 \pm 0.3$ \\
\hline triphenylene & 1.09 & 0.89 & \\
\hline chrysene & 5.10 & 3.39 & \\
\hline benzo $[b+j]$ fluoranthene & 8.82 & 7.34 & \\
\hline benzo[k]fluoranthene & 2.89 & 2.19 & \\
\hline benzo[a]fluoranthene & 0.53 & & \\
\hline benzo[e]pyrene & 5.16 & 3.09 & \\
\hline benzo[a]pyrene & 4.78 & 2.90 & $2.9 \pm 0.5$ \\
\hline perylene & 1.21 & 1.24 & \\
\hline indeno[1,2,3-cd]pyrene & 3.60 & 3.39 & $3.3 \pm 0.5$ \\
\hline benzo[ghi]perylene & 4.78 & 4.61 & $4.5 \pm 1.1$ \\
\hline $\begin{array}{l}\text { a } 5 \text { minutes ultrasonic extract } \\
\text { b } 16 \text { hour soxhlet extraction } \\
\text { c Certified concentrations. }\end{array}$ & $\begin{array}{l}\text { orometh } \\
\text { methane }\end{array}$ & $\begin{array}{l}\text { g), uncertair } \\
\text { uncertainti }\end{array}$ & $\begin{array}{l}\text { mated at } \pm 10 \% \\
\text { ated at } \pm 10 \%\end{array}$ \\
\hline
\end{tabular}


Table 8. PAH Contamination (ng) in XAD Laboratory and Field Blanks ${ }^{\mathrm{a}}$

\begin{tabular}{||l|c|c|}
\hline \multicolumn{1}{|c|}{ PAH } & XAD Laboratory Blank & XAD Field Blank \\
\hline naphthalene & 2.1 & 9.5 \\
\hline & & 1.0 \\
\hline 2-methylnaphthalene & 0.3 & 0.8 \\
\hline 1-methylnaphthalene & 0.3 & 1.0 \\
\hline & & 1.0 \\
\hline biphenyl & $<0.3$ & \\
\hline & & 2.7 \\
\hline phenanthrene & 1.8 & 0.8 \\
\hline
\end{tabular}

a Estimated detection limits for PAHs not observed in the XAD blank extracts is $0.3 \mathrm{ng}$. 


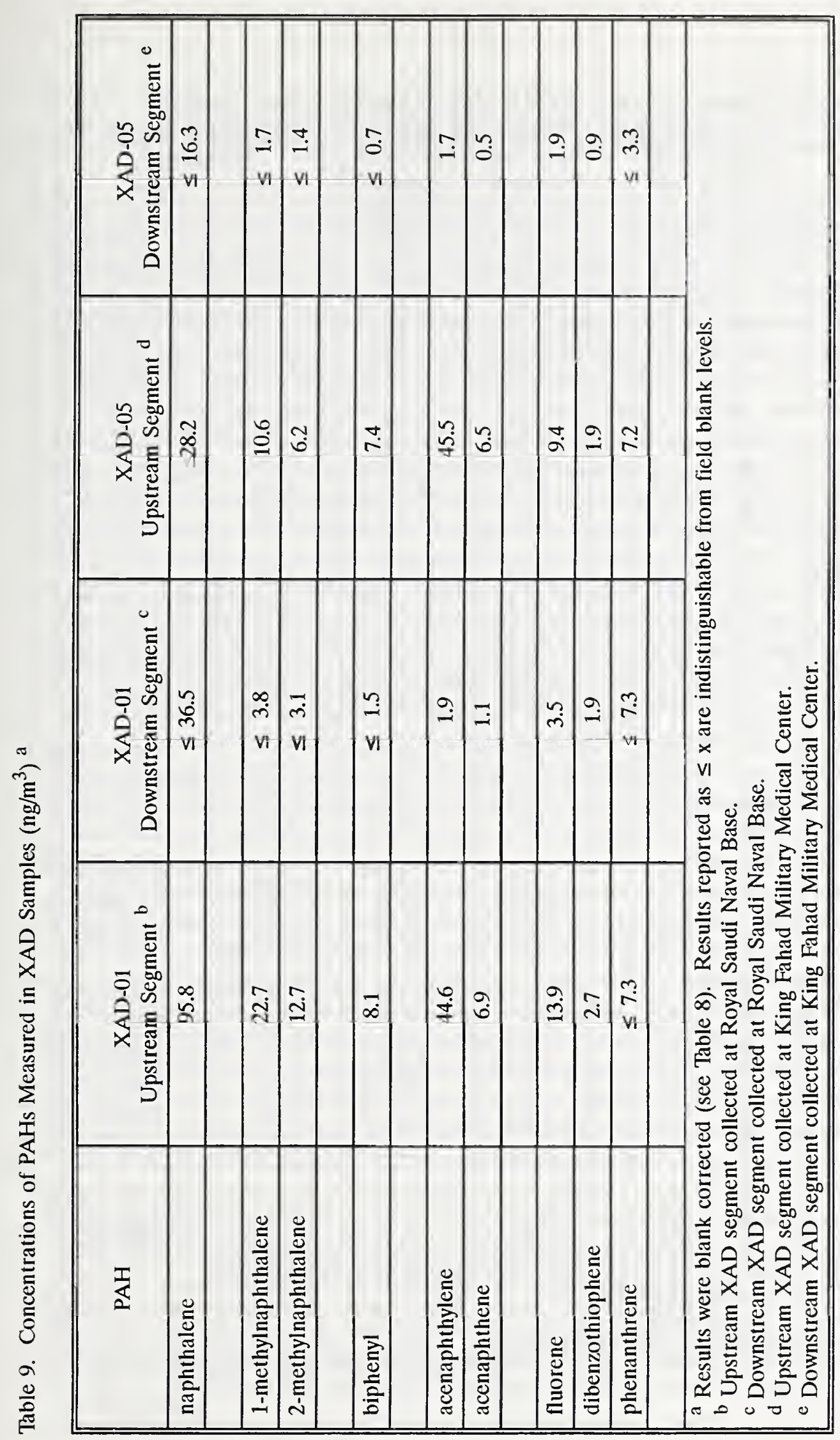


Table 10. Concentrations and Detection Limits of PAHs Measured in Teflon Filter Samples a

\begin{tabular}{|c|c|c|c|c|c|}
\hline PAH & $\begin{array}{c}\text { Teflon Filter } \\
\text { Blank } \\
\text { (ng) }\end{array}$ & $\begin{array}{c}\text { Teflon } \\
\text { (ng) }\end{array}$ & $\begin{array}{l}\text { PAH-01 } \\
\text { B) }{ }^{\mathrm{b}} \\
\left(\mathrm{ng} / \mathrm{m}^{3}\right)\end{array}$ & $\begin{array}{l}\text { Teflor } \\
(\mathrm{ng})\end{array}$ & $\begin{array}{l}\text { PAH-05 } \\
\text { C) } \\
\left.\mathrm{ng}^{\mathrm{c}} / \mathrm{m}^{3}\right)\end{array}$ \\
\hline naphthalene & 0.4 & $\leq 0.1$ & $\leq 1.5$ & 0.5 & 0.9 \\
\hline 2-methylnaphthalene & $\overline{0.1}$ & 0.2 & 0.8 & 0.2 & 0.3 \\
\hline 1-methylnaphthalene & 0.4 & $\leq 0.1$ & $\leq 0.4$ & $\leq 0.1$ & $\leq 0.2$ \\
\hline biphenyl & 0.1 & $\leq 0.1$ & $\leq 0.4$ & $\leq 0.4$ & $\leq 0.2$ \\
\hline acenaphthylene & 0.1 & $\leq 0.1$ & $\leq 0.4$ & $\leq 0.1$ & $\leq 0.2$ \\
\hline acenaphthene & $<0.2$ & $<0.2$ & $<0.6$ & $<0.2$ & $<0.3$ \\
\hline fluorene & $<0.1$ & $<0.4$ & $<0.4$ & $<0.1$ & $<0.2$ \\
\hline dibenzothiophene & $<0.8$ & $<0.8$ & $<3.1$ & $<0.8$ & $<1.4$ \\
\hline phenanthrene & 3.4 & $\leq 3.4$ & $\leq 13.1$ & $\leq 3.4$ & $\leq 5.8$ \\
\hline anthracene & $<0.7$ & $<0.7$ & $<2.7$ & $<0.4$ & $<1.2$ \\
\hline 4,5-methylenephenanthrene & $<0.8$ & $<0.8$ & $<3.1$ & $<0.8$ & $<1.4$ \\
\hline 3-methylphenanthrene & $<0.6$ & $<0.8$ & $<3.1$ & $<0.8$ & $<1.4$ \\
\hline 2-methylphenanthrene & $<0.8$ & $<0.8$ & $<3.1$ & $<0.8$ & $<1.4$ \\
\hline 4- and 9-methylphenanthrene & $<0.8$ & $<0.8$ & $<3.1$ & $<0.8$ & $<1.4$ \\
\hline 1-methylphenanthrene & $<0.8$ & $<0.8$ & $<3.1$ & $<0.8$ & $<1.4$ \\
\hline fluoranthrene & $<0.6$ & 0.7 & 2.7 & 0.6 & 1.0 \\
\hline acephenanthrylene & $<0.6$ & $<0.6$ & $<2.3$ & $<0.8$ & $<1.0$ \\
\hline pyrene & $<0.5$ & 0.6 & 2.3 & $<0.5$ & $<0.9$ \\
\hline benz[a]anthracene & $<0.6$ & $<0.6$ & $<0.3$ & $<0.6$ & $<1.0$ \\
\hline triphenylene & $<0.8$ & $<0.6$ & $<2.3$ & $<0.6$ & $<1.0$ \\
\hline chrysene & $<0.6$ & $<0.6$ & $<2.3$ & $<0.6$ & $<1.0$ \\
\hline benzo[b+j]fluoranthene & $<0.4$ & $<0.4$ & $<1.5$ & $<0.4$ & $<0.7$ \\
\hline benzo[k]fluoranthene & $<0.4$ & $<0.4$ & $<1.5$ & $<0.4$ & $<0.7$ \\
\hline benzo[a]fluoranthene & $<0.4$ & $<0.4$ & $<1.5$ & $<0.4$ & $<0.7$ \\
\hline benzo[e]pyrene & 2.4 & 4.1 & 15.8 & $\leq 2.4$ & $\leq 4.1$ \\
\hline benzo[a]pyrene & $<0.4$ & $<0.4$ & $<1.5$ & $<0.4$ & $<0.7$ \\
\hline perylene & $<0.4$ & $<0.4$ & $<1.5$ & $<0.4$ & $<0.7$ \\
\hline indeno[1,2,3-cd]pyrene & $<0.3$ & $<0.3$ & $<1.1$ & $<0.3$ & $<0.5$ \\
\hline benzo[ghi]perylene & $<0.3$ & $<0.3$ & $<0.1$ & $<0.8$ & $<0.5$ \\
\hline
\end{tabular}


Table 11. Concentrations and Detection Limits of PAHs Measured in PM10 Filter Samples ${ }^{\text {a }}$

\begin{tabular}{|c|c|c|c|c|c|c|c|}
\hline PAH & $\begin{array}{l}\text { PM10 } \\
\text { Blank } \\
\text { (ng) }\end{array}$ & \multicolumn{2}{|c|}{$\begin{array}{l}\text { PM10-01 } \\
(\mathrm{KFMMC})^{\mathrm{b}} \\
(\mathrm{ng}) \quad\left(\mathrm{ng} / \mathrm{m}^{3}\right)\end{array}$} & \multicolumn{2}{|c|}{$\begin{array}{c}\text { PM10-02 } \\
(\mathrm{KFMMC})^{\mathrm{c}} \\
(\mathrm{ng}) \quad\left(\mathrm{ng} / \mathrm{m}^{3}\right)\end{array}$} & \multicolumn{2}{|c|}{$\begin{array}{c}\text { PM10-03 } \\
(\text { RSNB) } \\
\text { (ng) } \quad\left(n g / \mathrm{m}^{3}\right)\end{array}$} \\
\hline naphthalene & 27.3 & $\overline{52.4}$ & 37.1 & 53.6 & 44.7 & 29.6 & $<60$ \\
\hline 2-methylnaphthalene & $<10.0$ & $<10.0$ & $<14.8$ & $<10.0$ & $<17.0$ & $<16.3$ & $<22.2$ \\
\hline 1-methylnaphthalene & $<10.0$ & $<10.0$ & $<14.8$ & $<10.0$ & $<17.0$ & $<16.3$ & $<22.2$ \\
\hline biphenyl & $<10.0$ & $<10.0$ & $<14.8$ & $<10.0$ & $<17.0$ & $<10.0$ & $<22.2$ \\
\hline acenaphthylene & $<10.0$ & $<10.0$ & $<14.8$ & $<10.0$ & $<17.0$ & $<16.8$ & $<22.2$ \\
\hline acenaphthene & $<10.0$ & $<10.0$ & $<14.8$ & $<10.0$ & $<17.0$ & $<14.8$ & $<22.2$ \\
\hline fluorene & $<10.0$ & $<10.0$ & $<14.8$ & $<10.0$ & $<17.0$ & $<14.8$ & $<22.2$ \\
\hline dibenzothiophene & $<5$ & 18.5 & 27.4 & 32.0 & 54.4 & $<5$ & $<11.1$ \\
\hline phenanthrene & 43.7 & 89.2 & $\overline{67.5}$ & 77.4 & $\overline{57.5}$ & $<43.7$ & $<97$ \\
\hline anthracene & $<5$ & 10.0 & $\overline{10.8}$ & 28.8 & 49.0 & $<5$ & $<11.1$ \\
\hline 4,5-methylenephenanthrene & $<5$ & $<5$ & $<7.4$ & $<5$ & $<8.5$ & $<5$ & $<11.1$ \\
\hline 3-methylphenanthrene & $<5$ & 24.5 & 36.3 & 17.6 & 29.9 & $<5$ & $<11.1$ \\
\hline 2-methylphenanthrene & $<5$ & 28.6 & 42.4 & 21.6 & 37.2 & 52.9 & 117 \\
\hline 1-methylphenanthrene & $<5$ & 23.3 & 34.6 & 62.3 & 106 & 53.9 & 110 \\
\hline fluoranthrene & 16.4 & 103 & 128 & 88.7 & 123 & 51.8 & 78.3 \\
\hline acephenanthrylene & $<5$ & 25.5 & 37.8 & 21.6 & 36.7 & 10.0 & 22.2 \\
\hline pyrene & 12.0 & 116 & 154 & 103 & 155 & 53.2 & 91.3 \\
\hline benz[a]anthracene & 3.4 & 111 & 160 & 137 & 226 & 35.9 & 72.1 \\
\hline triphenylene & 1.8 & \multicolumn{2}{|c|}{ not resolved ${ }^{e}$} & \multicolumn{2}{|c|}{ not resolved ${ }^{e}$} & 20.8 & 42.1 \\
\hline chrysene & $\overline{5.5}$ & 246 & 354 & 349 & 582 & $\overline{59.5}$ & 120 \\
\hline & & & & & & $\dot{-}$ & \\
\hline benzo[b+j]fluoranthene & $<5$ & 467 & 693 & 536 & 911 & 129 & 286 \\
\hline benzo[k]fluoranthene & 10.6 & 103 & 195 & 158 & 250 & 33.1 & 49.9 \\
\hline benzo[a]fluoranthene & $<5$ & 48.9 & $\overline{72.5}$ & 59.2 & 101 & 12.1 & 26.8 \\
\hline benzo[e]pyrene & 2.9 & 245 & 359 & 289 & 486 & 72.1 & $\overline{153}$ \\
\hline benzo[a]pyrene & $\overline{3.6}$ & 227 & 332 & 301 & 505 & 53.3 & 110 \\
\hline perylene & $<5$ & 30.2 & 44.8 & 42.7 & $\overline{72.6}$ & 9.5 & 21.1 \\
\hline indeno[1,2,3-cd]pyrene & 5.2 & 316 & 460 & 373 & 624 & 91.6 & 192 \\
\hline benzo[ghi]perylene & 5.4 & 554 & 814 & 653 & 1102 & 168 & 361 \\
\hline $\begin{array}{l}\text { a Airborne concentrations (p } \\
\text { b KFMMC - King Fahad Mi } \\
\text { c KFMMC - King Fahad Mi } \\
\text { d RSNB - Royal Saudi Nav } \\
\text { e Triphenylene not resolved } \\
\text { concentrations. }\end{array}$ & $\begin{array}{l}\text { ledical } \\
\text { Al-Jul } \\
\text { arysene. }\end{array}$ & $\begin{array}{l}\text { Or fil } \\
\text { Dha } \\
\text { Dha } \\
\text { of of } \\
\text { sene }\end{array}$ & $\begin{array}{l}\text { roor } \\
\text { roof } \\
\text { tal. } \\
\text { s repr }\end{array}$ & $\begin{array}{l}\text { lation. } \\
\text { ital. } \\
\text { tment }\end{array}$ & g. & & \\
\hline
\end{tabular}


Results for three PM-10 filter samples and a filter blank are shown in Table 11. Though it would be expected to exist mainly in the vapor phase under the conditions of sampling, naphthalene was detected above filter blank concentrations in two of the three filter samples (PM-10-01 and PM10-02, collected at two sites at KFMMC). The PM-10-01 and PM-10-02 had comparable levels of PAHs, with filter PM-10-02 having somewhat higher concentrations of the higher molecular weight species (benzo[b+j]fluoranthene through benzo[ghi]perylene). Although PM-10-03 was collected near the heavily-industrialized coastal city of Al-Jubail, airborne PAH concentrations for this sample were typically 2 to 4 times lower than those measured in samples PM-10-01 and PM-10-02, collected at the King Fahad Military Medical Center, near Dhahran. Atmospheric concentrations of PAHs and other species (e.g., trace elements) vary over orders of magnitude depending on source emissions (local and regional) and meteorology. The fact that we observed higher PAH concentrations at what was thought to be a background site (KFMMC), suggests that perhaps a local source (i.e., the hospital incinerator) and/or the meteorology (vertical mixing height) influenced the collected samples. Only after collecting and analyzing a larger number of samples, as during a monitoring program, would we have a better feel for which site routinely had higher airborne PAH concentrations. Comparing the three samples collected in Saudi Arabia with those collected as part of studies in the United States, geometric mean PAH concentrations for 36 samples collected in Boise, Idaho (U.S.A) were at least a factor of ten higher than the three collected in the Kingdom. Samples collected in Roanoke, Virginia (U.S.A) as part of a study similar to that of Boise yielded PAH concentrations of the same order of magnitude as the Saudi samples. These comparisons are limited by the small number of Saudi samples. We feel that the value of a long-term monitoring program in Saudi Arabia is evident by the data discussed in this report. A program involving the collection and analysis of air samples (e.g., PM-10 Hi-Vol) in a Saudi Arabian city (e.g., Riyadh, Al-Jubail, Dhahran) would provide valuable data for determining current airborne $\mathrm{PAH}$ concentrations as well as for devising air pollution control strategies for the future.

\subsection{Laser Microprobe Mass Spectrometry}

Contributed by -

Mr. Robert A. Fletcher

Surface and Microanalysis Science Division

Chemical Science and Technology Laboratory, NIST

\subsubsection{Introduction}

The laser microprobe mass spectrometer (LMMS) is a time-of-flight mass spectrometer that utilizes a high powered laser to vaporize and ionize the sample material. The sample is viewed optically and a particle is selected for analysis by aiming a co-aligned pilot helium-neon (HeNe) laser beam spot onto the particle. The ionizing laser is a high power, pulsed Nd:YAG laser frequency quadrupled to provide UV radiation $(266 \mathrm{~nm})$. The radiation is focused onto the sample by a quartz optical microscope objective. The high power pulse, 10 nanoseconds in duration, evaporates the sample and in the process ionizing some of the atoms. All ions generated are accelerated to uniform translational energy and mass-separated by time-of-flight mass spectrometry. In time-of-flight mass 
spectrometry, flight time in the drift tube is proportional to the square root of the mass-to-charge ratio. The arrival of the ion packets at the end of the drift tube is determined by a secondary ion/electron multiplier detector.

The instrument used, the LAMMA 500, has transmission geometry which refers to having the laser beam and the mass spectrometer in-line. A complete description of LMMS is given by Denoyer et al. [14], Hercules et al. [15] and Simons [16]. Single particle analysis is discussed by Kaufmann [17], by De Waele and Adams [18] and by Wieser and Wurster [19]. Early work in aerosol research applications is presented by Wieser, Wurster and Seiler [20].

Some of the important aspects of the LMMS instruments are nominal micrometer spatial resolution, high detection sensitivity and detection capability for either positive and negative ions produced in the laser ionization. In addition, it is usually possible to determine the elemental, isotopic and in many cases even the molecular composition of a particle. LMMS is generally not considered quantitative even for major constituents, except with regard to isotope abundance. Matrix effects in the sample play a dominant role during the laser beam-sample interaction, making quantitation difficult. The main strength of LMMS lies in providing useful qualitative information.

\subsubsection{Sample Preparation and Analysis}

The samples analyzed by LMMS came from the Mylar and stainless steel impactor substrates and a quartz fiber filter. Particles collected on Mylar from stage 8, 7, 6 and 5 (MA-02-8, MA-2-7, MA-2-6 and MA-2-5) that correspond to particle cut sizes of $0.6,1,2$ and $3.5 \mu \mathrm{m}$ were transferred to Formvar [a poly(vinyl formal)resin] coated copper transmission electron grids and mounted into the LAMMA 500 without further preparation. Particles from these stages and from MA-01-8 (stainless steel substrate) were also mounted on the back side of the quartz coverslip to analyze primarily for carbon. Quartz fibers containing attached particles taken from the PM-10-01 filter were mounted across an uncoated copper TEM grid and individual particles were ablated from the fibers. This fiber filter collects all particles less than $10 \mu \mathrm{m}$. Quartz fiber filters are especially efficient for small, submicrometer particles due to the large surface area and the relatively high diffusion coefficient of small particles.

Both single and multiple particles were ablated with the laser and mass analyzed. By ablating more than one particle, sensitivity for trace elements and compounds is enhanced. The samples mounted on the quartz coverslip were analyzed using a large, defocused laser beam that ionizes material from particles on the coverslip in a 50 to $100 \mu \mathrm{m}$ diameter spot. The defocus mode allows detection of molecular species, especially organic compounds that may be present in the sample. Both positive and negative ion spectra were taken. Over 200 spectra were collected at both the highest sensitivity available to the instrument and at a factor of ten lower sensitivity.

\subsubsection{Results and Discussion}

The results of analysis by LMMS indicate that the samples are primarily inorganic fine dust particulate material. This is based on the fact that for all the samples analyzed, the characteristic carbon cluster pattern was not found in abundance. However, some of the samples did show carbon to be present in small amounts as evidenced by the sequence of $\mathrm{m} / \mathrm{z}$ peaks at $12,24,36, \ldots 72$. No organic molecular species were detected in the samples. An optical micrograph in transmitted light is presented in Figure 1 of MA-02-8 mounted on a quartz coverslip. The particles appear, for the most part, to be less than $1 \mu \mathrm{m}$ and somewhat rounded in shape. 


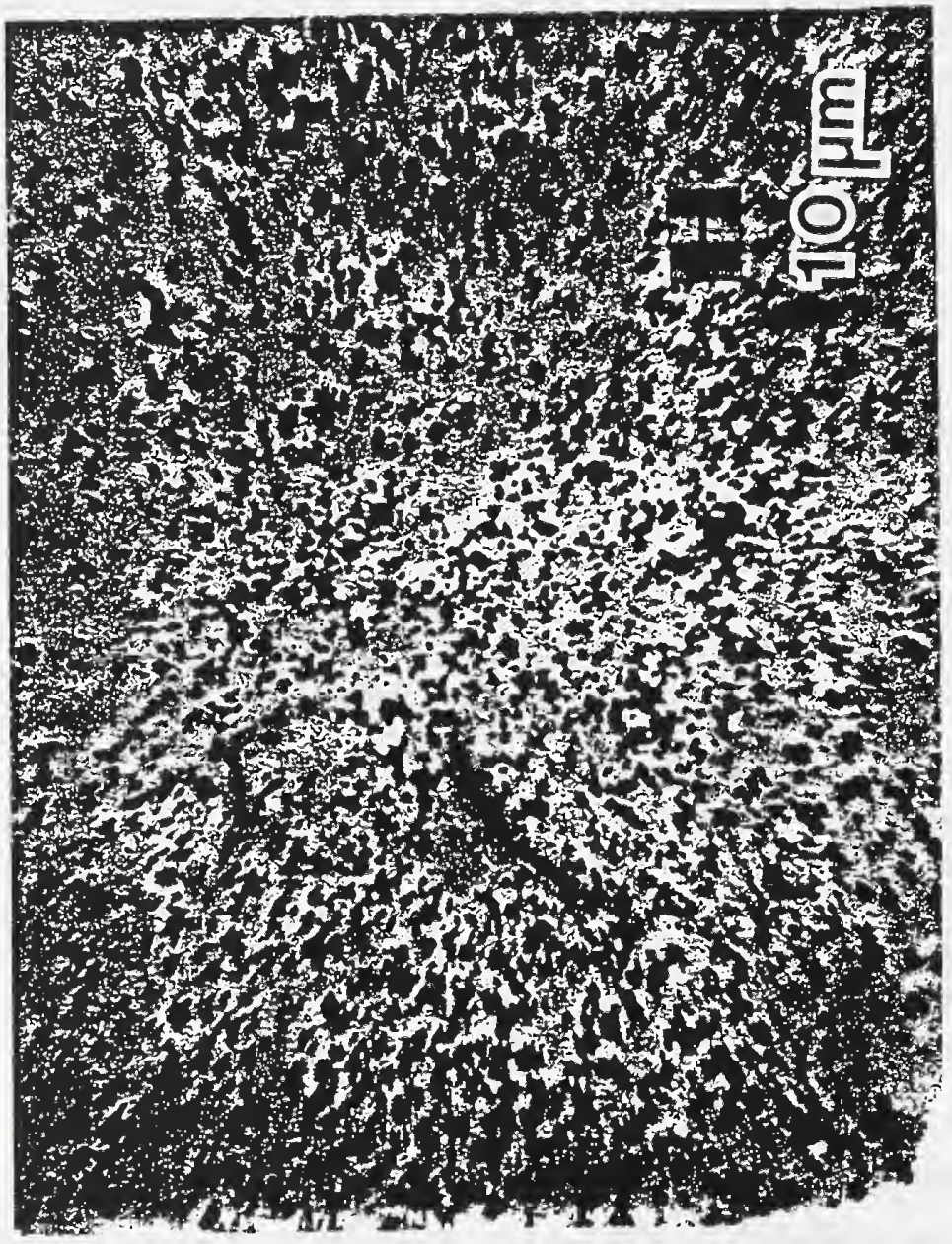




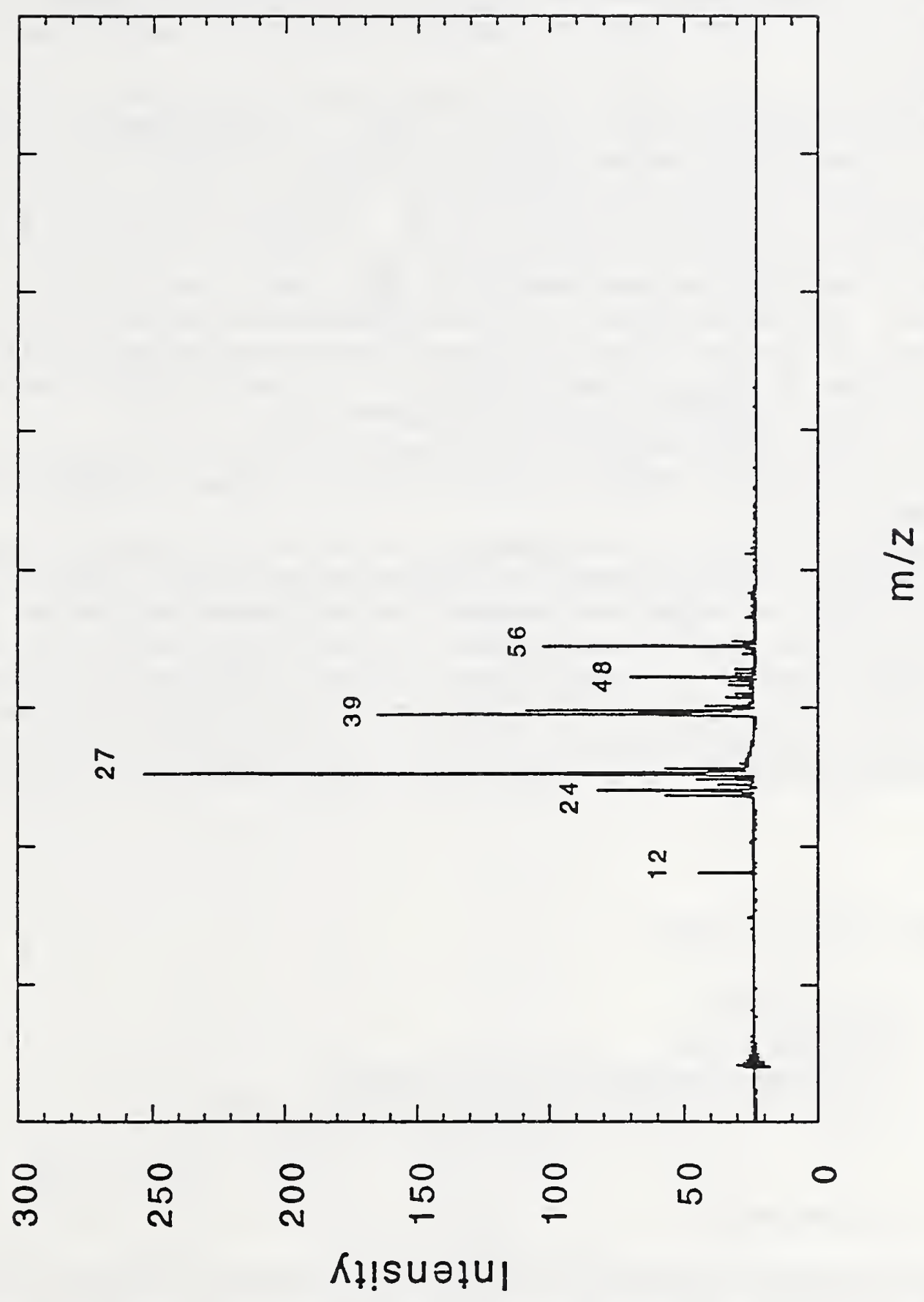

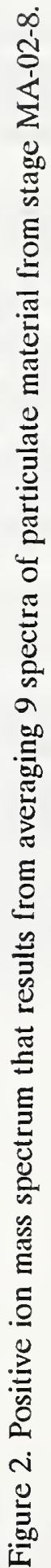


A positive ion spectrum is presented in Figure 2 that is composed of the average of 9 spectra from MA-02-8. The positive ions identified in various spectra taken of MA-02-8 material are presented in Table 12.

Evidence for these identifications is based on peak patterns resulting from isotopic abundances and from the cluster ions that form from the major constituents. Figure 3 shows an expanded scale of the average spectrum shown in Figure 2. A typical negative ion spectrum of MA01-8 particulate material is shown in Figure 4. The negative ions observed and their identification is found in Table 6.

Samples MA-02-7, MA-02-6, and MA-02-5 produced mass spectra similar to MA-02-8. A positive ion average spectrum for MA-02-7 is shown in Figure 5. Peak identification is similar to MA-02-8. A typical negative ion mass spectrum is shown in Figure 6 for MA-02-7 which is likewise similar to the respective spectra found for MA-02-8 material. Particles attached to quartz fibers from the filter mentioned above indicated the presence of $\mathrm{Pb}$. A positive ion average (of 8 spectra) spectrum of particles attached to the quartz fibers is presented in Figure 7. An expanded low sensitivity single particle mass spectrum is shown in Figures 8 and 9. Note the isotopes of $\mathrm{Pb}$ are clearly shown in Figure 9. Lead was not found on any of the impactor surfaces analyzed, but was readily found on the fibers. It is thought that the $\mathrm{Pb}$ particles are $<0.1 \mu \mathrm{m}$ in size and thus are not collected on the impaction stages. However, since the fiber filter serves as an excellent collection material for small particles, the small particles containing $\mathrm{Pb}$ were collected there.

Particulate material from MA-01-8, the lowest impactor stage with stainless steel substrates, was transferred to a cleaned quartz coverslip for LMMS analyzing for carbon. Negligible carbon was found in the positive ion mode.

In summary, the particulate matter collected on the bottom four stages of the impactor sampler were analyzed by LMMS and found to be primarily inorganic fine dust. Minimum sample preparation was required, the particles were transferred from the impactor substrate onto either a formvar coated grid surface or onto a quartz coverslip. Over 200 mass spectra were taken in both positive and negative ion mode. This material appears to be fine particle matter that is composed of $\mathrm{Na}, \mathrm{Mg}, \mathrm{Al}, \mathrm{Si}, \mathrm{K}, \mathrm{Ca}, \mathrm{Fe}, \mathrm{Ti}$, and some $\mathrm{Ba}$. Particles collected by PM-10-01 quartz fibers were analyzed by ablating the particles directly from the fibers. The particles found on the quartz fiber filter contained lead. There appears to be very little carbon molecular species present in the samples analyzed.

\subsection{Micro-Raman Analysis}

Contributed by -

Dr. Edgar S. Etz

Surface and Microanalysis Science Division

Chemical Science and Technology Laboratory, NIST

\subsubsection{Introduction}

Micro-Raman analysis was performed on several air particulate samples collected by a cascade impactor sampler. The particulate material collected on two of the impactor stages, i.e., stages MA01-6 (cut-off diameter 2.0 $\mu \mathrm{m}$ ) and MA-01-8 (cut-off diameter $0.6 \mu \mathrm{m}$ ), was examined in the Raman 


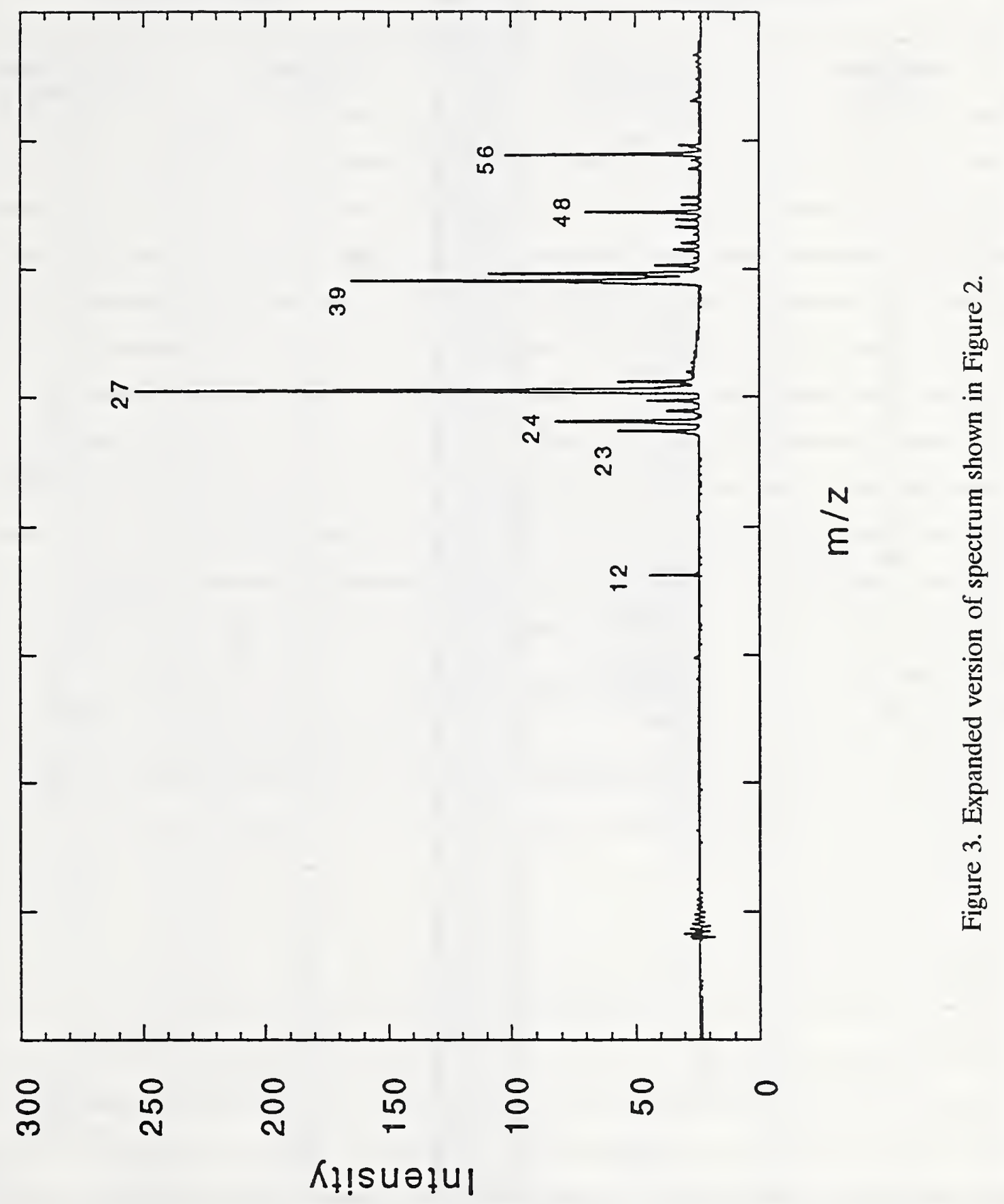


Table 12. Particles Analyzed from Mylar Substrate of Marple Cascade Impactor

\begin{tabular}{|c|c|c|c|}
\hline \multicolumn{2}{|c|}{$\begin{array}{l}\text { Possible Identification of Particles from } \\
\text { Sample MA-02-108 }\end{array}$} & \multicolumn{2}{|c|}{$\begin{array}{l}\text { Possible Identification of Particles from } \\
\text { Sample MA-02-107 }\end{array}$} \\
\hline $\begin{array}{l}\text { Mass/Charge } \\
(\mathrm{m} / \mathrm{z})\end{array}$ & $\begin{array}{l}\text { Possible Positive } \\
\text { Ion Species }\end{array}$ & $\begin{array}{l}\text { Mass/Charge } \\
(\mathrm{m} / \mathrm{z})\end{array}$ & $\begin{array}{l}\text { Possible Negative } \\
\text { Ion Species }\end{array}$ \\
\hline 6 & $\mathrm{Li}$ & 1 & $\mathrm{H}$ \\
\hline 7 & $\mathrm{Li}$ & 12 & $\mathrm{C}$ \\
\hline 12 & $\mathrm{C}$ & 13 & $\mathrm{CH}$ \\
\hline 23 & $\mathrm{Na}$ & 16 & 0 \\
\hline 24 & $\mathrm{Mg}, \mathrm{C}_{2}$ & 17 & $\mathrm{OH}$ \\
\hline 27 & $\mathrm{Al}$ & 24 & $C_{2}$ \\
\hline 28 & $\mathrm{Si}$ & 25 & $\mathrm{C}_{2} \mathrm{H}$ \\
\hline 39 & $\mathrm{~K}$ & 26 & $\mathrm{CN}, \mathrm{C}_{2} \mathrm{H}_{2}$ \\
\hline 40 & $\mathrm{Ca}$ & 31 & $\mathrm{P}$ \\
\hline 48 & $\mathrm{Ti}$ & 35,37 & $\mathrm{Cl}$ \\
\hline 56 & $\mathrm{Fe}, \mathrm{CaO}$ & 36 & $\mathrm{C}_{3}$ \\
\hline 57 & $\mathrm{CaOH}$ & 42 & $\mathrm{CNO}$ \\
\hline \multirow[t]{10}{*}{138} & $\mathrm{Ba}$ & 59 & $\mathrm{AlO}_{2}$ \\
\hline & & 60 & $\mathrm{SiO}_{2}, \mathrm{C}_{3}$ \\
\hline & & 69 & $?$ \\
\hline & & 72 & $\mathrm{C}_{6}, \mathrm{FeO}$ \\
\hline & & 76 & $\mathrm{SiO}_{3}$ \\
\hline & & 84 & $C_{7}$ \\
\hline & & 97 & $?$ \\
\hline & & 103 & $?$ \\
\hline & & 119 & $\mathrm{AlSiO}_{4}$ \\
\hline & & 179 & $\mathrm{AlSi}_{2} \mathrm{O}_{6}$ \\
\hline & & & \\
\hline
\end{tabular}




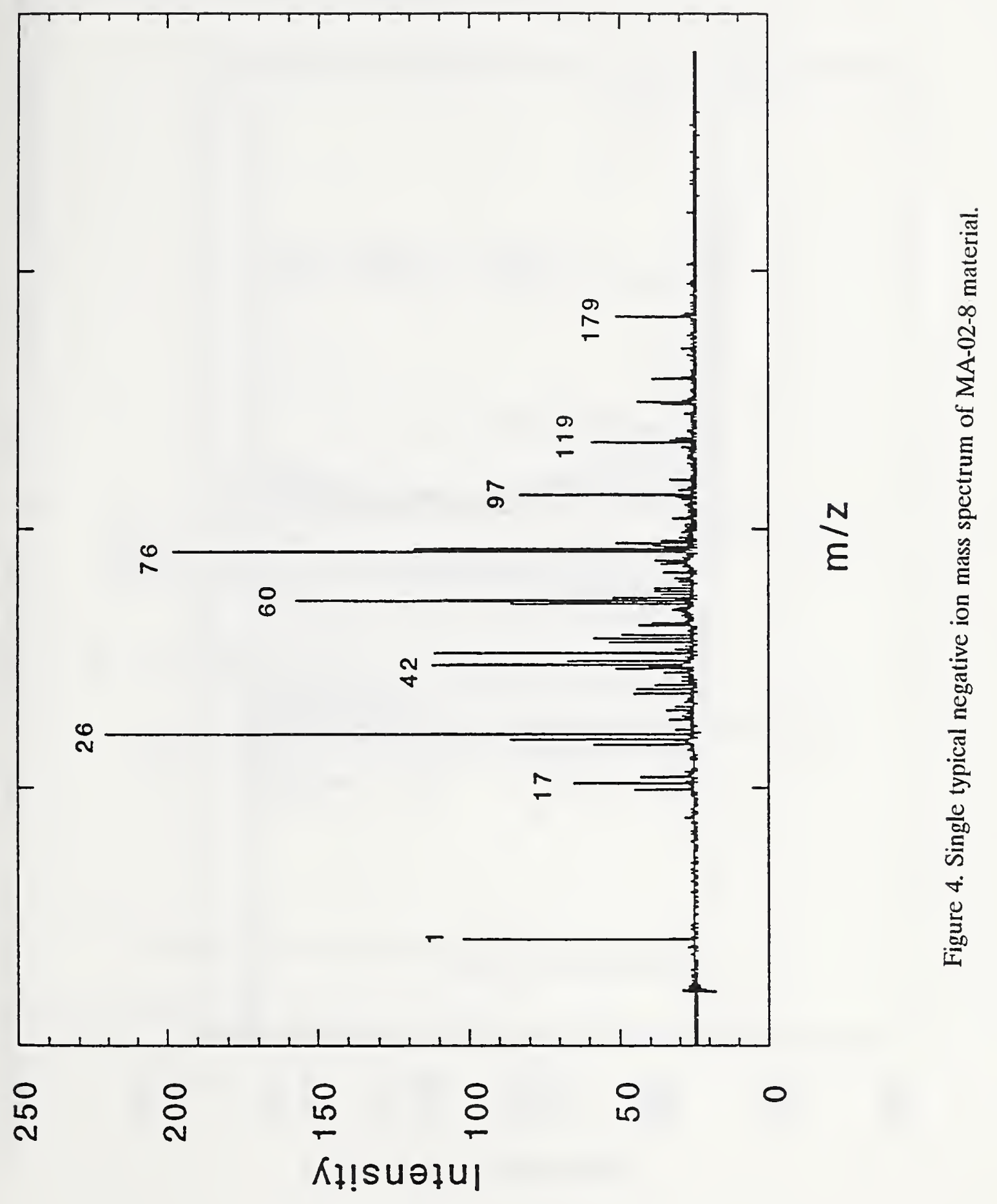




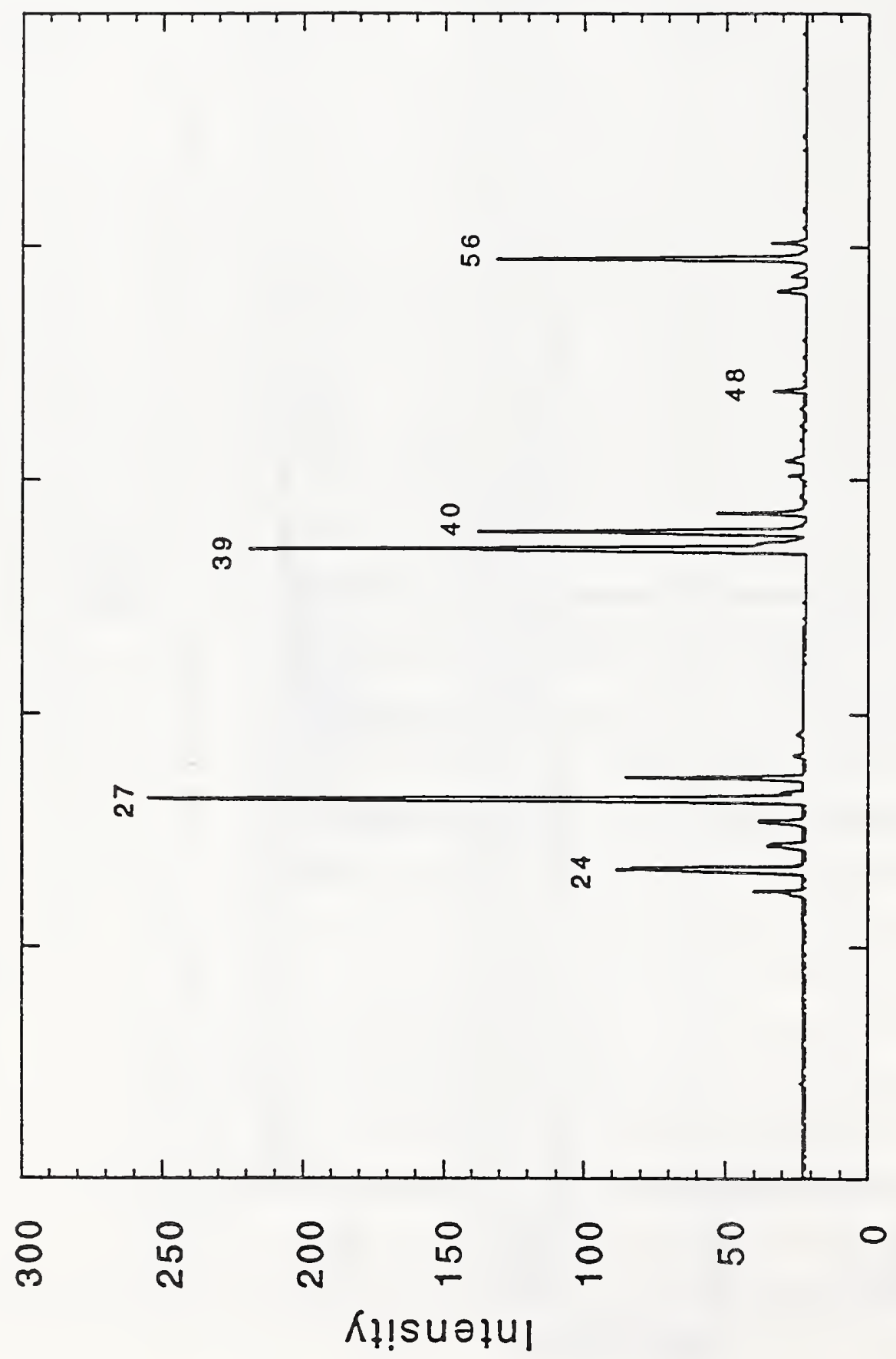

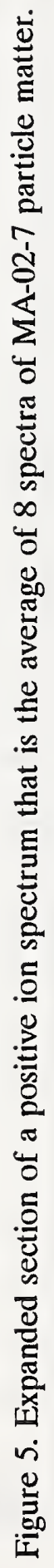




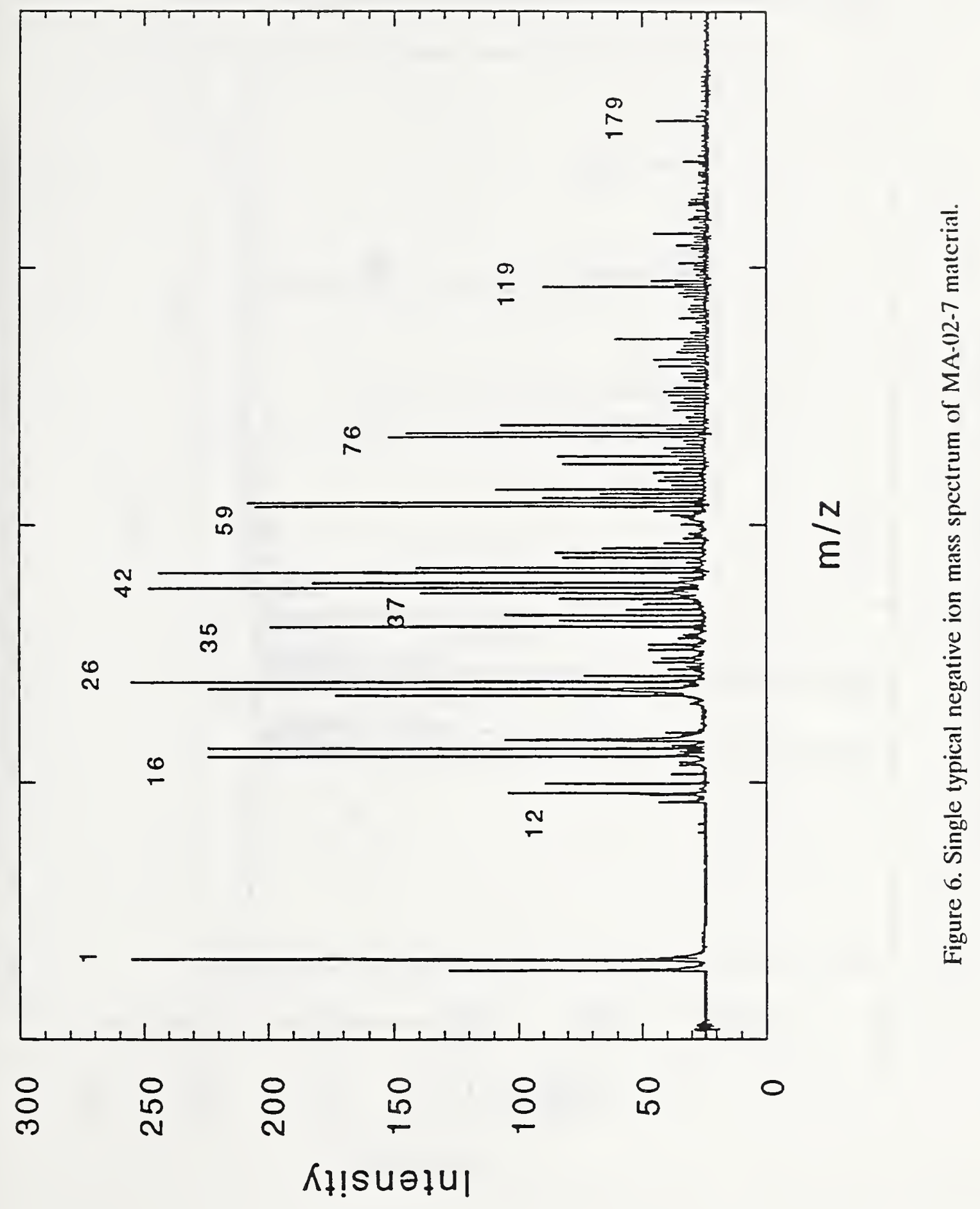




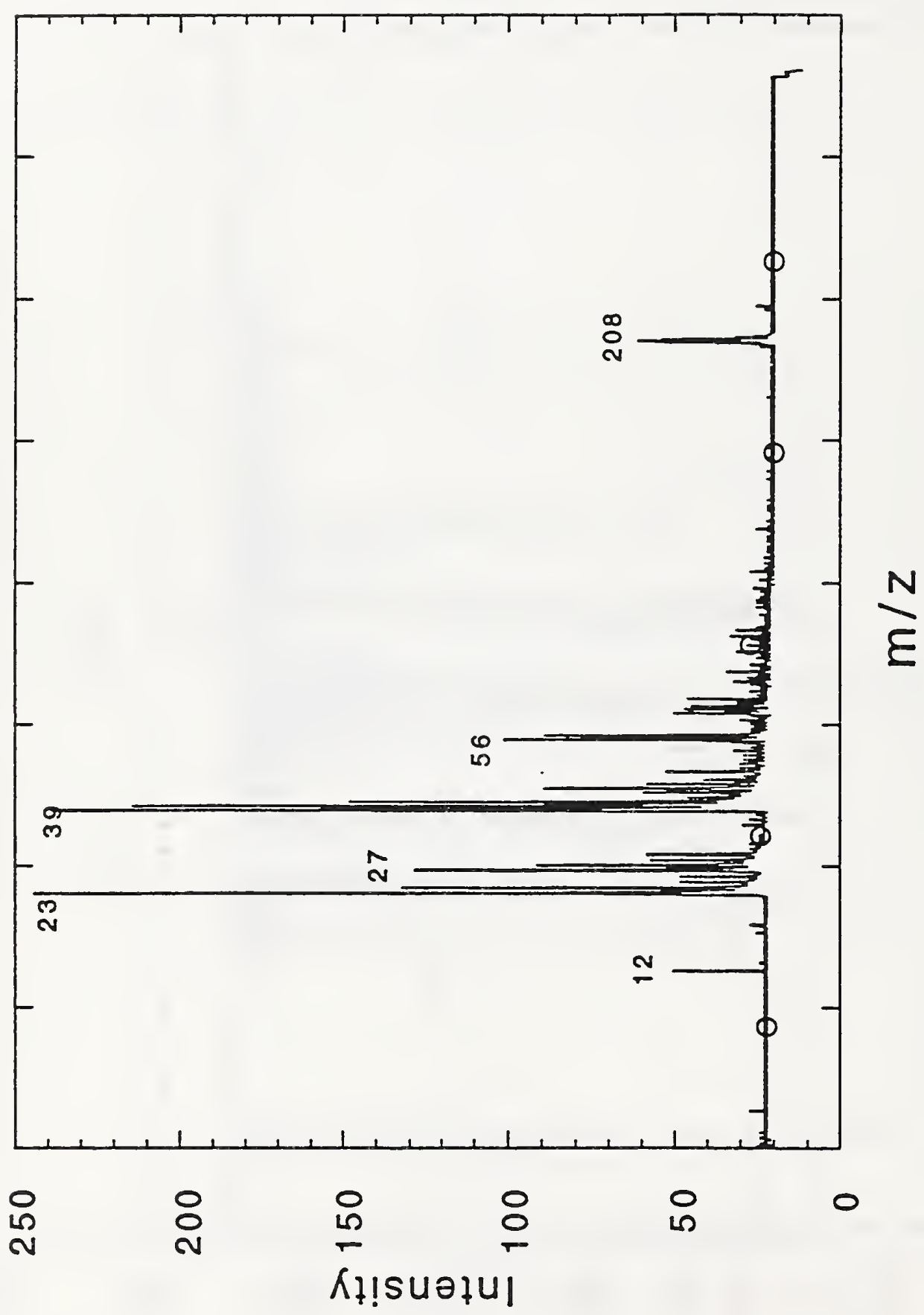

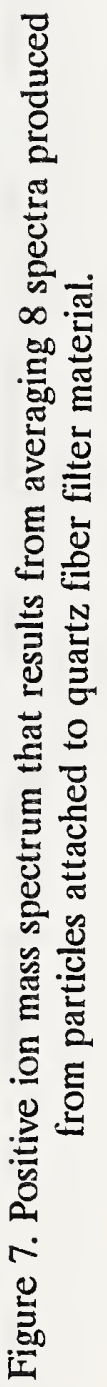




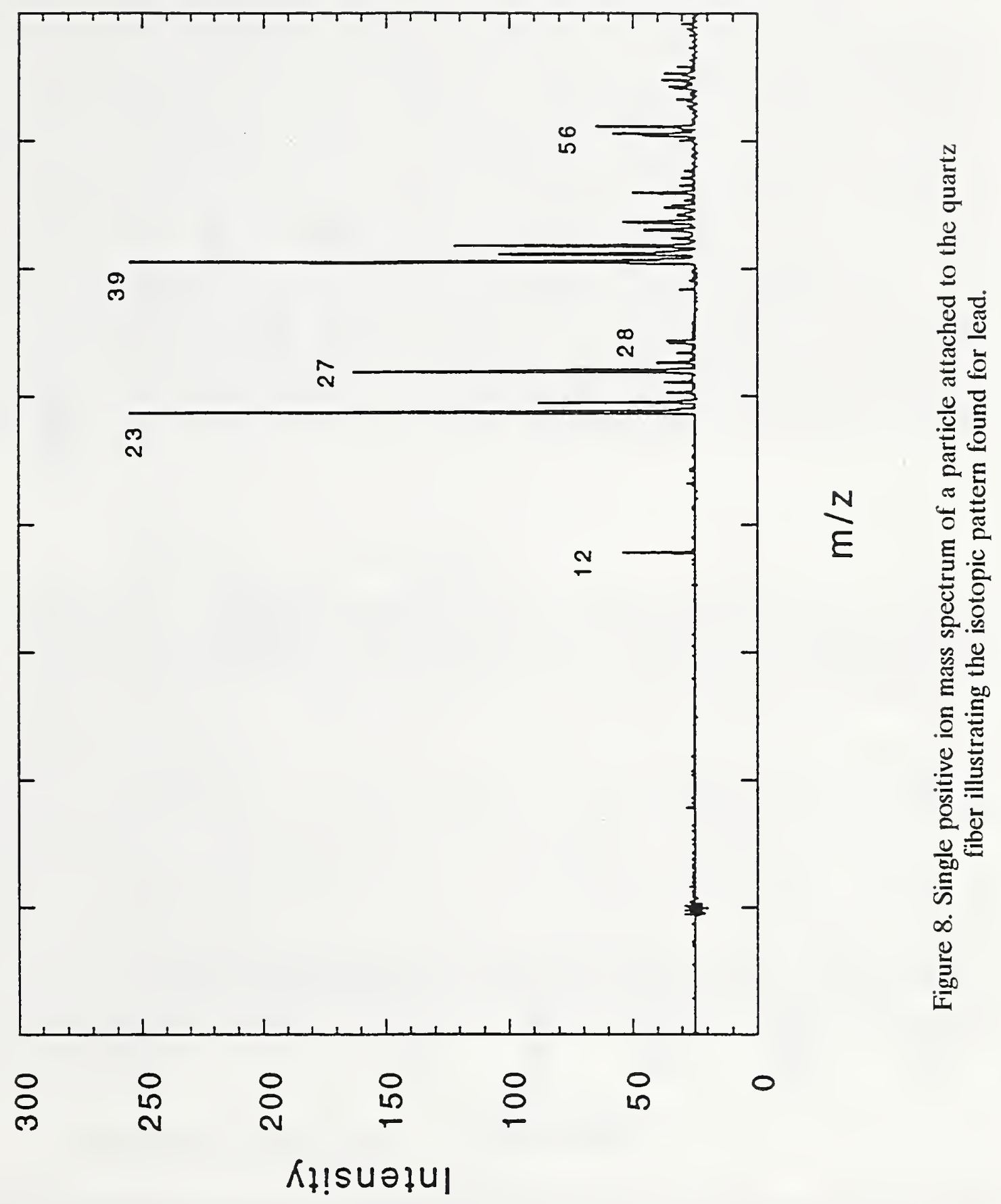




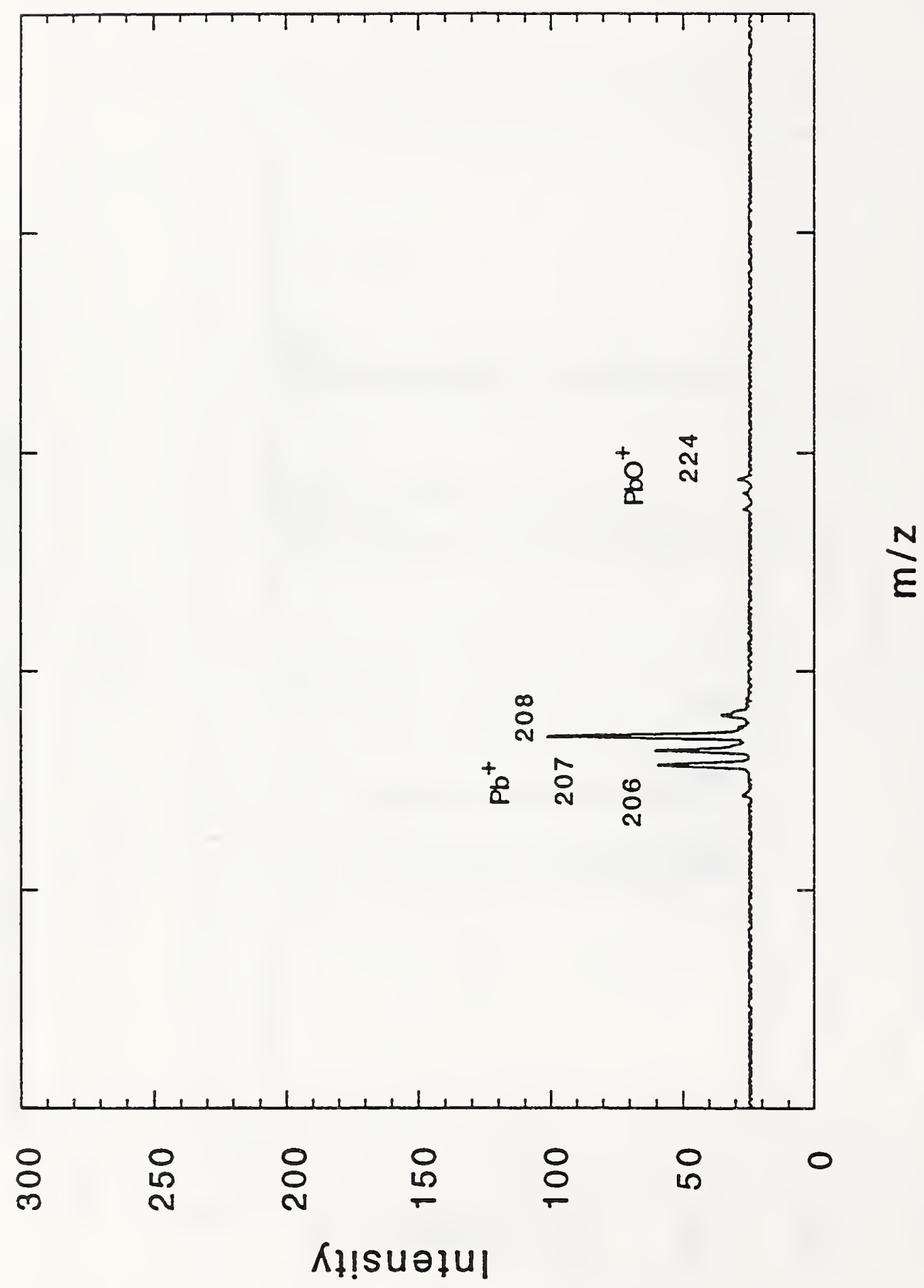

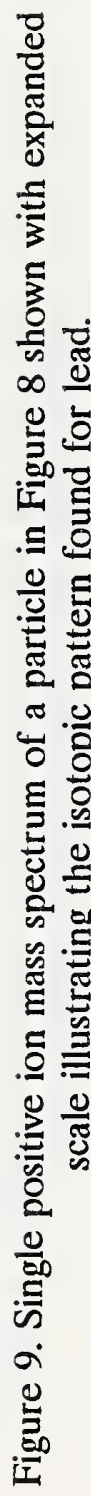


microprobe with the aim of obtaining molecular, or compound, information on the collected material.

Raman spectroscopy furnishes a vibrational spectrum indicative of chemical bonding and of crystallographic structure, in the case of molecular solids. In the absence of any interfering fluorescence or luminescence from the sample, the Raman spectrum of most compounds generally serves as a diagnostic "fingerprint", much like the closely related infrared spectrum. Present-day Raman microprobes, permitting probing the sample at the microscopic level, can acquire this analytical information with spatial information down to $1 \mu \mathrm{m}$ and a detection limit of about $1 \mathrm{pg}$.

To illustrate the specificity of the Raman spectrum for common natural minerals, the microprobe spectra of natural calcite $\left(\mathrm{CaCO}_{3}\right)$ and natural quartz $(\alpha-\mathrm{SiO})$ are shown in Figures 10 and 11. As molecular solids become more complex, in terms of the variety of chemical bonds that are Raman active, the complexity of the vibrational spectrum increases, manifesting itself in a multitude of characteristic vibrational bands, indicative of functional group vibrations. This is illustrated in Figure 12 with the spectrum of the organic explosive HMX (1,3,5,7-tetranitro-1,3,5,7-tetraazacyclooctane) showing numerous bands over the Raman frequency range plotted out. The Raman microprobe spectra of the two common minerals referred to here (Figure 10 and 11) and that of the organic nitro-compound (Figure 12) each exhibit good signal-to-background relationships, whereby the expected (and observed) Raman bands are unobscured by a possibly moderate or high spectral background that sometimes arises from sample fluorescence or luminescence. The source of any sample fluorescence or luminescence may often be sample impurities, such as trace contaminants, or may stem from the sample itself. Polynuclear aromatic hydrocarbons (PAHs) tend to be intrinsically highly fluorescent (due to their electronic structure) in Raman measurements with visible laser excitation.

\subsubsection{Sample Preparation and Analysis}

To examine the particulate material collected by the size-segregating impactor sampler, we employed a commercial Raman microprobe. This instrument is of the dispersive design, employing an optical multichannel detector (SIT-diode array), and using the monochromatic emission lines from either an Argon-ion laser (e.g., $514.5 \mathrm{~nm}, 488.0 \mathrm{~nm}$ ), or a Krypton-ion laser (e.g., $647.1 \mathrm{~nm}$ ) as excitation sources.

We obtained the Raman spectra of these samples with both $514.5 \mathrm{~nm}$ (green) and $647.1 \mathrm{~nm}$ (red) excitation to examine the fluorescence behavior of these samples at these two different excitation frequencies. In general, any sample fluorescence observed with $514.5 \mathrm{~nm}$ excitation is usually less pronounced, and often totally absent, when the spectra are excited at $647.1 \mathrm{~nm}$.

With the focused laser spot (beam spot of $\approx 2 \mu \mathrm{m}$ diameter) of the Raman microprobe we could examine the impacted particulate material for homogeneity of composition, to discern any differences in composition, if present. The particulate material collected on the stainless-steel foils of stages MA-01-6 and MA-01-8 of the impactor consists of extensively aggregated, piled-up, finelysized dust of uniform appearance and morphology. Microscopic aggregates of this material in various parts of these two collection surfaces were examined in the Raman microprobe by entirely routine measurement procedures.

\subsubsection{Results and Discussion}

Every part of this collected fine dust, on both stages, gave rise to intense, diffuse yellow luminescence as the spectra were excited with $514.5 \mathrm{~nm}$ radiation. This luminescence did not 


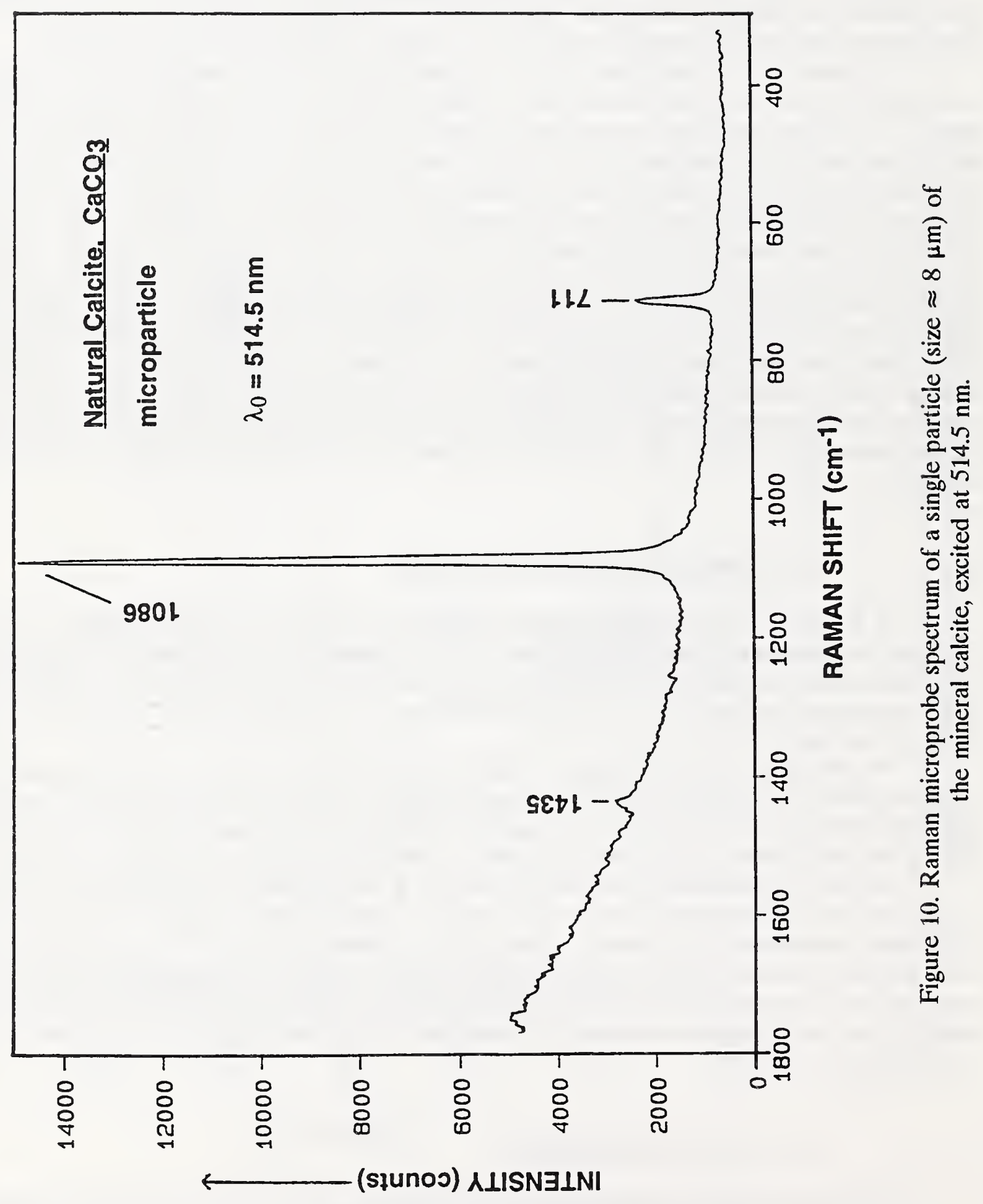




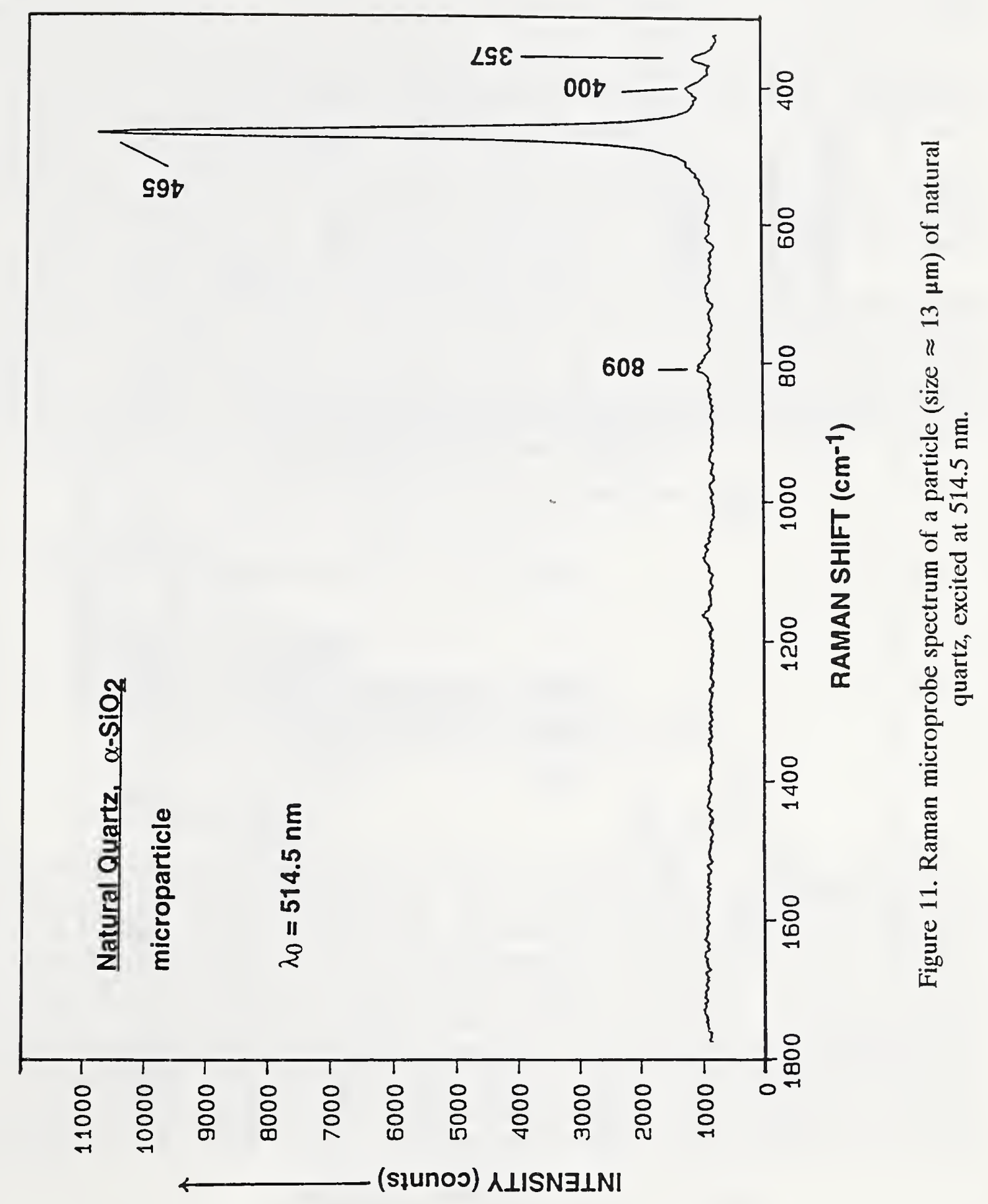




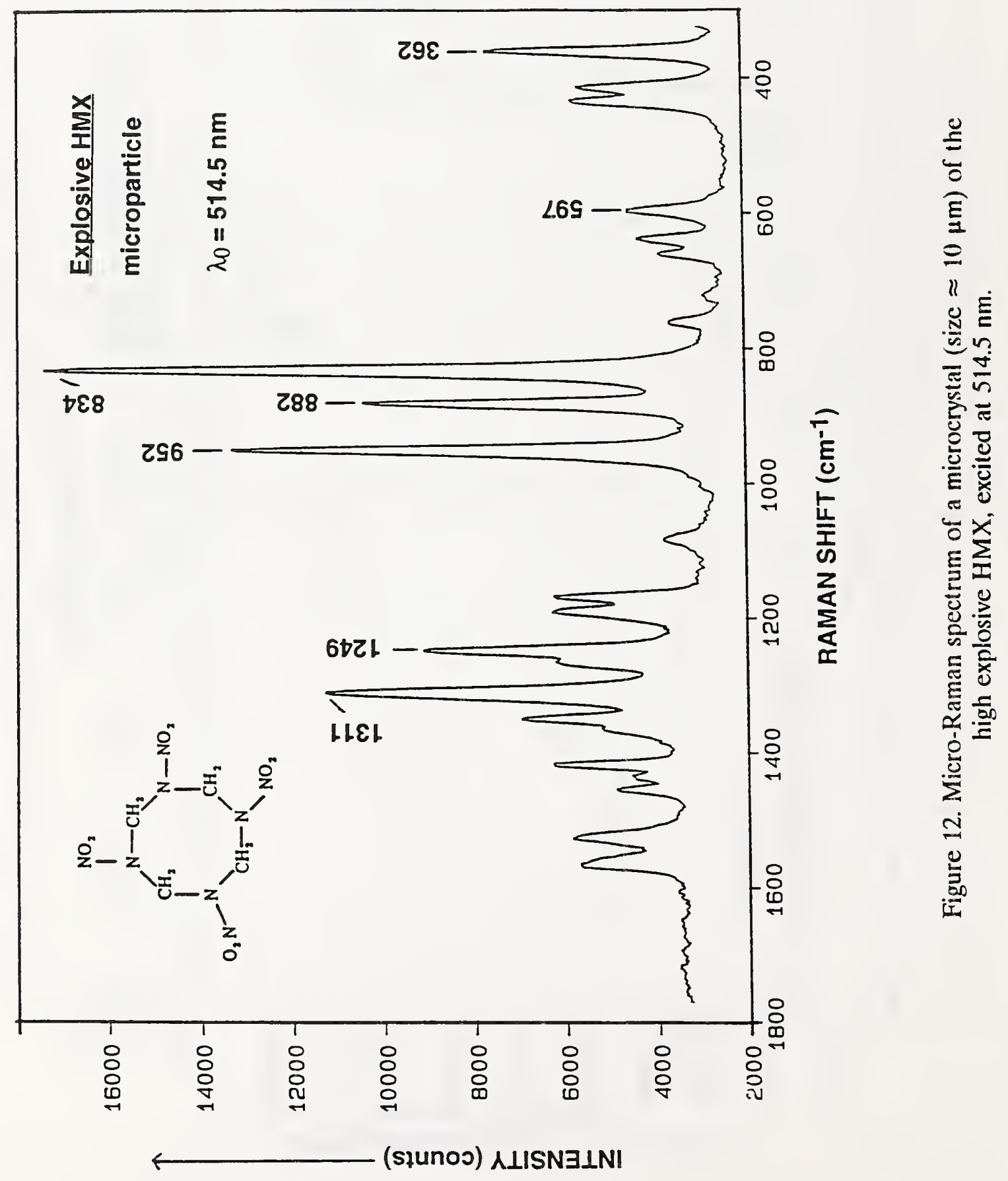


sufficiently bleach away and diminish with time, upon prolonged irradiation, to permit informative spectra to be obtained.

Figures 13 and 14 show representative micro-Raman spectra of the particulate material collected on stages MA-01-6 and MA-01-8, excited at $514.5 \mathrm{~nm}$. Both particulate fractions gave spectra showing broad-band fluorescence only, which in these cases masked any Raman features which may have been present in this spectral region. Common minerals, such as from earth's crustal material, invariably show Raman bands in the region from 300 to $1800 \mathrm{~cm}^{-1}$, and so do most organic compounds and polymers.

When these same particulate fractions (on stages MA-01-6 and MA-01-8) were examined with $647.1 \mathrm{~nm}$ excitation (Figure 15), equally intense laser-excited luminescence was observed that prevented any Raman data to be obtained. Again, any potential Raman information was masked by these non-Raman emissions whose origin(s) are not known at this time.

We should point out that the spectra of the "reference" samples (Figures 10 to 12, of calcite, quartz, and HMX) were acquired in parallel with the impactor samples of this study, employing identical measurement conditions. Their spectra display the expected analytical information unobscured by a masking (fluorescent or luminescent) spectral background.

We speculate that a likely source of the observed luminescence from these air-particulate collections may be adsorbed, highly-fluorescing, organic material, or residue, present in sufficient concentrations, or even as a surface coating, to give rise to this overwhelming laser-excited luminescence. A careful removal of this presumed organic contamination, by either low-temperature ashing or solvent extraction, may clean up this particulate fraction enough to render this material in a form that will allow analytically useful Raman spectra to be obtained.

\subsection{Environmental Scanning Electron Microscopy}

Contributed by -

Mr. Scott A. Wight

Surface and Microanalysis Science Division

Chemical Science and Technology Laboratory, NIST

\subsubsection{Introduction}

The Environmental Scanning Electron Microscope (ESEM) is appropriately suited to investigate particles (Wight and Zeissler [21]). The sample chamber in the ESEM operates at low vacuum [280-693 $\mathrm{Pa}$ (2.1-5.2 Torr)] and the gas molecules present are utilized to both drain surface charge and provide imaging gain. The neutralization of surface charge makes it possible to investigate insulating and particulate samples without applying a conductive coating. Use of the ESEM allows the sample to be later analyzed by other analytical techniques without the potential bias of conductive coatings and related preparation processes. The low vacuum of the sample chamber opens up electron microscopy to many samples (wet, volatile, loose particles, particles in oil, and loose fibers to name a few) that may not have been compatible with the high vacuum of conventional electron microscopy. A thorough review of the theory and operation of the ESEM can be found in Danilatos [14]. 


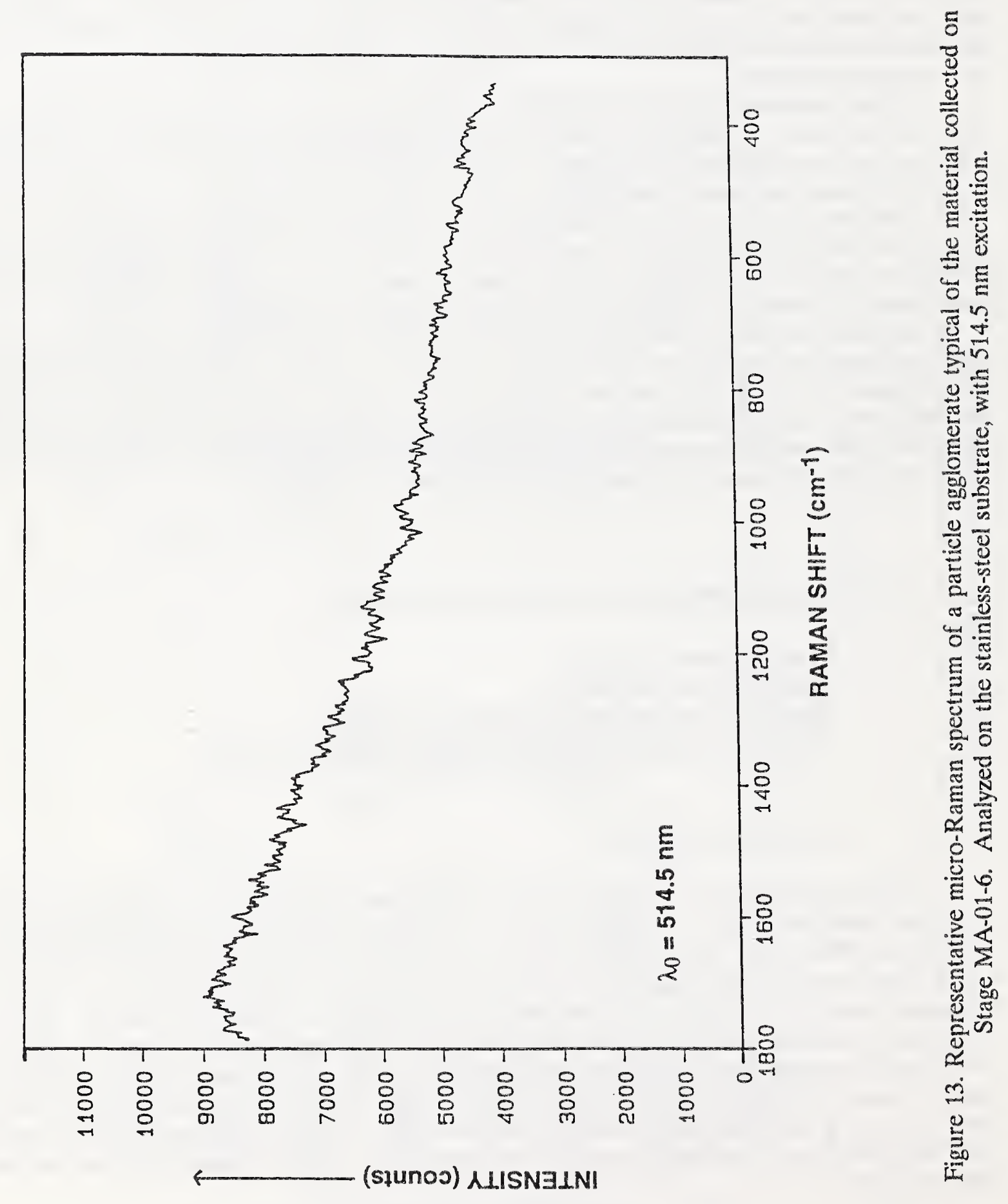




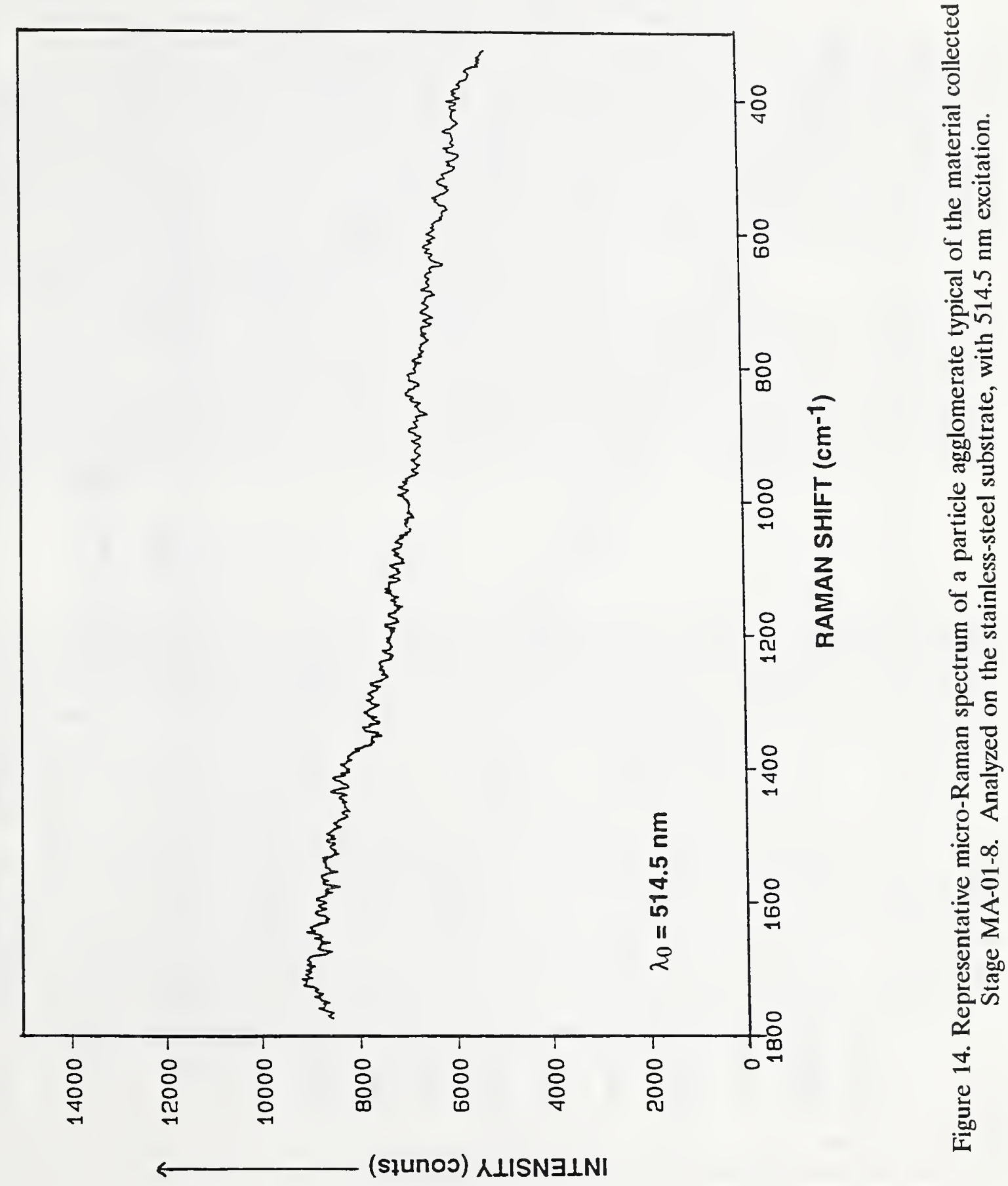




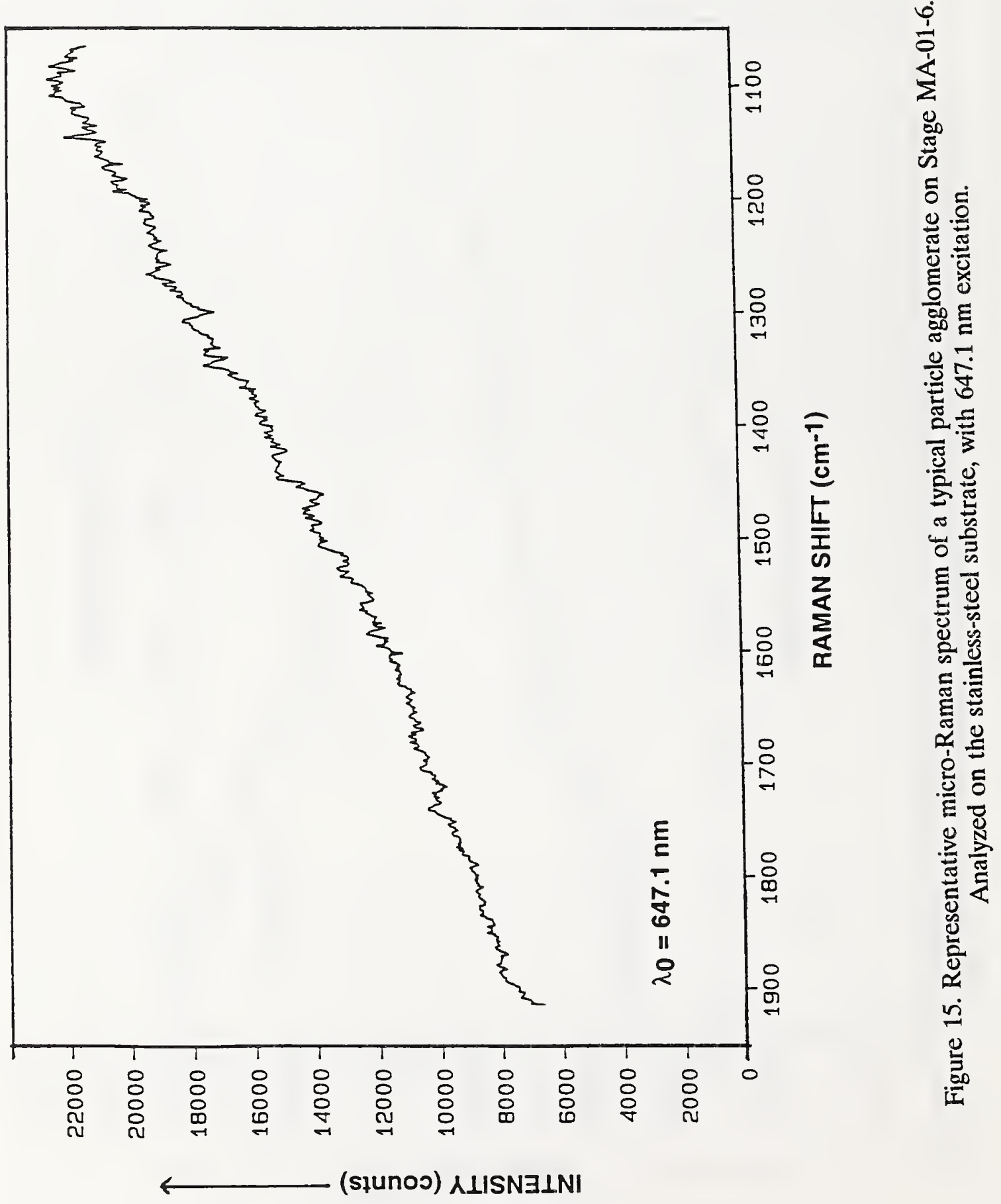




\subsubsection{Sample Preparation and Analysis}

The samples were investigated in an Electroscan ESEM equipped with a gaseous detection device (Danilatos [15]) for secondary electron imaging and a scintillating backscatter detector. The instrument was equipped with a Noran Pioneer $\mathrm{x}$-ray analysis system.

The samples consisted of XAD adsorbent, PM-10 filters, and impactor stages. XAD is an adsorbent used to collect organic vapors from the air after a Teflon filter has collected the particles. Sample XAD-01 was used in the Saudi Arabia sampling and sample XAD-06 was a laboratory blank, an unused sorbent tube. The used $\mathrm{XAD}$ was compared to the unused laboratory blank. The sample particulates collected on the PM-10 filters contained size segregated particles with aerodynamic diameters less than $10 \mu \mathrm{m}$. These particulates were collected on quartz fiber filters. A section of the filter was cut and mounted on a stub for analysis. The filter was searched in backscattered mode and high average atomic number particles were analyzed by Energy Dispersive Spectrometry (EDS). Approximately 20 particles per stage were analyzed by EDS.

The cascade impactor samples are size segregated by aerodynamic sizing which occurs during collection in the eight stage impactor. The stages of interest are MA-02-5, MA-02-6, and MA-02-7 with cut sizes $3.5,2$, and $1 \mu \mathrm{m}$ respectively. These size particles are of particular interest because of their impact on respiratory health and visibility reduction. Substrates were searched in backscattered mode and high average atomic number particles were analyzed by EDS in an effort to identify any toxics or heavy metals. Approximately 10 particles were analyzed by EDS from each impactor substrate.

\subsubsection{Results and Discussion}

Analysis of the XAD sorbent media indicated that the surface appears smooth on both XAD01 and XAD-06 and there was surface contamination on both types. The used sorbent (XAD-01) had more surface contamination (Figure 16) than the unused sorbent (Figure 17). This may have been the result of some small particles getting through the upstream filter. There was tweezer damage on both particle types which may contribute to the contamination. The interior appeared to have submicrometer structure and at $10 \mathrm{keV}$ the exterior of the used (XAD-01) sorbent (Figure 18) appeared to be smoother than the unused (XAD-06) sorbent (Figure 19).

Analysis of the PM-10 filter samples suggested that the major particles were silicates and lead/bromine particles. Minor particles were barium particles and iron containing silicates. Figure 20 shows the loading of particles on the glass fiber filter. The EDS background of the quartz fiber filter is in Figure 21. Figure 22 is a typical lead/bromine particle EDS spectrum and Figure 23 shows a barium containing particle spectrum. A small agglomerate (primary particle size $\approx 0.5-1.0 \mu \mathrm{m}$ ) was identified by EDS as sodium and chlorine. Particles were difficult to pick out against the complex background of the fiber mat in secondary mode. The filter was searched in backscattered mode in order to simplify particle identification (Figure 24).

Analysis of the cascade impactor substrates, Mylar and stainless steel, provided a chance to compare the two materials for sample collection. Figure 25 is a low magnification view of the stainless steel substrate which in sharp contrast to the fiber filter (Figure 23) is well suited to electron microscopy. It has a much smoother surface, it is conductive, and particles are identified more easily. The Mylar substrate has the advantage of being even smoother with no background lines in the EDS spectrum, but it tends to charge under the beam in conventional scanning electron microscopy. 


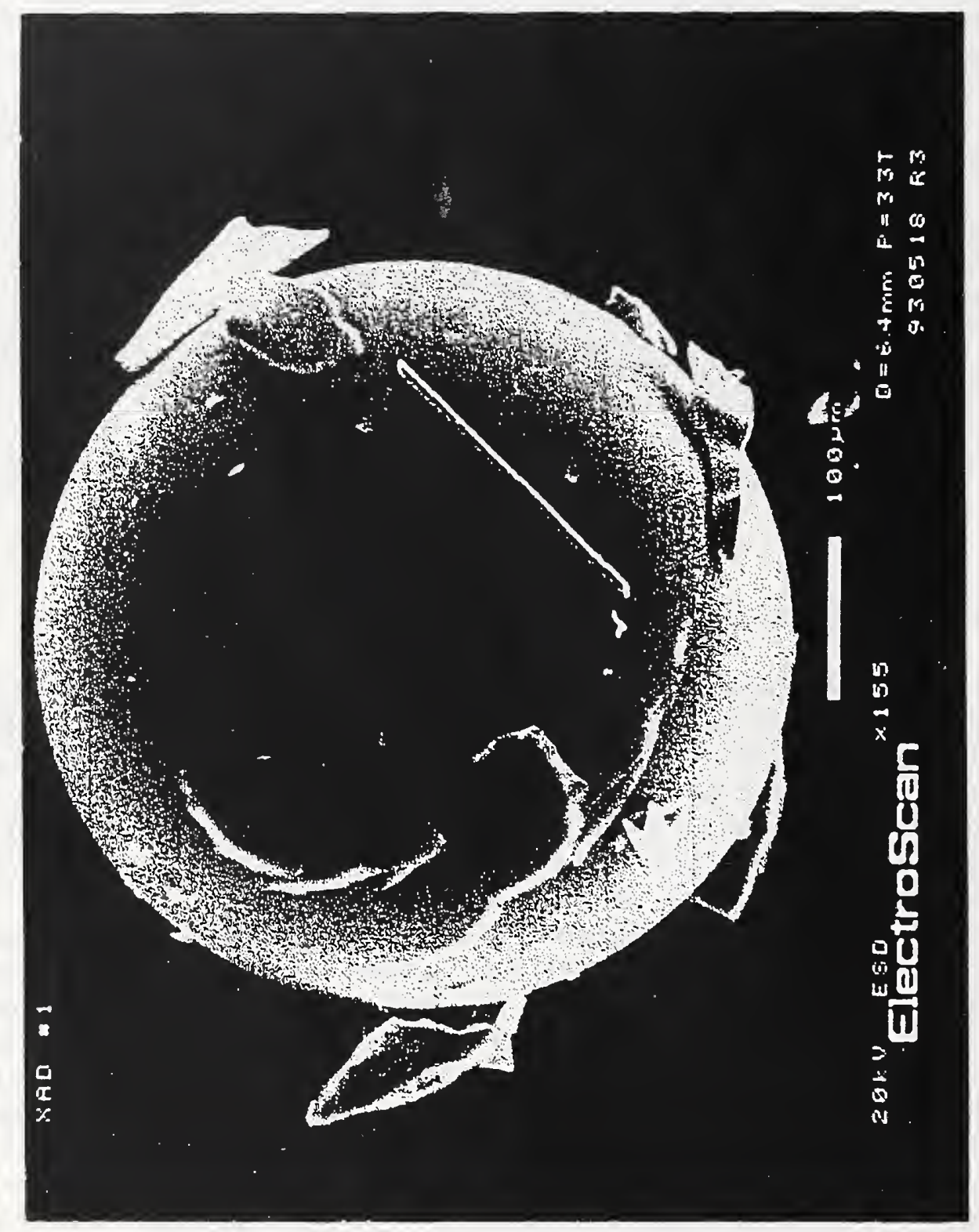

ن 


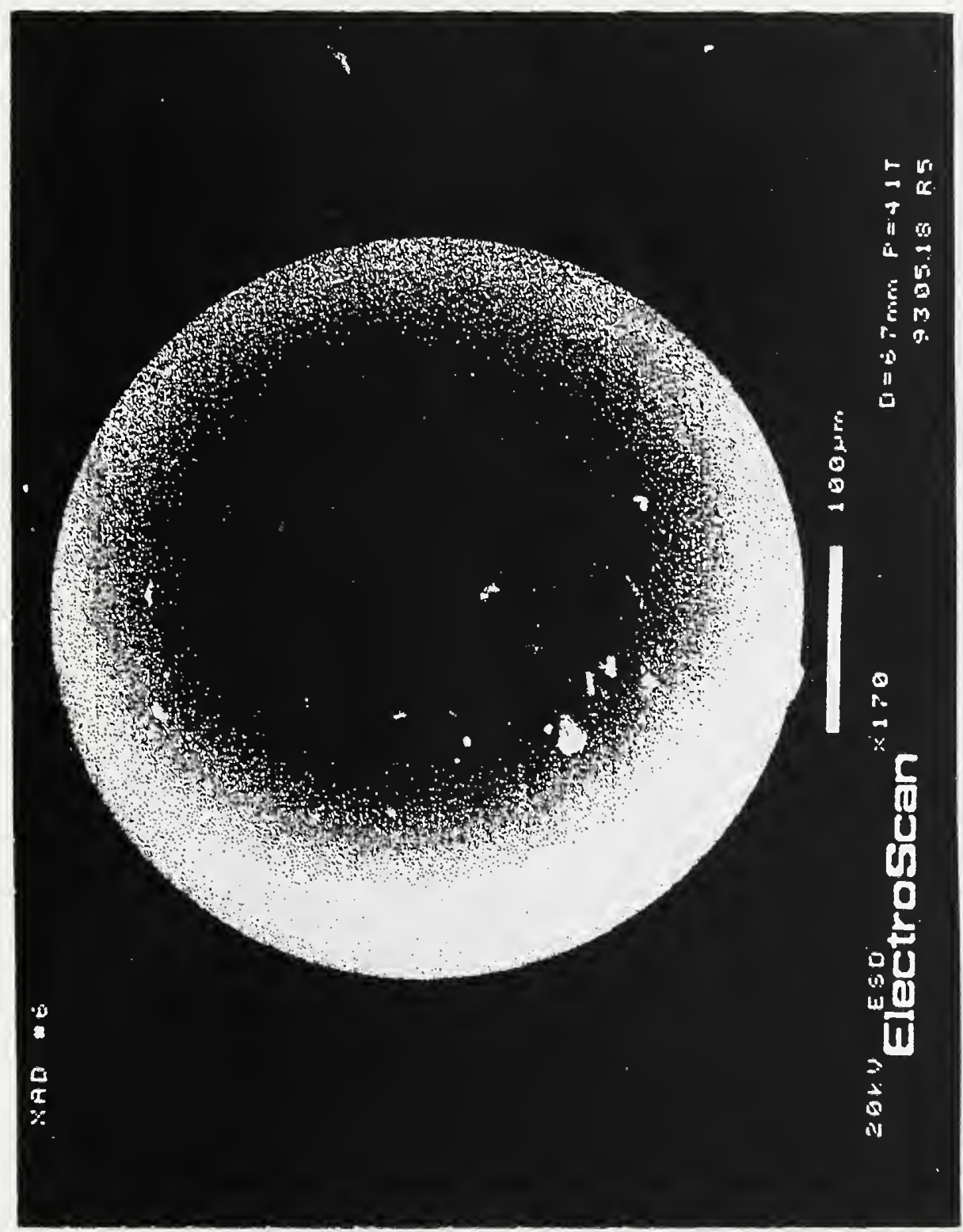

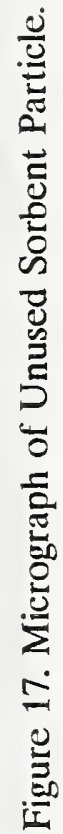




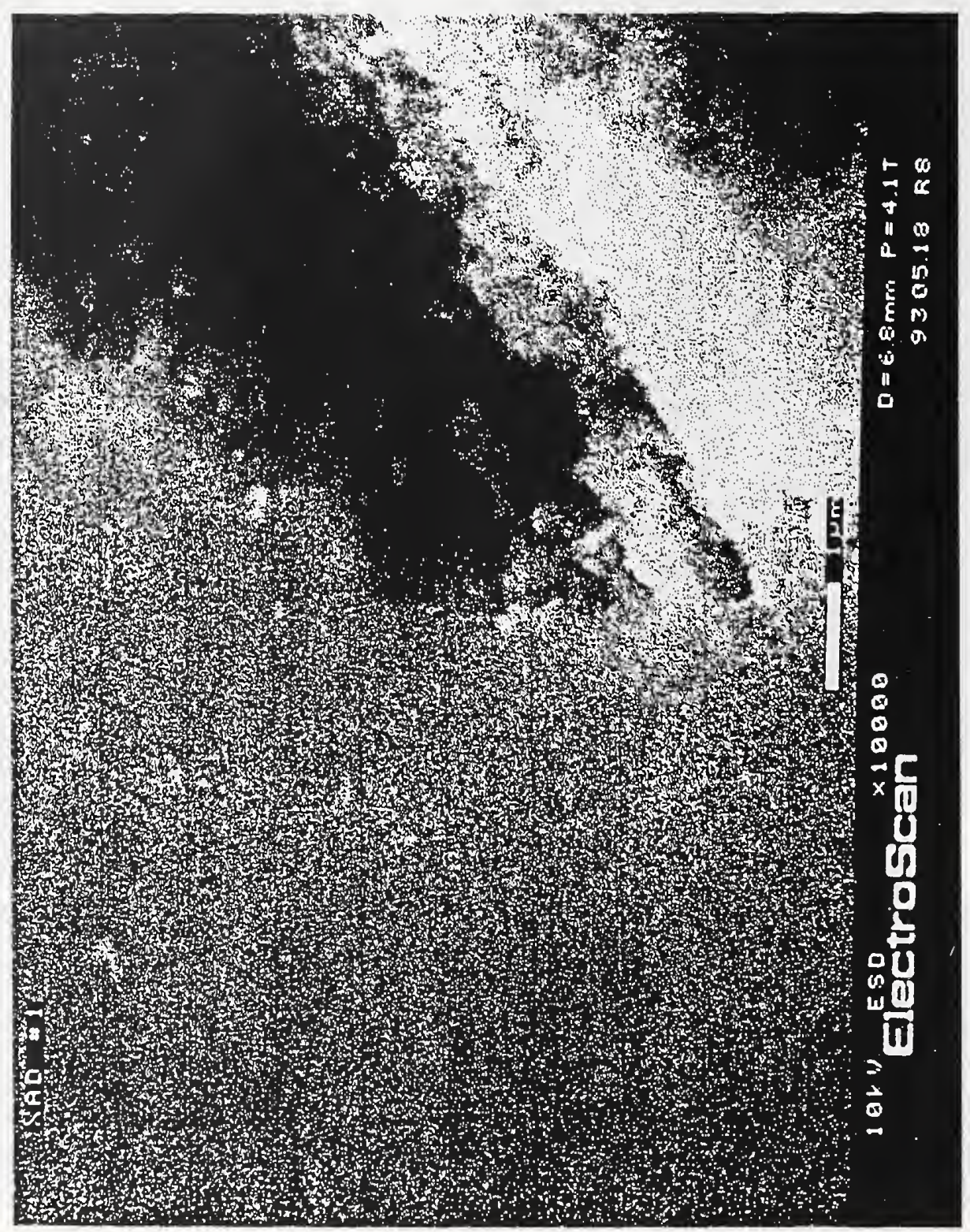

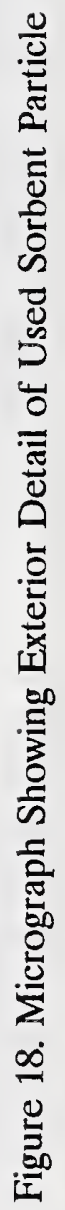




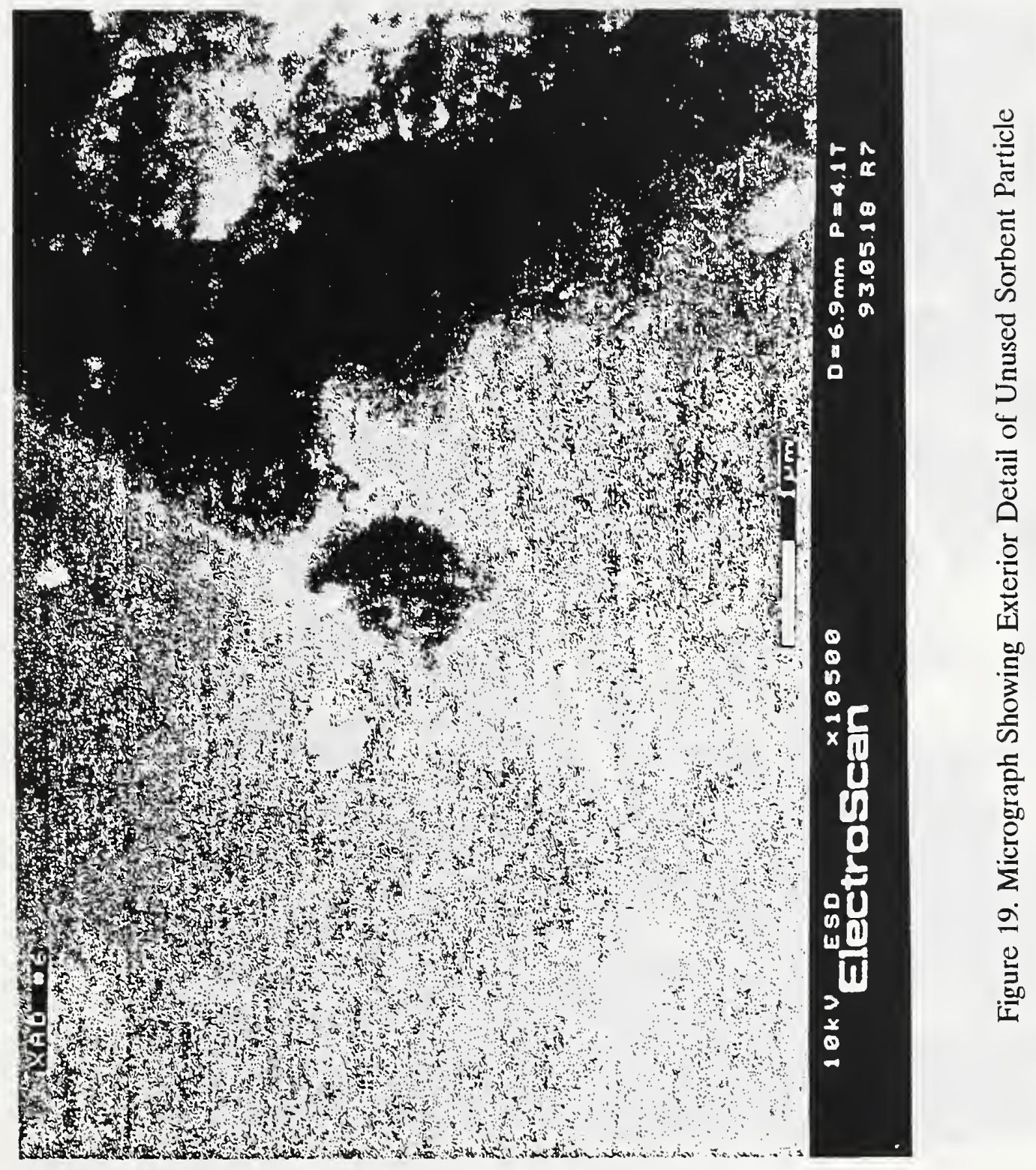




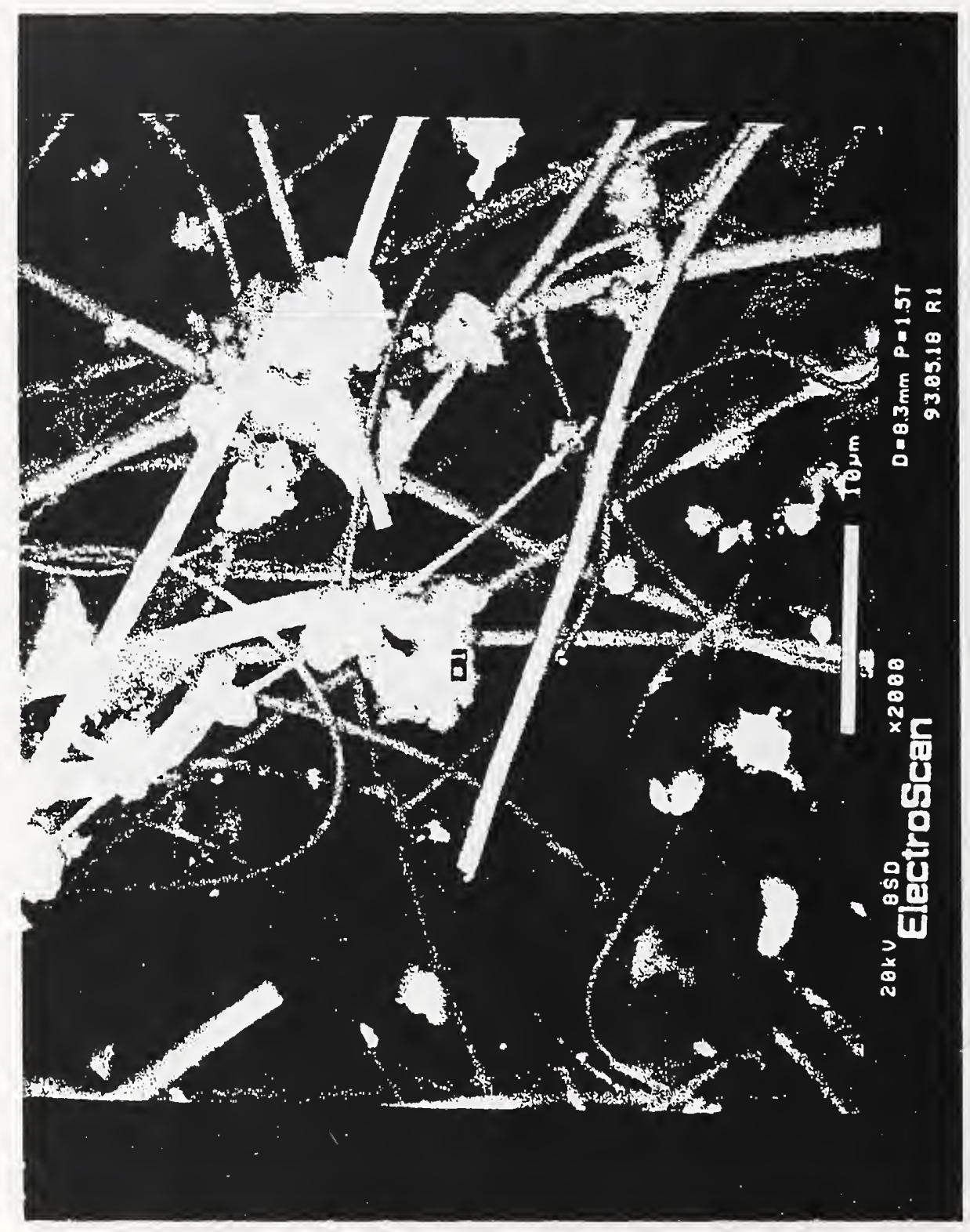

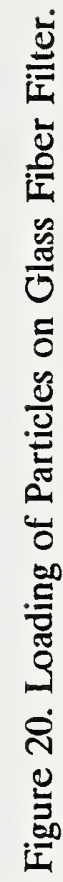




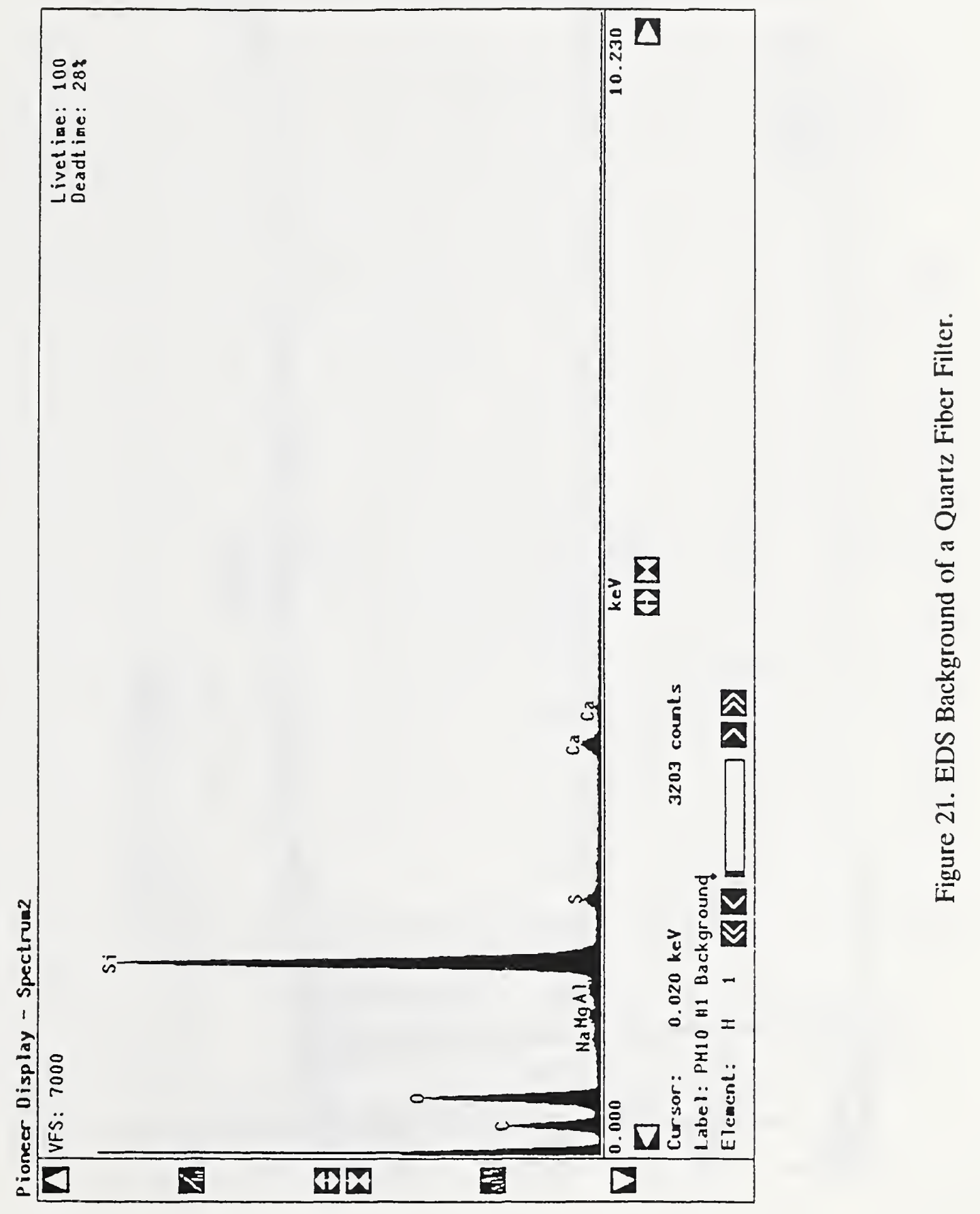




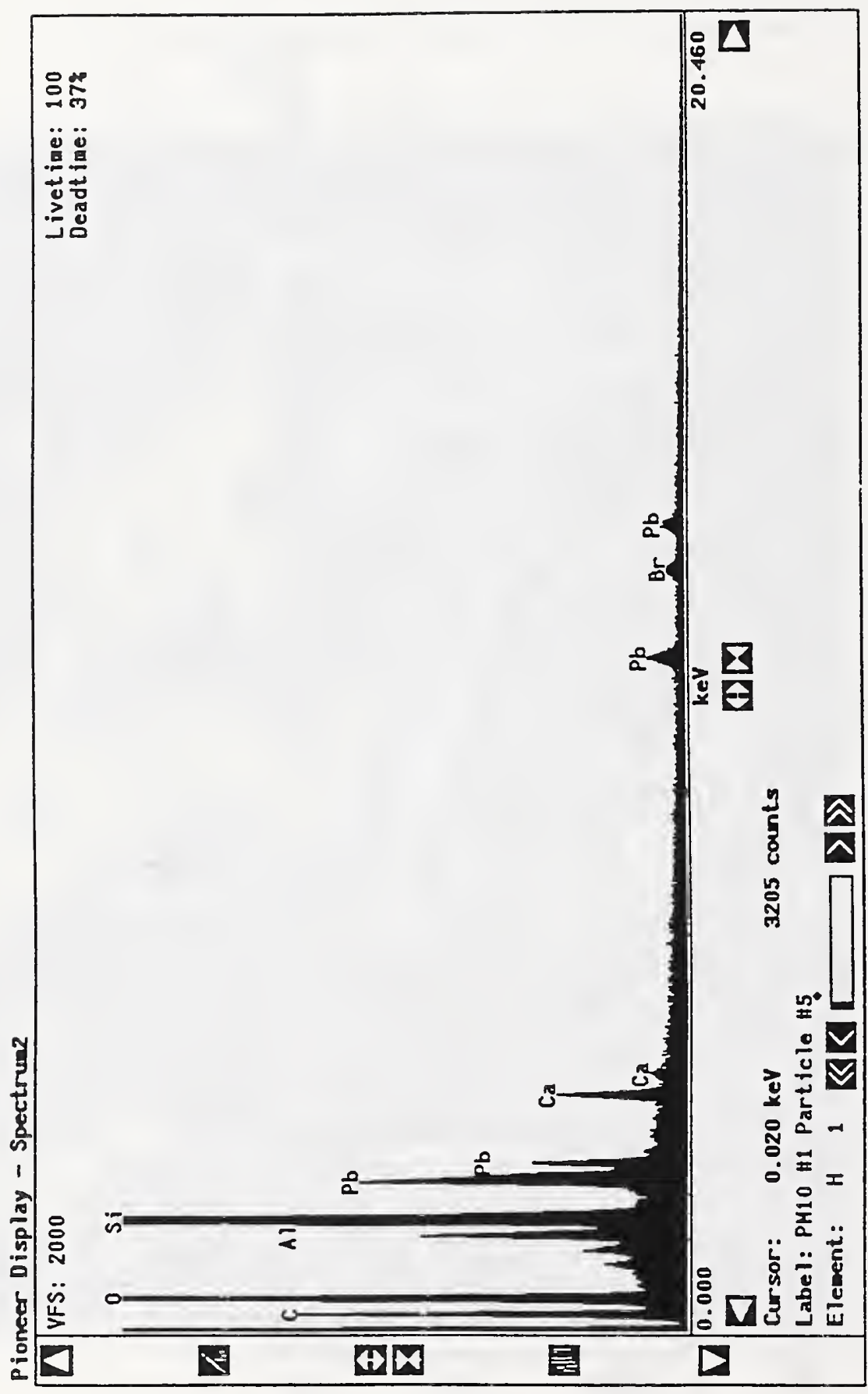

हี่ 


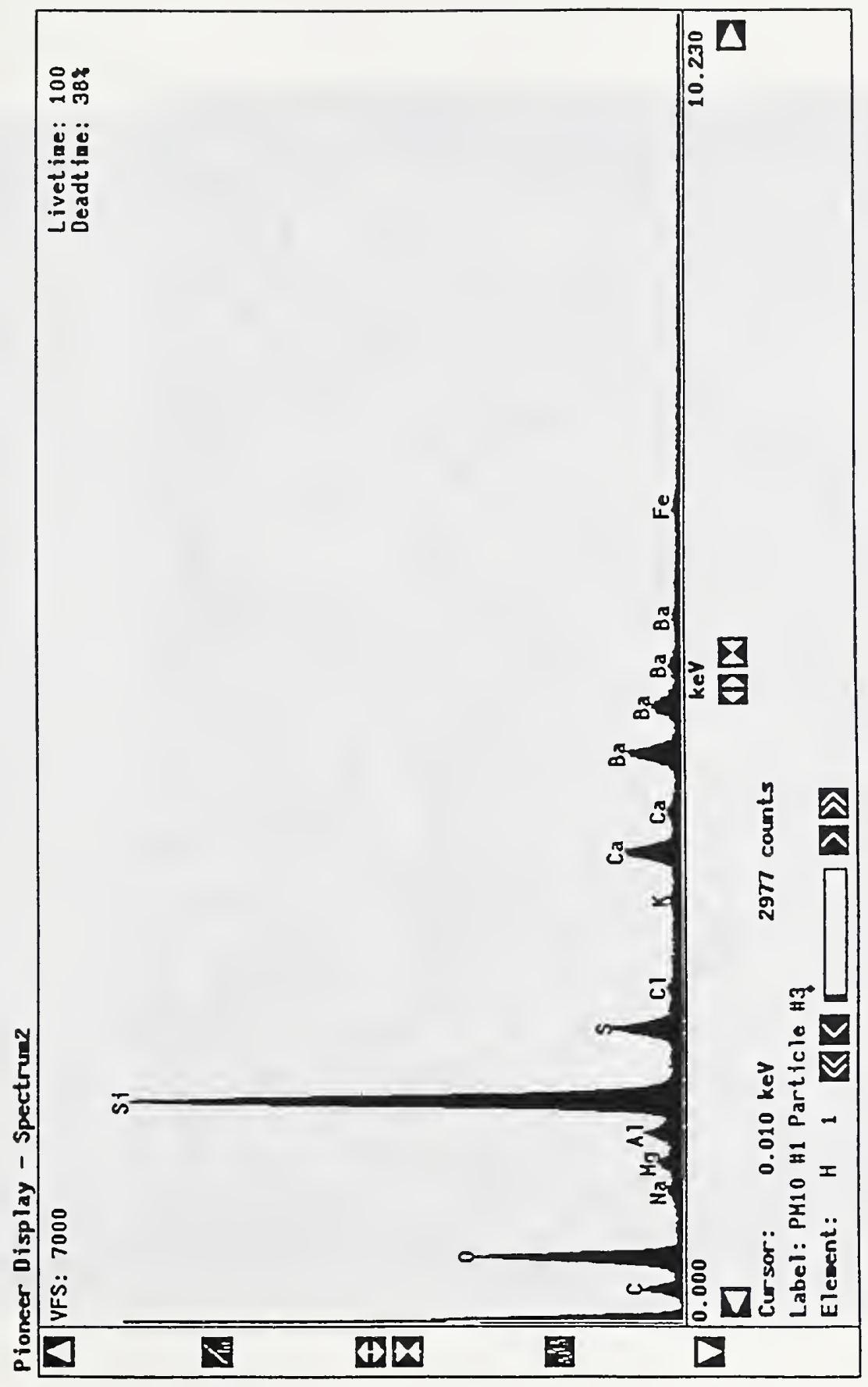

ט 


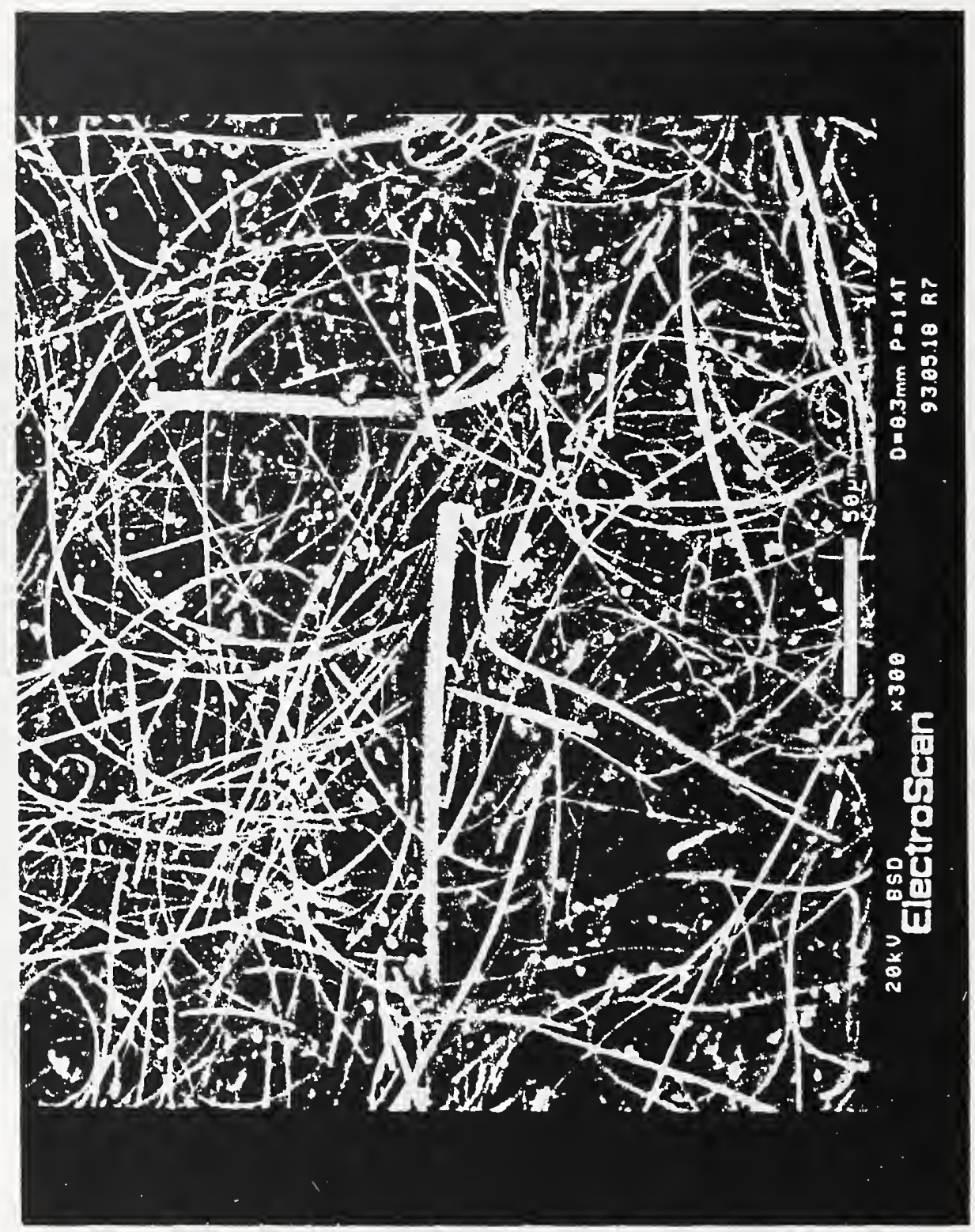

 


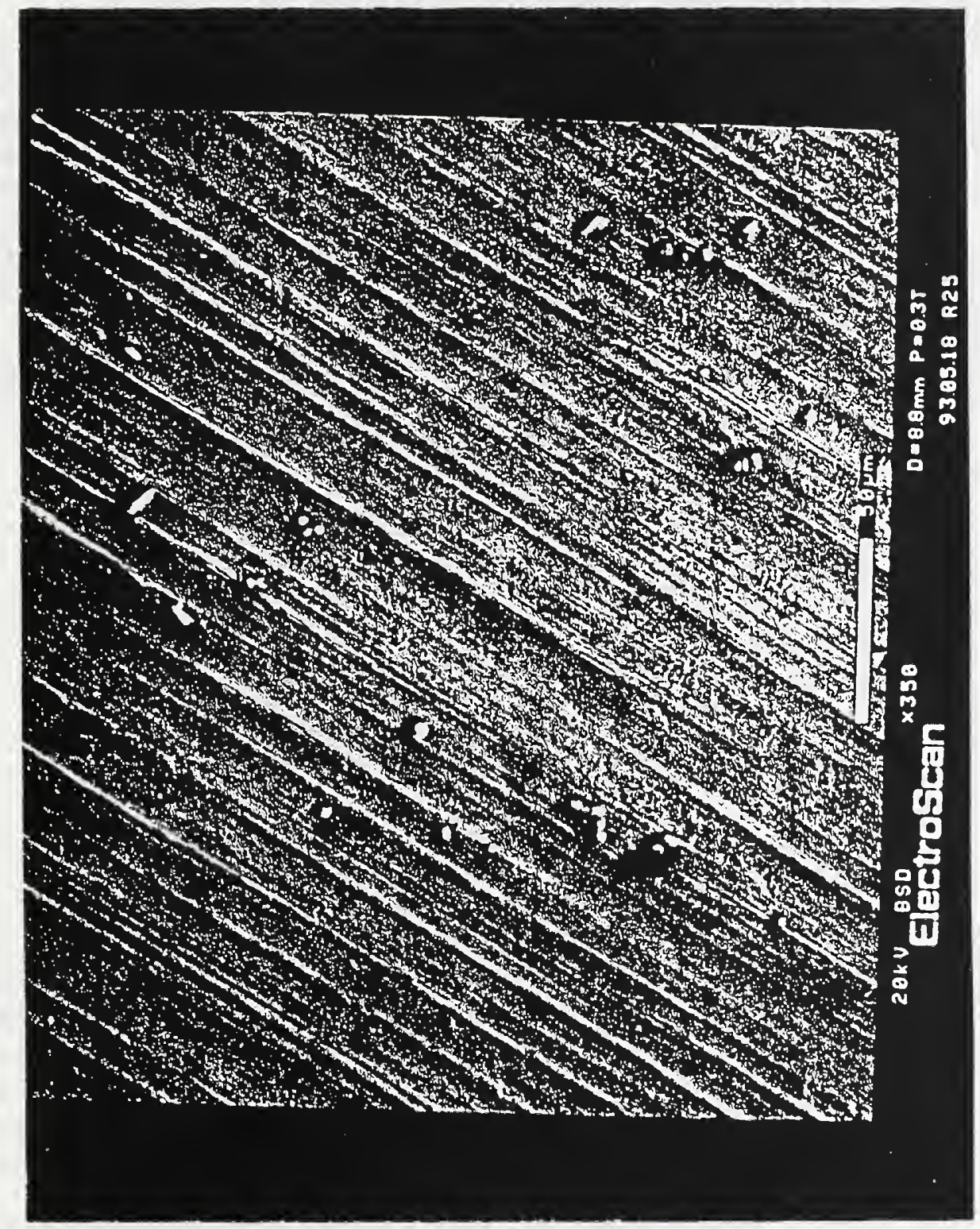

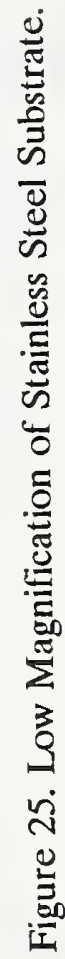


The stainless steel substrate, impactor stage 6 (MA-01-6) demonstrated mounds of silicate particles (Figure 26), most of which are irregularly shaped with sharp edges. A titanium-containing particle (Figure 27) was found on the surface of a silicate (Figure 28). A unique particle which had major phosphorus, sulfur, and oxygen and minor calcium, cerium, and titanium was found. EDS of the stainless steel substrate material yielded chromium, iron, nickel, and trace molybdenum (Figure 29). The sample loading on impactor stage 5 (MA-01-5), the second stainless steel substrate was very light. Calcium-containing and magnesium-aluminum-silicates made up the majority of the particles analyzed.

On the Mylar substrate MA-02-6, impactor stage 6, the majority of particles are silicates ( $\mathrm{Si}$, $\mathrm{Mg}, \mathrm{Al}, \mathrm{Ca}$ ). Most of the particles were irregularly shaped with sharp edges. There was one particle with major titanium and four particles with iron and titanium. On the second Mylar sample, impactor stage 7 (MA-02-7), the particles appeared similar to other stages except the impact area was smaller and approached roundness. Calcium seemed to be the major element in these smaller particles.

In summary, the ESEM was particularly suited to the investigation of the PM-10 quartz fiber filters. The filter material is insulating and fibers tend to charge as in a conventional scanning electron microscope. The neutralization of surface charge in the low vacuum environment of the ESEM made it possible to analyze the particles directly on the filter.

There was a high concentration of mineral silicates of respirable size. Lead/bromine particles, presumably from gasoline burning, made up roughly five percent of the particles analyzed. Titanium/iron particles were much less abundant and may be mineral in origin.

\title{
4.5 Thermal-Optical Analysis For Organic/Elemental Carbon
}

\author{
Contributed by - \\ Dr. Robert A. Cary \\ Sunset Laboratory \\ Forest Grove, Oregon
}

\subsubsection{Sample Preparation and Analysis}

The current instrument is capable of analyzing aerosol particles for both organic carbon and elemental carbon. As with all current techniques, though, it is a method-defined analysis. However, it was designed to specifically address some of the problems seen by other techniques in assigning carbon to either the organic or elemental fraction. By careful control of operating conditions and constant monitoring of the optical absorbance of the sample during the analysis, this method is able to both prevent any undesired oxidation of original elemental carbon and make corrections for the inevitably-produced carbon-char formed by the pyrolytic conversion of some organics into additional elemental carbon.

The instrument is similar to that described by Johnson et al. [16]. However there are certain modifications, one being that the absorbance is monitored by transmitting the laser light through the sample filter rather than by observing the back-scattered light off the surface containing the sample deposit. Another is that the analysis starts at room temperature with pure helium and continues through four temperature steps $\left(250,385,580\right.$, and $\left.770^{\circ} \mathrm{C}\right)$. The second stage of the analysis starts after reducing the temperature to $525^{\circ} \mathrm{C}$ and introducing oxygen (2\%). It then 


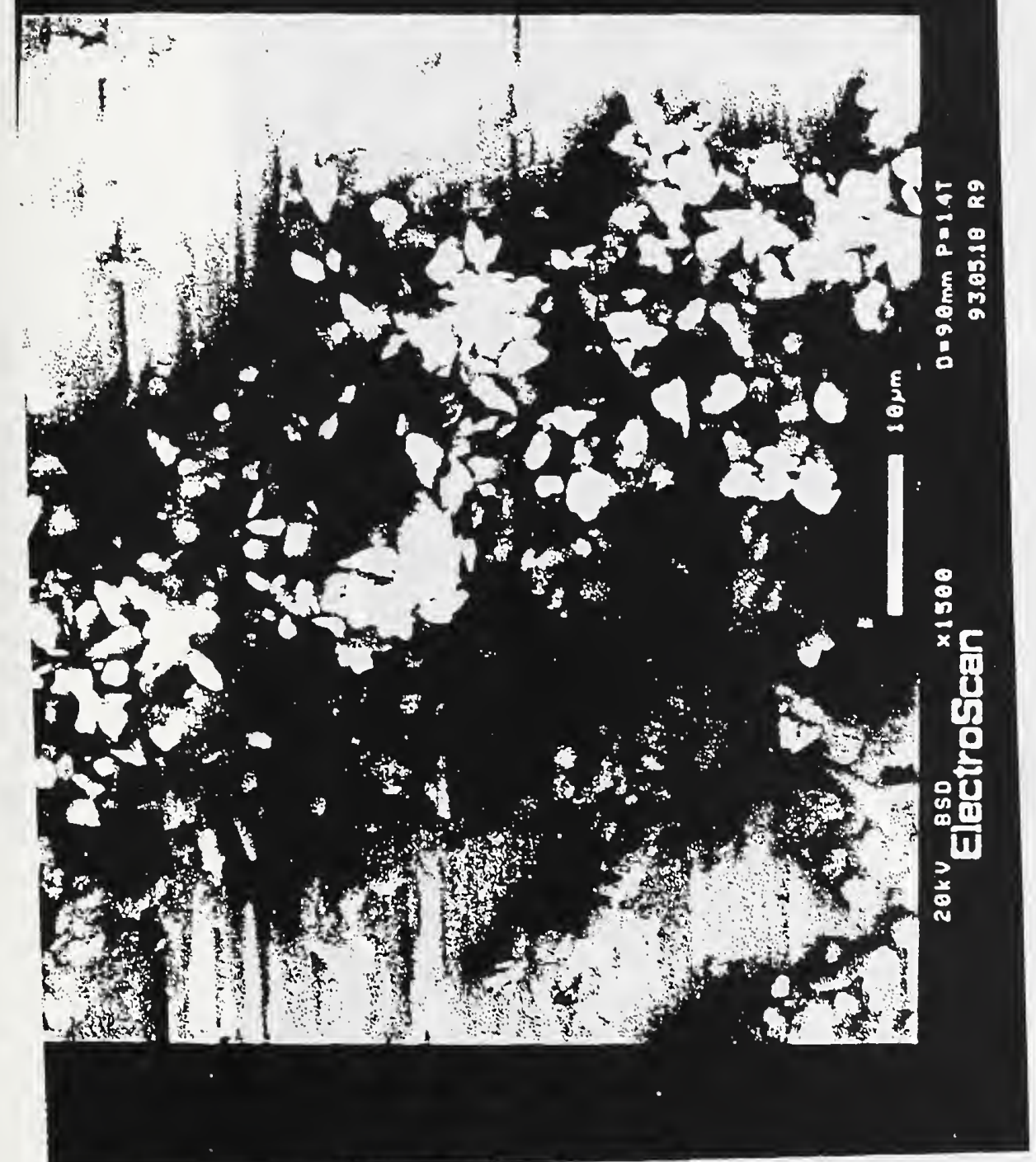

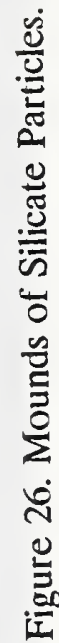




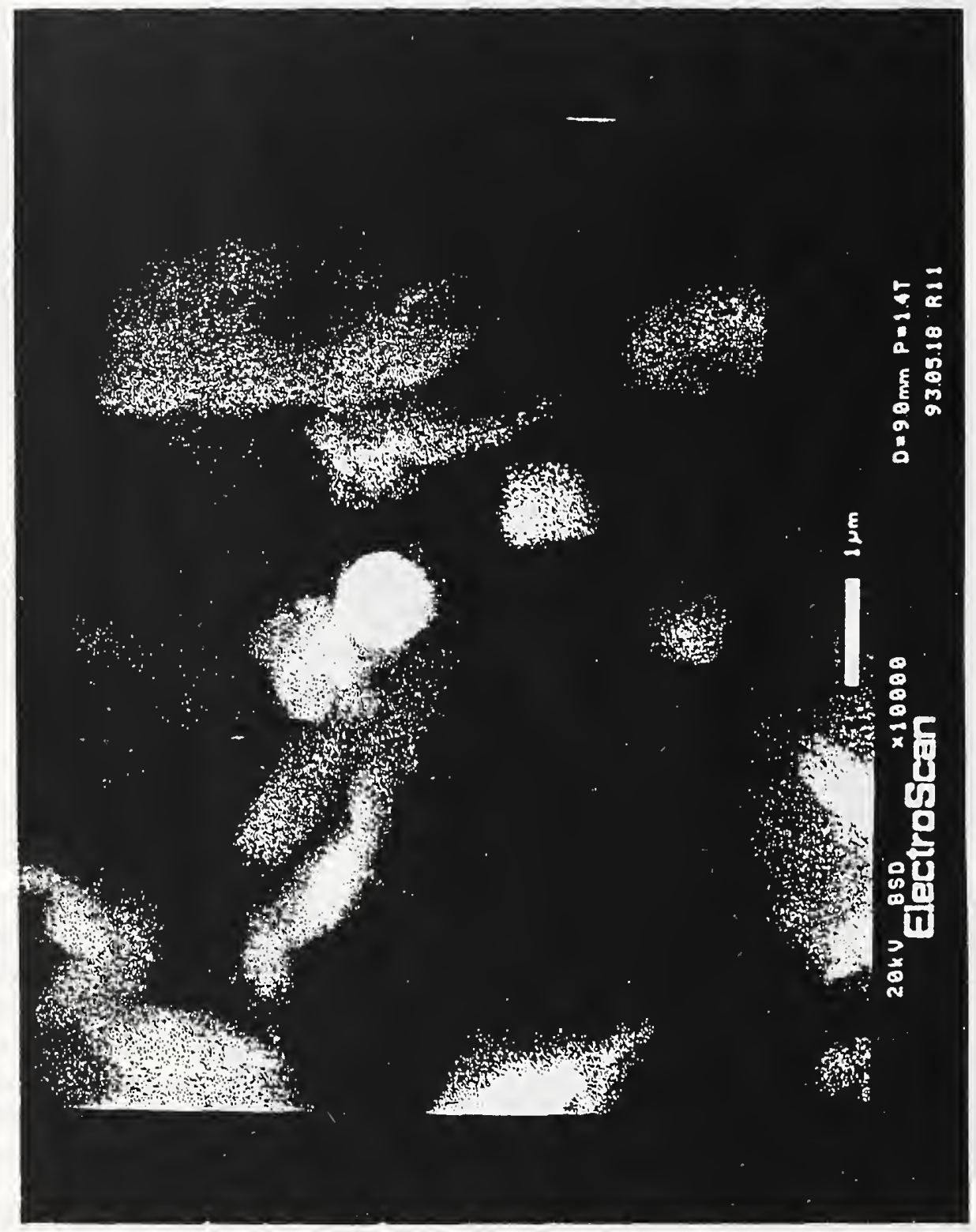

 


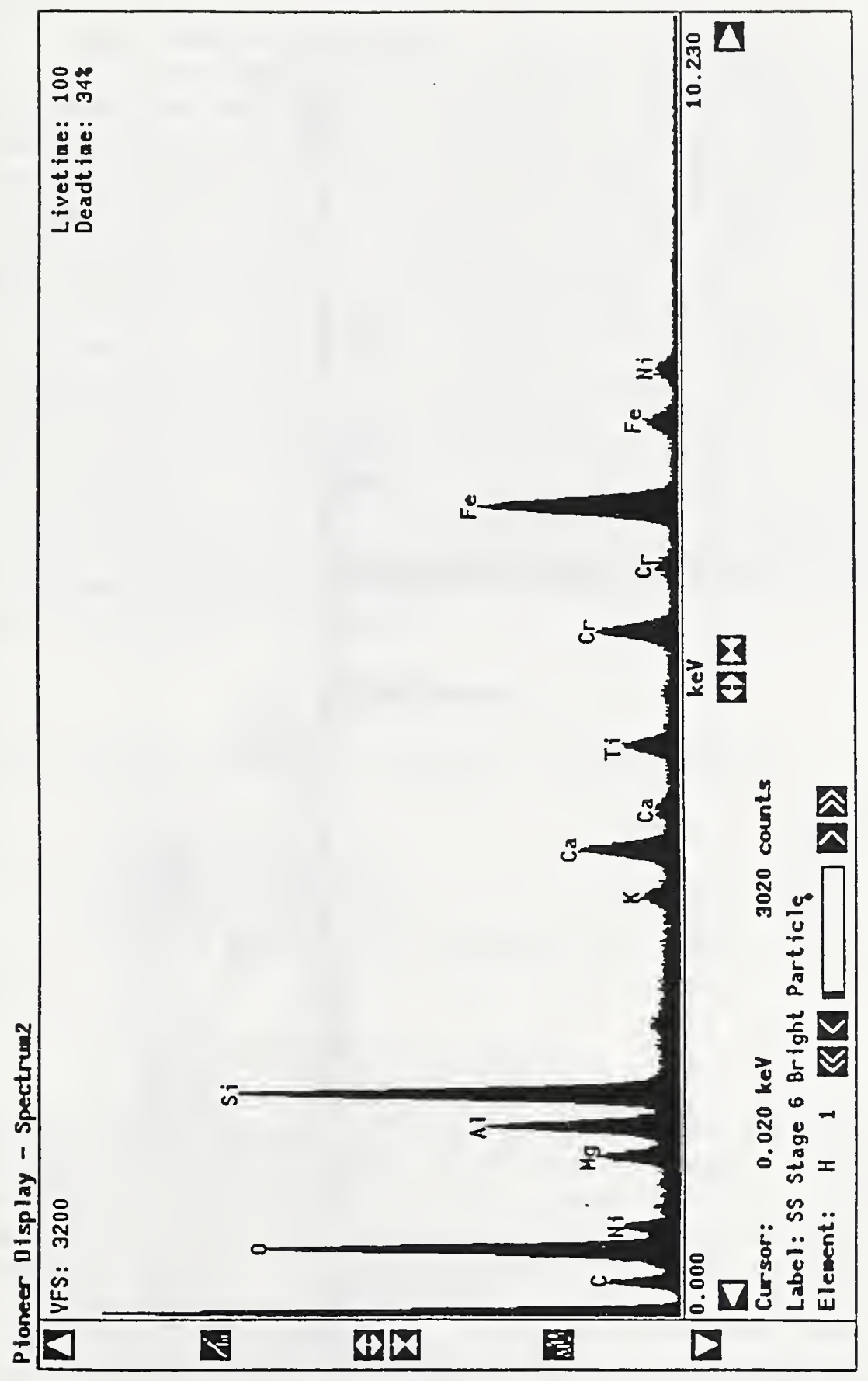

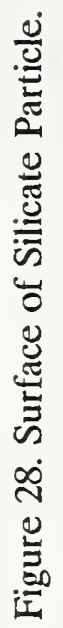




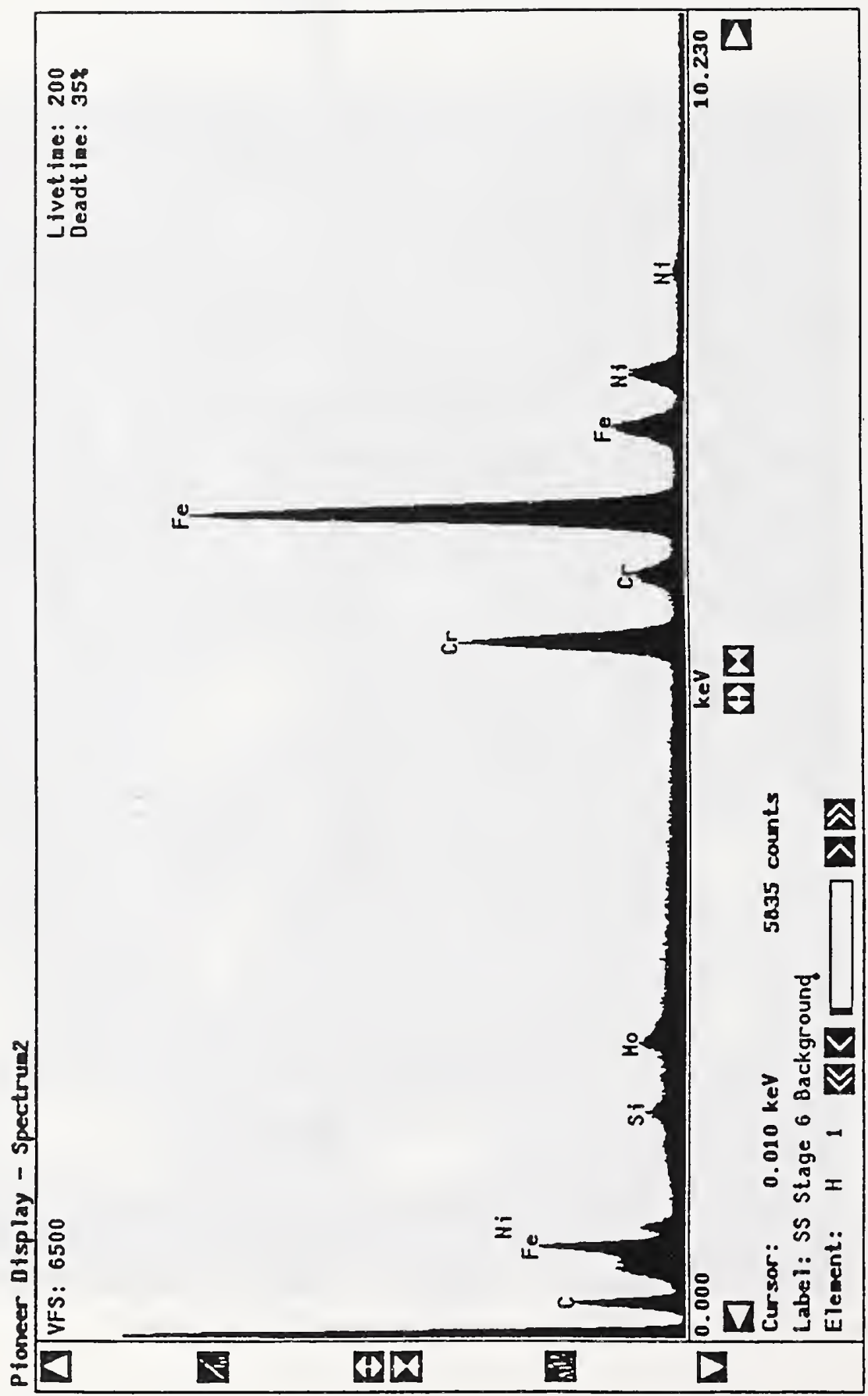

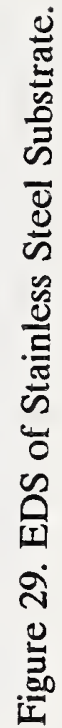


continues with two more steps at $600^{\circ} \mathrm{C}$ and $770{ }^{\circ} \mathrm{C}$. The final part of the analysis is the injection of a known amount of methane which serves as an internal quantifying standard as well as a quality assurance step.

\subsubsection{Results and Discussion}

Each filter sample was analyzed for organic, elemental, and inorganic carbonate carbon. The organic carbon usually represents hydrocarbons which have simply evaporated from open liquid pools or have been partially pyrolized by a hydrocarbon fueled fire. Elemental carbon is suggestive of more complete combustion than the organic fraction. The inorganic carbonate content indicates that a fraction of the particulates probably originate from soil or sand. The fine sand or soil particles can be entrained by winds generated by the fire plume or simply by natural wind action.

Six quartz filter samples, PM-10-1, PM-10-2, PM-10-3, PM-10-4, Q-01, and Q-10 were analyzed for organic, elemental and inorganic carbonate content (Table 13). PM-10-1 and PM-10-2 were very similar in total carbon mass, 31.81 and $33.57 \mu \mathrm{g} / \mathrm{cm}^{2}$. Both PM-10-1 and PM-10-2 were collected at KFMMC. Consistent with the lower PAH results, PM-10-3 had less total carbon mass, but total collection volume was also smaller than for PM-10-1 and PM-10-2. All three PM-10 samples exhibited approximately $27 \%$ elemental carbon/total carbon ratio. The inorganic carbonate fraction suggests that fine soil dusts contributed about $13 \%$ of the aerosol mass for the filters collected at KFMMC. Very little inorganic carbonate carbon was found on PM-10-3 which was collected at AlJubail. The $47 \mathrm{~mm}$ quartz filter, Q-01, produced similar organic mass loadings as the PM-10 filters, but elemental carbon appeared to be absent.

\subsection{Gas Chromatographic Analysis of Grab-Bag Samples}

Contributed by -

Mr. James E. Brown

Fire Science Division

Building and Fire Research Laboratory, NIST

\subsubsection{Sample Preparation and Analysis}

Two gas grab-bag samples, B-07 and B-06 were analyzed for carbon dioxide and carbon monoxide using a Hewlett Packard model 5890 Gas Chromatograph (GC) interfaced with HP 3396A Integrator. The $\mathrm{GC}$ was equipped with a thermal conductivity detector operated at $200{ }^{\circ} \mathrm{C}$. The carrier gas was helium which flowed at $25 \mathrm{~mL} / \mathrm{min}$ through a stainless steel column $183 \mathrm{~cm}$ long by $0.3175 \mathrm{~cm}$ outside diameter. The gas head pressure on the column was 160 kilopascals (22 psi). Separate columns, having the same dimensions, were used for the $\mathrm{CO}_{2}$ and $\mathrm{CO}$ measurements. A column with Poropaq $\mathrm{N}$ packing was used for the $\mathrm{CO}_{2}$ analysis while the oven was operated. For the $\mathrm{CO}$ analysis a molecular sieve $5 \mathrm{~A}$ column was used in the oven operated isothermally at $50^{\circ} \mathrm{C}$. The gas specimens were injected from either of two sample loops collected from a flow stream of the sample into the atmosphere and then injected onto the column through the injection port maintained at $150^{\circ} \mathrm{C}$. 


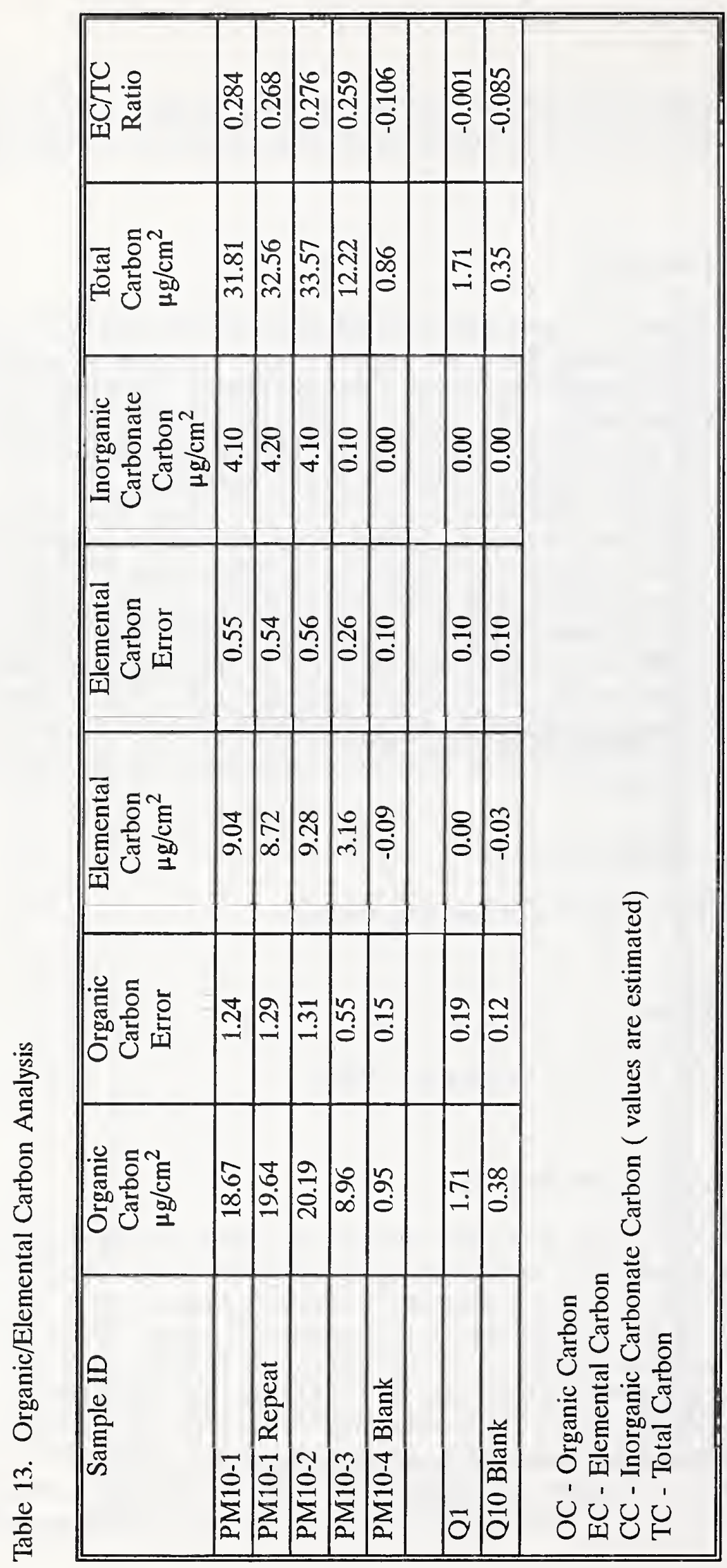


The responses of the TCD and retention times of the $\mathrm{CO}_{2}$ and $\mathrm{CO}$ in the respective columns were determined using a reference gas containing $798 \mathrm{ppm} \mathrm{CO}_{2}$ and $407 \mathrm{ppm} \mathrm{CO}$ in nitrogen. At least 10 specimens of this gas were injected into the respective column to determine the TCD calibrations. Response data for calibration were used after the detector indicated that all air had been swept from the sample lines. This usually required 3 to 5 injections.

After establishing the TCD response and calibrating the TCD with a reference gas, the two grab-sample bags were analyzed first for carbon dioxide and then for carbon monoxide.

\subsubsection{Results and Discussion}

The results of gas chromatographic analyses of two grab samples of air for carbon dioxide and carbon monoxide are shown in Table 14. The concentrations of carbon dioxide in both samples were about 0.036 percent. Although routine monitoring of $\mathrm{CO} 2$ would help to establish the range of background levels, these concentrations do not appear to be significantly above the 0.033 percent [17] levels generally accepted for ambient air. Carbon monoxide was not detectable in either of the grab-bag samples. Since $\mathrm{CO}$ and $\mathrm{CO}_{2}$ are products of combustion, both of these two gases would be expected to be elevated in a cloud or plume generated by a fire. Since the samples collected at KFMMC Dhahran and RSNB Al-Jubail at relatively ambient conditions, i.e., not in a plume or near a fire source, it was not surprising that the $\mathrm{CO}$ and $\mathrm{CO}_{2}$ were not significantly higher than background levels. However, additional sampling and a routine monitoring program would be important to establish better what typical background levels are within the Kingdom.

\subsection{Discussion}

Sample analyses including polycyclic aromatic hydrocarbon, laser microprobe mass spectrometry, micro-Raman analysis, environmental scanning electron microscopy, thermal-optical analysis, and gas chromatography provide a snapshot of the physical and chemical properties of the aerosol sampled at KFMMC and RSNB. This very limited snapshot of the aerosol around KFMMC and RSNB does not provide a reasonable basis for estimating the short- or long-term health risk due to exposure to smoke and gaseous emissions. While these results do suggest significant levels of PAH and dust particulates, the data set is very limited and a program involving the collection and analysis of air samples (HiVol PM-10) in or around Saudi Arabian urban areas, such as Riyadh, Al-Jubail, and Dhahran, would provide valuable data for determining current airborne PAH concentrations as well as for devising air pollution control strategies for the future.

Most of the short-term exposure samples which were collected over a relatively short time period do not suggest significant levels of smoke or gaseous species. The PAH analysis of the Teflon filters and XAD-2 sorbent tubes, the $\mathrm{CO}$ and $\mathrm{CO}_{2}$ analysis of the grab-bag samples, and the thermaloptical analysis of the quartz filters all suggest that the concentrations of $\mathrm{PAHs}, \mathrm{CO}$, and $\mathrm{CO}_{2}$ were not significantly elevated above background levels. But, one of the quartz filters, Q-05, did collect significant amounts of particulates. Other results suggest that most of these particulates were fine soil dust. These samples, which were collected during a dust storm, indicate relatively high levels, 3 $\mathrm{mg} / \mathrm{m}^{3}$, of total particulates; and probably a high fraction of the particulates were classified as inhalable. The observed particulate concentrations are about half the Occupational Safety and Health Administration standards for respirable nuisance dust, $5 \mathrm{mg} / \mathrm{m}^{3}$, but are approximately 50 times 


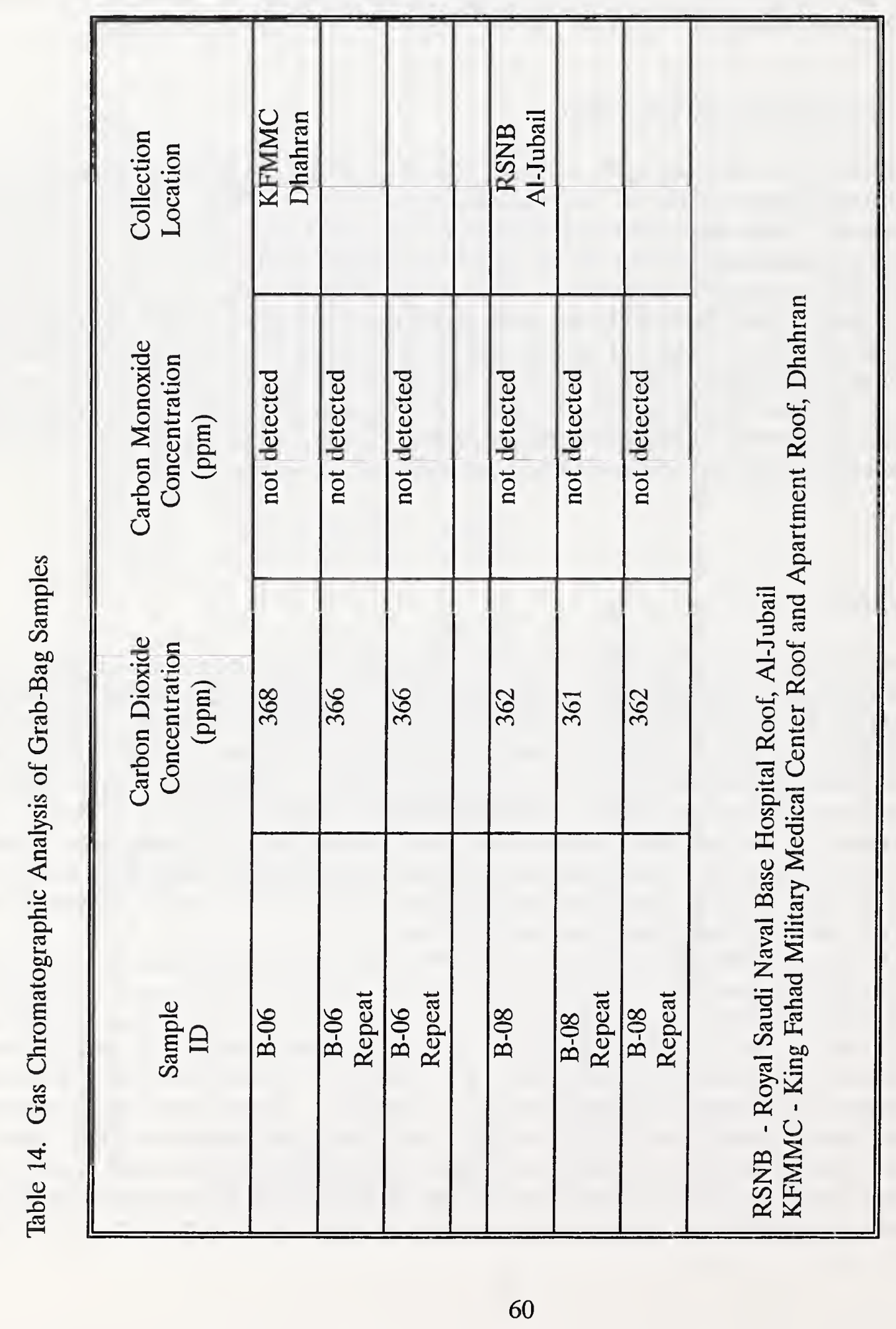


greater than the National Institute of Occupational Health and Safety Standard for respirable crystalline silica, $0.05 \mathrm{mg} / \mathrm{m}^{3}[18]$. A qualified medical specialist would use the total particulate concentration, the respirable fraction, and the chemical composition of the particles to assess the potential health risk to the local population.

In addition to the dust collected on the quartz filter, several of the samples collected at KFMMC during the dust storm had observable amounts of reddish-tan particulates on the filter. The results of analysis by Laser Microprobe Mass Spectrometry indicate that the reddish-tan particulates are primarily inorganic fine dust particulate material. This material appears to be fine particle matter that is composed of $\mathrm{Na}, \mathrm{Mg}, \mathrm{Al}, \mathrm{Si}, \mathrm{K}, \mathrm{Ca}, \mathrm{Fe}, \mathrm{Ti}$, and some $\mathrm{Ba}$. The particles found on the quartz fiber filter contained lead. As reported in the PAH analyses of the reddish-tan particulates, there appears to be very little carbon molecular species present in the samples analyzed. The ESEM examination indicated that there was a high concentration of mineral silicates of respirable size. Lead/bromine particles, presumably from leaded gasoline combustion, made up roughly five percent of the particles analyzed. Titanium/iron particles were much less abundant and may be mineral in origin. The inorganic carbonate fraction reported by the thermal-optical analysis suggests that fine soil dusts contributed about $13 \%$ of the aerosol mass for the PM10 filter samples collected at KFMMC.

While most of the PAHs were essentially not detectable for the Teflon filters and XAD-2 sorbent tubes, the PAH analysis of the PM-10 filters detected significant levels of the higher molecular weight PAHs. This was not unexpected because the PM-10 HiVol samplers are ambient monitors and PAH sampling trains are usually employed for more acute episodes. The HiVol samplers pull between 1000 and 1500 liters through the PM-10 filter each minute while the portable pumps pull about 2 liters per minute through the PAH sampling train. In order to accumulate sufficient material to be easily detected by standard analytical techniques, the HiVol samplers are designed to sample and filter very large volumes of aerosol. The portable pump and PAH sampling train allow sampling the high concentration of PAHs in a smoke plume or cloud. But, both the PM$10 \mathrm{HiVols}$ and the portable systems are important components to an air monitoring program. The ambient samplers collect routine samples for archival background purposes and the portable pump and PAH sampling train help characterize more acute episodes.

The results of the thermal-optical analysis show the same trend as the PAH results. The thermal-optical results suggest that from 60 to 70 percent of the carbon on the PM-10 filters was organic, but very little organic carbon was observed on the $47 \mathrm{~mm}$ quartz filters. Again, the organic carbon, including the PAH compounds, were detected on the relatively large volume PM10 samples, but not on the quartz filters which sampled a small volume. Overall, the different analytical techniques all help to characterize the physical and chemical properties of the aerosol sample around Dhahran and Al-Jubail. As in the case of the high levels of dust particulates, the particulate sampling and sizing instrumentation demonstrated that it is possible to quickly determine particulate mass concentrations. The particulate samples were then returned to the laboratory for more specialized analysis which helped to confirm the source of the fine particulates. The appearance of significant concentrations of PAHs in what was expected to provide background levels indicates that a more comprehensive sampling program should be implemented to characterize the levels and the distribution of PAHs throughout the Kingdom. 


\subsection{Conclusions}

The gas and aerosol particulate samples collected in Saudi Arabia by the MODA and NIST researchers demonstrates that NIST through the training course and collaborative sampling work was able to provide MODA personnel with the tools to begin local monitoring of smoke and gaseous emissions. Ranging from simple gravimetric weighing to laser micro-probe techniques, the analytical methods successfully illustrated what types of chemical and physical information can be extracted from smoke and gas samples. MODA personnel have obtained the necessary skills to initiate a local monitoring and sampling program.

The limited number of smoke and gas samples collected does not provide an adequate data set to determine the health risks to the population. Establishing short- and long term health effects on population groups was beyond the scope of this limited project which was designed to provide MODA personnel with the tools to collect their own samples. The results of this project do indicate that additional samples do need to be collected to allow a better assessment of the type and distribution of PAHs, gases, and particulates throughout Saudi Arabia.

\subsection{Recommendations}

The NIST visitors and the RAFMH personnel discussed the implementation of a program involving the sampling of air in Saudi Arabia and the subsequent measurement of health-related species. A program could be divided into:

- Developing a plan for monitoring particulate matter and gas concentrations;

- Collect and archive particulate matter and gas samples;

- Develop analytical methodology for measuring specific sample constituents in order to determine their toxicological significance;

o Implement quality control program to insure high confidence in data.

\subsection{Planning}

Any planning for this project should involve a thorough search of the technical literature so that all the subsequent aspects of the project, from sample collection and analysis to data analysis are carefully researched. There are currently a number of on-line computer databases including Chemical Abstracts (from the American Chemical Society), Environmental Abstracts and Analytical Abstracts that could be used to obtain literature citations supporting the sampling and analysis of airborne pollutants. In addition, CA Selects from the American Chemical Society offers subscriptions for bimonthly computer searches of a number of topics related to atmospheric chemistry (e.g., Environmental Pollution, Air Pollution - Books and Reviews, Pollution Monitoring, Indoor Air Pollution). Using these databases is an good way of determining what work has been done in an area of interest, how the work was done and what additional research needs to be performed to solve the problem and/or complete the project. Reviewing the appropriate literature prior to beginning a project lessens the chance that time will be wasted developing a method or technique that has already been thoroughly evaluated. 


\subsection{Sample Collection}

The RAFMH group has already collected a number of air samples in Dhahran and Al-Jubail using their new air sampling equipment. Some of the equipment is useful for collecting ambient inhalable particulate matter (IPM, PM-10 Hi-Vol samplers) for later measurement of IPM and organic/inorganic compound concentrations. Other pieces of equipment would be useful in measuring gases (EXOTOX gas meters) and particles (MINIRAM particle counters) under acute pollution situations such as might occur indoors and/or very near a fire. Since the RAFMH group now has PM-10 samplers, it is recommended that permanent monitoring sites be established in the Riyadh vicinity to obtain samples for IPM determinations. 'These samples could then be stored in freezers for later measurements of organic (PAHs) and inorganic species (heavy metals, organic/inorganic carbon) once the appropriate methods are developed. These data will be useful in establishing baseline concentrations of IPM and chemical species in the Riyadh atmosphere. Purchase of additional PM-10 samplers would be desirable in order to establish a comprehensive sampling network around Riyadh as well as for equipping mobile air sampling systems.

\subsection{Sample Analysis}

There are a number of established techniques for measuring organic and inorganic species in the atmosphere. The PAHs, for example, can be measured by spiking the sample with a standard containing perdeuterated PAHs, extracting the sample with dichloromethane and measuring the PAHs by GC-MS. Important considerations in such measurements include filter blank concentrations, detection limits and IPM sample loading.

\subsection{Quality Assurance}

For such method development at RAFMH, it would be advisable to purchase standard samples that have been thoroughly characterized for PAHs. The NIST offers a number of Standard Reference Materials (SRM) that are useful in validating analytical methods for PAHs and other chemical species. By processing the appropriate SRM through one's analytical scheme and comparing the results with those in the SRM's Certificate of Analysis, one can decide if the method is valid and that the data obtained is of the highest quality.

\subsection{Split Sample Analysis}

In the early stage of an air monitoring program, it may be useful to split the collected samples with a laboratory established in the field for airborne pollutant measurement. This along with analysis of appropriate reference materials (e.g., SRMs), would help insure that the data generated would be of the highest quality possible. 


\section{Appreciation}

We wish to thank Lt. Colonel Al-Nasser for all the arrangements of accommodations, transportation and use of facilities in Riyadh, Dhahran and Al-Jubail. We are also much appreciative of Captain Al-Hedaithy, Lieutenant Kholaify and Mr. Al-Asmari for their valuable help during the field sampling. Finally, we would like to thank Lt. Colonel Al-Nasser and Mr. Al-Asmari for detailed discussion concerning the formation of a center for monitoring health-related compounds in the atmosphere over Saudi Arabia.

We have very much enjoyed visiting Riyadh and the RAFMH and look forward to collaborating with RAFMH in the future. We hope to be able to provide additional input for the future establishment of the environmental aerosol and gas monitoring center. 


\subsection{References}

1. Cook, F., "Pneumoconiosis-Producing Dusts", Fundamentals of Industrial Hygiene, edited by Olishifski, J.B. and McElroy, F.E., National Safety Council, Chicago, 95-105, 1971.

2. Sax, N.I., and Lewis, R.J., Dangerous Properties of Industrial Materials, Seventh Ed., Vol. 3, Van Nostrand Reinhold, New York, 2523 and 3146-3147, 1989.

3. Harland, W.A., Anderson, R.A., "Causes of Death in Fires," Proceedings, Smoke and Toxic Gases from Burning Plastics, 15/1 - 15/9, January 6-7, 1982, London, England.

4. Harwood, B., Hall, J.R., "What Kills in Fires: Smoke Inhalation or Burns?" Fire J. 83, 29-34, May/June 1989.

5. Sax, N.I., and Lewis, R.J., Dangerous Properties of Industrial Materials,Seventh Ed., Vol. 2, Van Nostrand Reinhold, NewYork, 710-711, 1989.

6. Purser, D.A., "Toxicity Assessment of Combustion Products," SFPE Handbook of Fire Protection Engineering, First Ed., National Fire Protection Association, Quincy MA and Society of Fire Protection Engineers, Boston, MA, 1-200 to 1-245, 1988.

7. Tokura, I., Saito, K. Altenkirch, R.A., and Evans, D.D., "Study of Crude Oil Combustion: Thermal Conductivity of Condensed Phase," Proceedings, Combustion Institute/Central States Section, edit Saito, K., Argonne, IL, p.1-6, 1988.

8. Evans, D.D., Baum, H.R., Mulholland, G.W., Bryner, N.P., and Forney, G.P., "Smoke Plumes From Crude Oil Burns," Proceedings, Arctic and Marine Oil Spill Program Technical Seminar, 12th, June 7-9, 1989, Calgary, Canada, p. 1-22, 1989.

9. Saito, K, Inamura, T., Ito, A., Ling, S., Tagavi, K, and Evans, D.D., "Study of Crude Oil Combustion Supported on Water," Combustion Science and Technology, 86:105-119, 1992.

10. Evans, D.D., Walton, W.D., Baum, H.R., Mulholland, G.W., Lawson, J.R., Koseki, H., and Ghoniem, A., "Smoke Emission From Burning Crude Oil," Proceedings Arctic and Marine Oil Spill Program Technical Seminar, 14th, June 12-14, 1991, Vancouver, Canada, p. 421-449, 1991.

11. McGrattan, K.B., Putorti, A.D., Twilley, W.H., and Evans, D.D., Smoke Plume Trajectory From In-Situ Burning of Crude Oil in Alaska, National Institute of Standards and Technology Internal Report 5273, p. 1-70, 1993.

12. Benner, Jr., B.A., Bryner, N.P., Wise, S.A., Mulholland, G.W., Lao, R.C., and Fingas, M.F., "Polycyclic Aromatic Hydrocarbon Emissions from the Combustion of Crude Oil on Water," Environmental Science Technology, 24:9, p. 1418-1427, 1990. 
13. Mulholland, G.W., Benner, Jr., B.A., Fletcher, R.A., Steel, E., Wise, S.A, May, W.E., Madrzykowski, D., and Evans, D.D., "Analysis of Smoke Samples from Oil Well Fires in Kuwait," National Institute of Standards and Technology Report of Test FR3985, p. 1-15, 1991.

14. Denoyer, E. R. Van Grieken, F. Adams, D.F. S. Natusch, "Laser microprobe mass spectrometry 1: basic principles and performance characteristics," Anal. Chem. 54, 28A-41A, 1982.

15. Hercules, D.M., R. Day, K. Balasanmugam, T. A. Dang, and C.P. Li, "Laser microprobe mass spectrometry 2. Applications to structural analysis," Anal. Chem. 54(2): 208A-305A, 1982.

16. Simons, D.S., "Laser microprobe mass spectrometry: description and selected applications," Appl. Surf. Sci. 31: 103-117, 1988.

17. Kaufmann, R., "Chap 13: Laser-microprobe mass spectroscopy (LAMMA) of particulate matter," Physical and Chemical Characterization of Individual Airborne Particles, edited by Spurny, K.R., John Wiley and Sons, New York, 227-244, 1986.

18. De Waele, J.K.E. and Adams, F.C., "Chap. 15: Laser-microprobe mass analysis of fibrous dusts," Physical and Chemical Characterization of Individual Airborne Particles, edited by Spurny, K.R., John Wiley and Sons, New York, 271-297, 1986.

19. Wieser, P. and Wurster, R., "Chap 14: Application of laser-microprobe mass analysis to particle collections," Physical and Chemical Characterization of Individual Airborne Particles, edited by Spurny, K.R., John Wiley and Sons, New York, 251-70, 1986.

20. Wieser, P., Wurster, R., and Seiler, H., "Identification of airborne particles by laser induced mass spectroscopy", Atmos. Environ 14: 485-94, 1980.

21. Wight, S. A., and Zeissler, C. Z., Microscopy Research and Technique, Vol 25, pp 393-397, 1993.

14. Danilatos, G. D., Journal of Microscopy, Vol. 162, Pt 3, June, 391-402, 1991.

15. Danilatos, G. D.,Proc. 50th Annual Meeting of the Electron Microscopy of America, 1302-1303, 1992.

16. Johnson, R.L., Shah, J.J., Cary, R.A., and Huntzicker, J.J., An Automated Thermal-Optical Method for the Analysis of Carbonaceous Aerosol; ACS Symposium Series, No. 167, Atmospheric Aerosol: Source/Air Quality Relationships. ed. by E. S. Macias and P.K. Hopke, 1981.

17. CRC Handbook of Chemistry and Physics, Sixtieth Edition, edited by Weast, R.C., CRC Press, Inc., Boca Raton, FL, p. F-211, 1979.

18. NIOSH Manual of Analytical Methods - Volume 2, edit. Eller, P.M., National Institute for Occupational Safety and Health, Cincinnati, Ohio, p. 0600/1-6 and 7500/1-6, 1984. 


\title{
APPENDIX A.
}

\section{Ground-Based Smoke Sampling Course Program}

The schedule for training MODA personnel to monitor particulate concentration and size, gas concentration, hydrocarbons, metals and metal salts will include:

Day 1 Introduction

Health Effects

MEPA and EPA Guidelines

Combustion Fundamentals

\author{
Inhalable Particulates - Total Mass Concentration \\ Light Scattering Cell \\ Calibration \\ Operation \\ Gravimetric Measurement \\ Portable Pump \\ Flow Calibration \\ Operation \\ Filter Media \\ Mettler Balance Operation
}

Day 2 Inhalable Particulates - Size Classification of Aerosols

Aerodynamic Sizing Theory

Personal Samplers

Marple Personal Cascade Sampler

Anderson Cascade Impactor

Ambient Samplers

High Volume PM10 Samplers

Data Reduction and Presentation

Chemical and Optical Properties of Smoke

Organic versus Elemental Carbon

Black Sooty Smoke

Grey Pyrolysis Smoke

Light Extinction

Absorption, Scattering and the TC-RN 
Gas Analyzers - Personal Monitors

Fundamentals of Electrochemical Cells

Portable Analyzers

Multi-Gas Monitors

Calibration

Operation

Single Gas Analyzers

Calibration

Operation

Day 3 Gas Sampling

Grab Bags

Sample Collection

Sample Analysis

Sorbent Tubes

Sample Collection

Sample Analysis

Hydrocarbon Monitoring

TUH Analyzers

Polycyclic Aromatic Hydrocarbons

Filter Samples

Preparation

Collection

Storage

Analysis

Sorbent Tube Samples

Collection

Analysis

Volatile Organic Hydrocarbons

Collection

Analysis

Metal Sampling and Monitoring

Filter Samples

Substrate Preparation

Sample Collection

Analysis via Neutron Activation 
Day 4

Day 5

Day 6

Day 7
Fire Test - Crude Oil Burn

Preparation for smoke sampling

Filter Weighing

Gas Analyzer Calibration

Pump Check-out

Real-time Measurements

Total Mass Concentration

Sulfur Dioxide

Nitrogen Dioxide

Hydrogen Sulfide

Carbon Monoxide

Carbon Dioxide

Samples for Laboratory Analysis

Total Mass Concentration

Size Classified Particulates

Organic versus Elemental Carbon

Gas Grab Bag Sampling

PAH

Filter Samples

Sorbent Tubes

VOC

Sorbent Tubes

Sample Storage

Data Reduction

Filter weighing

Fire Test - Crude Oil Burn

Same as Day 4 - more practice

in field sampling

Analytical Chemistry -

Sample preparation

Gas chromatography

Theory

Analysis of grab bag samples

Data Interpretation

Analytical Chemistry

Sample preparation

Liquid Chromatography

Theory 
Analysis of Filter Samples

Analysis of Sorbent Tube Samples

Data Interpretation

Day 8 Review 
APPENDIX B. Reconstructed Selected-Ion Chromatograms of Sorbent Tube Sample XAD-01 Collected at the Royal Saudi Naval Base (See Table B-1 for peak identification)
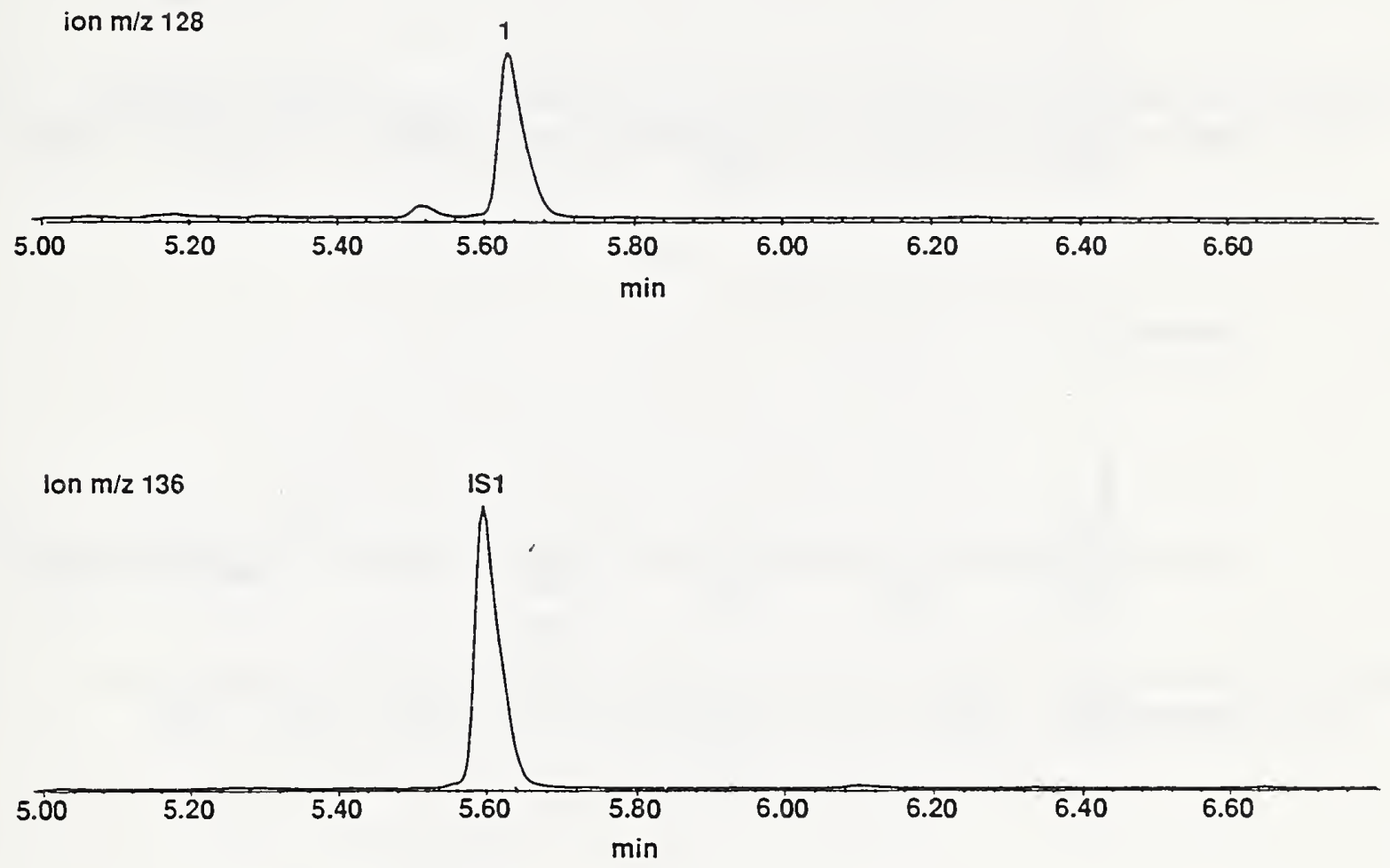

ion $\mathrm{m} / \mathrm{z} 142$

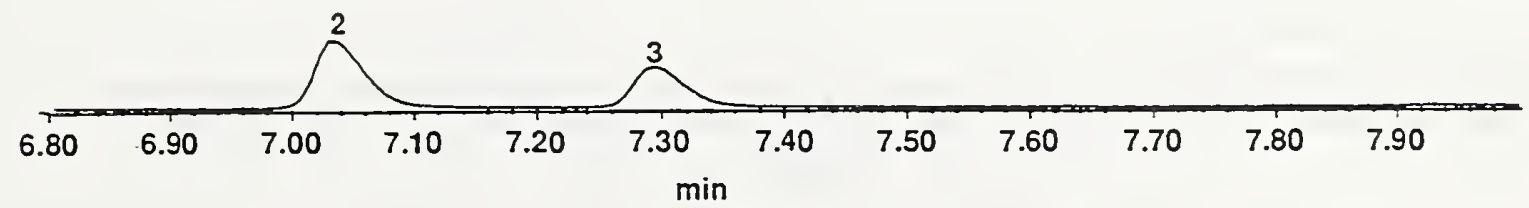


APPENDIX B. Reconstructed Selected-Ion Chromatograms of Sorbent Tube Sample XAD-01 Collected at the Royal Saudi Naval Base (See Table B-1 for peak identification)

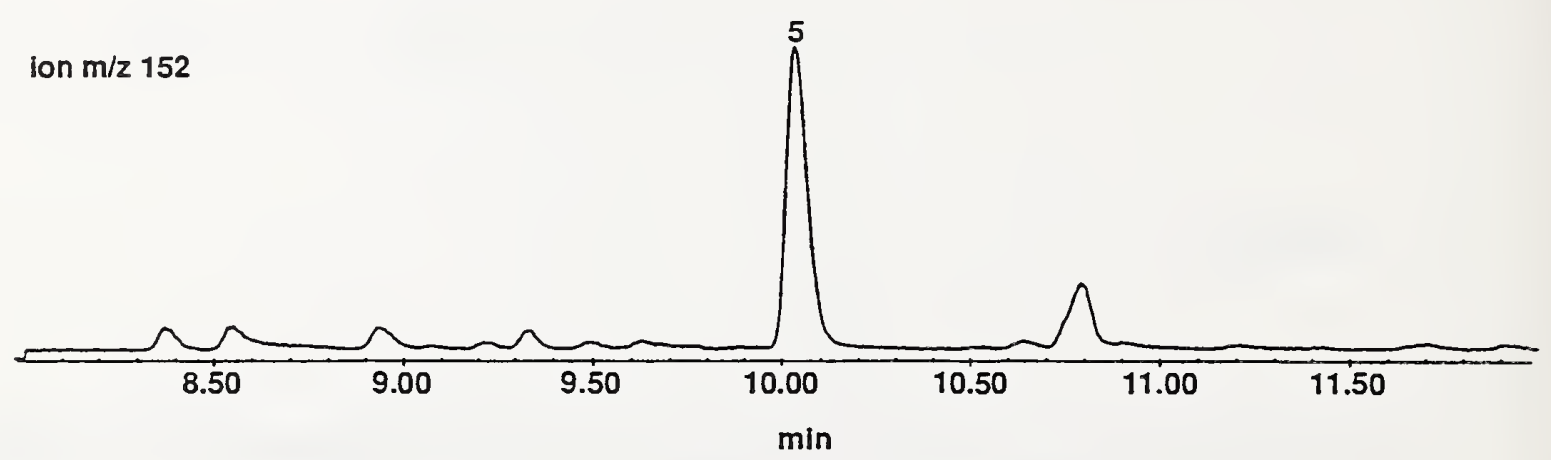

ion $\mathrm{m} / \mathrm{z} 154$

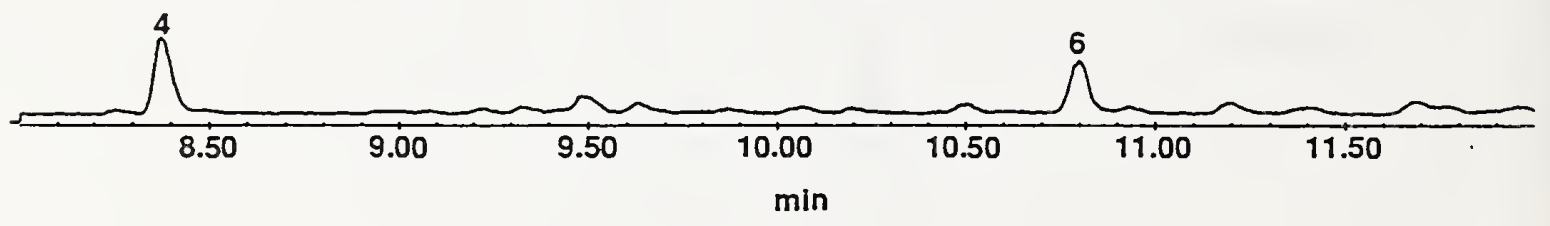

Ion $\mathrm{m} / \mathrm{z} 166$

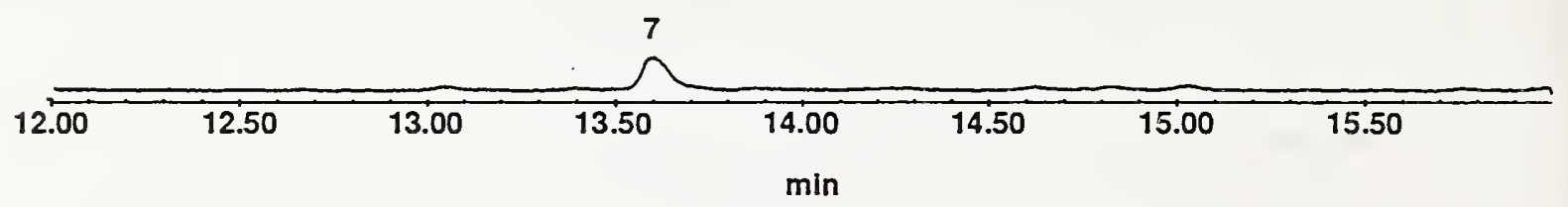

Ion $\mathrm{m} / \mathrm{z} 176$

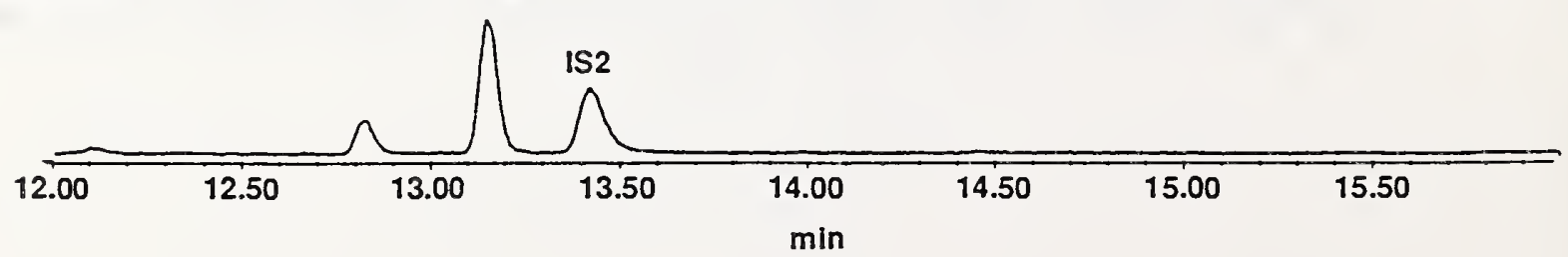


APPENDIX B. Reconstructed Selected-Ion Chromatograms of Sorbent Tube Sample XAD-01 Collected at the Royal Saudi Naval Base (See Table B-1 for peak identification)

Ion $\mathrm{m} / \mathrm{z} 184$

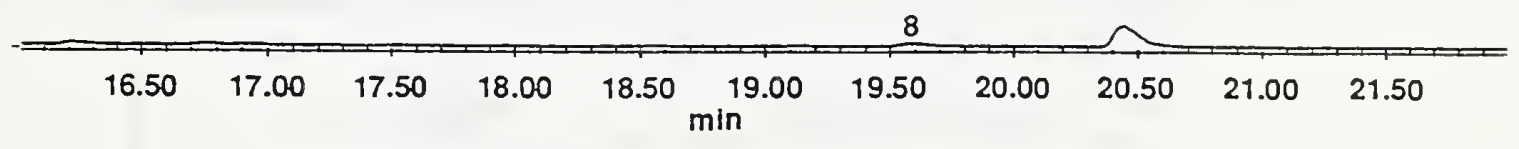

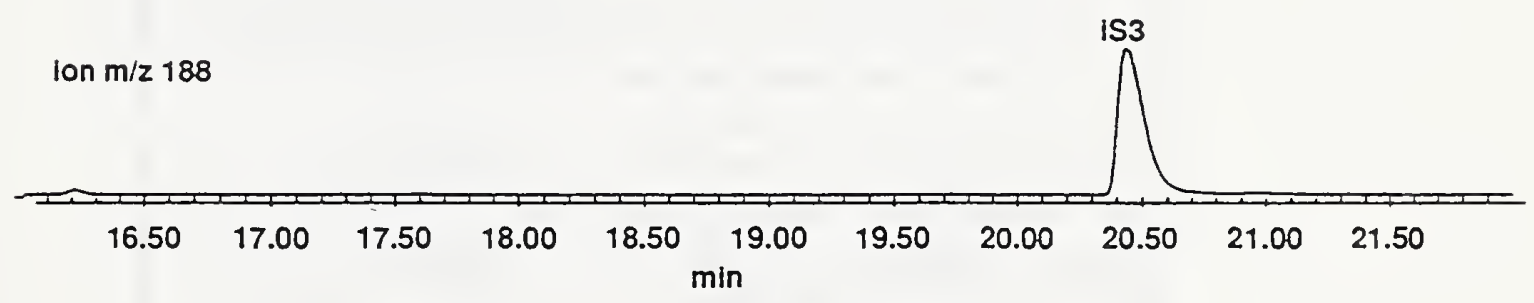

ion $\mathrm{m} / \mathrm{z} 178$

\begin{tabular}{|c|c|c|c|c|c|c|c|c|c|c|}
\hline 16.50 & 17.00 & 17.50 & 18.00 & 18.50 & $\begin{array}{l}19.00 \\
n\end{array}$ & 19.50 & 20.00 & 20.50 & 21.00 & 21.50 \\
\hline
\end{tabular}


Table B-1. Peak Identifications for Reconstructed Selected-Ion Chromatograms of Sorbent Tube XAD-01.

\begin{tabular}{|c|c|}
\hline Peak Number & $\begin{array}{l}\text { Polycyclic Aromatic } \\
\text { Hydrocarbon (PAH) }\end{array}$ \\
\hline 1 & naphthalene \\
\hline IS1 (Internal Standard) & naphthalene- $\mathrm{d}_{8}$ \\
\hline 2 & 2-methylnaphthalene \\
\hline 3 & 1-methylnaphthalene \\
\hline$\overline{4}$ & biphenyl \\
\hline 5 & acenaphthylene \\
\hline 6 & acenaphthene \\
\hline 7 & fluorene \\
\hline IS2 (Internal Standard) & fluorene- $d_{10}$ \\
\hline 8 & dibenzothiophene \\
\hline IS3 (Internal Standard) & phenanthrene- $d_{10}$ \\
\hline 9 & phenanthrene \\
\hline 10 & anthracene \\
\hline 11 & 4,5-methylenephenanthrene \\
\hline 10 & 3-methylphenanthrene \\
\hline 10 & 2-methylphenanthrene \\
\hline 10 & 4- and 9-methylphenanthrene \\
\hline 15 & 1-methylphenanthrene \\
\hline 16 & fluoranthene \\
\hline 17 & acephenanthrylene \\
\hline 15 & pyrene \\
\hline IS6 (Internal Standard) & pyrene-d $d_{10}$ \\
\hline 10 & benz[a]anthracene \\
\hline 20 & triphenylene \\
\hline 20 & chrysene \\
\hline IS5 (Internal Standard) & benz[a]anthracene- $d_{12}$ \\
\hline 22 & benzo[b]- and benzo[j]fluoranthene \\
\hline 23 & benzo[k]fluoranthene \\
\hline 24 & benzo[a]fluoranthene \\
\hline 25 & benzo[e]pyrene \\
\hline 26 & benzo[a]pyrene \\
\hline 27 & perylene \\
\hline IS6 (Internal Standard) & benzo[k]fluoranthene- $\mathrm{d}_{12}$ \\
\hline IS7 (Internal Standard) & benzo[e]pyrene-d 12 \\
\hline 28 & indeno[1,2,3-cd]pyrene \\
\hline 29 & benzo[ghi]perylene \\
\hline IS8 (Internal Standard) & benzo[ghi]perylene- $\mathrm{d}_{12}$ \\
\hline
\end{tabular}


APPENDIX C. Reconstructed Selected-Ion Chromatograms of HiVol Filter Sample PM10-01 Collected at the King Fahad Military Medical Center

(See Table C-1 for peak identification)

Ion $m / z 184$
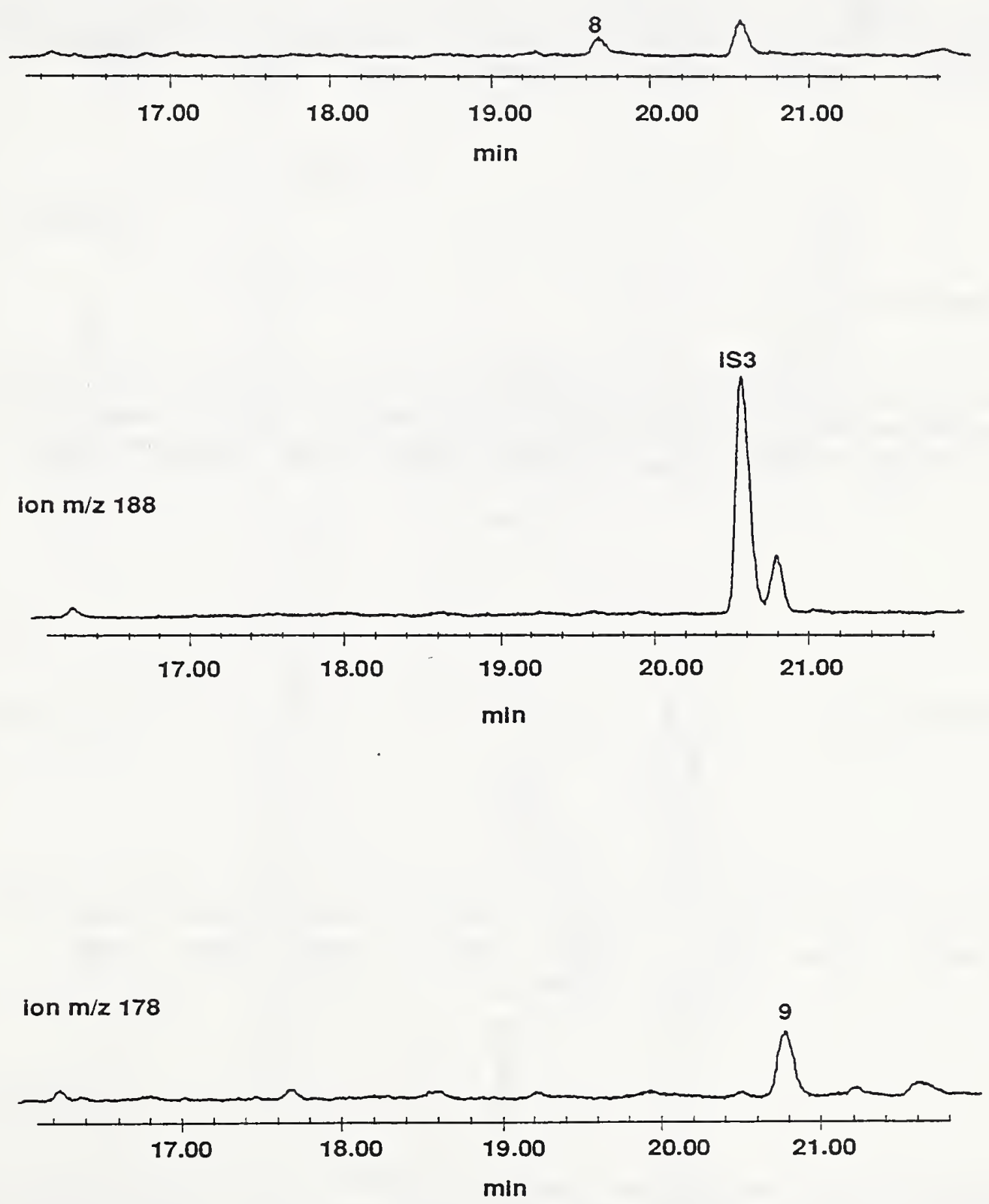
APPENDIX C. Reconstructed Selected-Ion Chromatograms of HiVol Filter Sample PM10-01 Collected at the King Fahad Military Medical Center

(See Table C-1 for peak identification)

Ion $\mathrm{m} / \mathrm{z} 192$
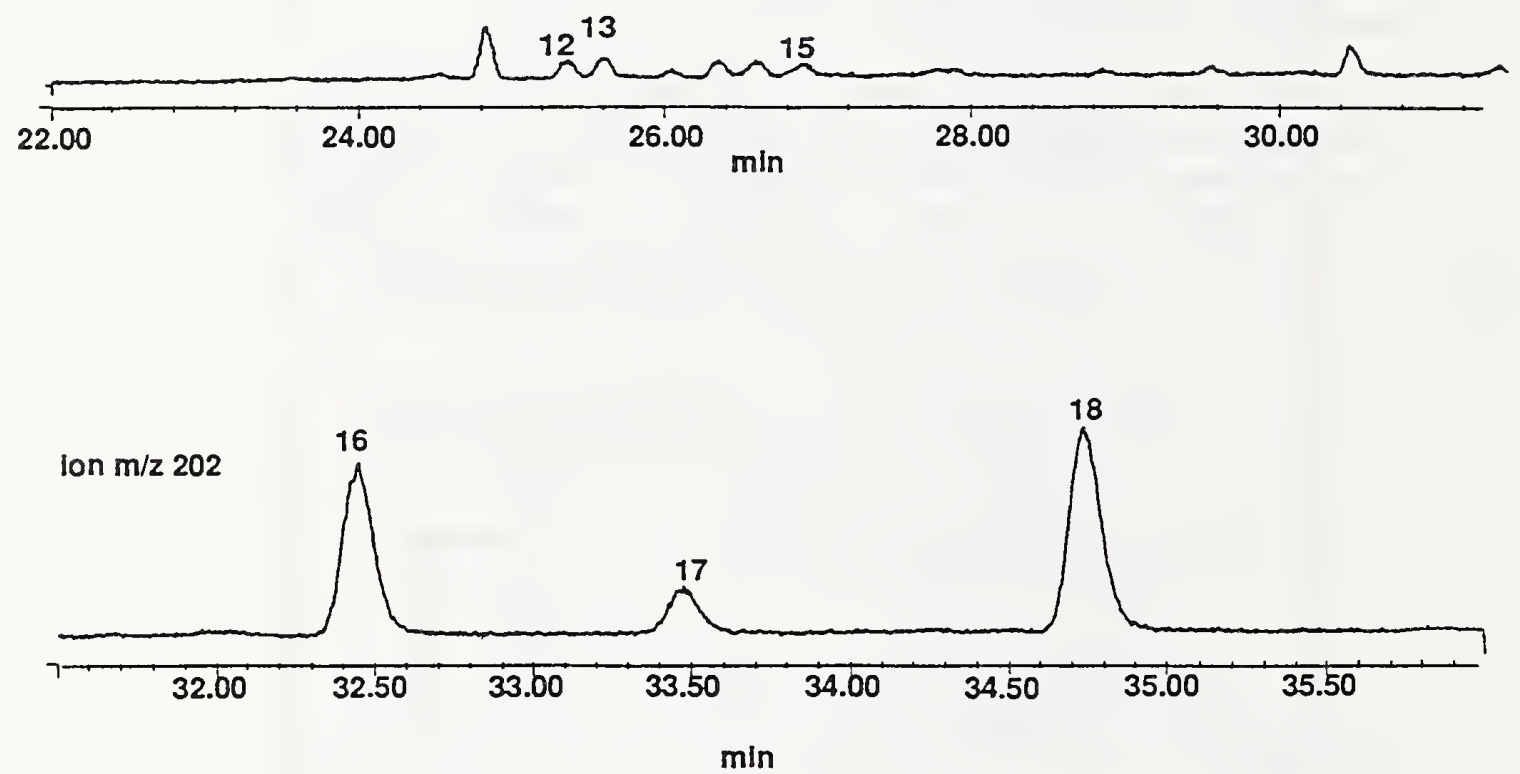

Ion $\mathrm{m} / \mathrm{z} 212$

IS4

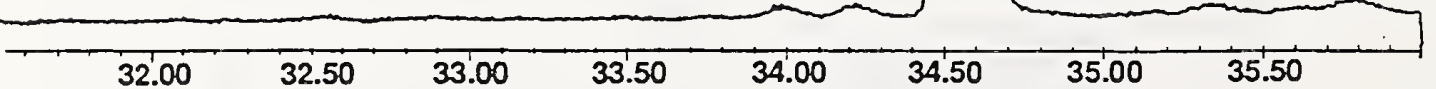

$\min$ 
APPENDIX C. Reconstructed Selected-Ion Chromatograms of HiVol Filter Sample PM10-01 Collected at the King Fahad Military Medical Center (See Table C-1 for peak identification)
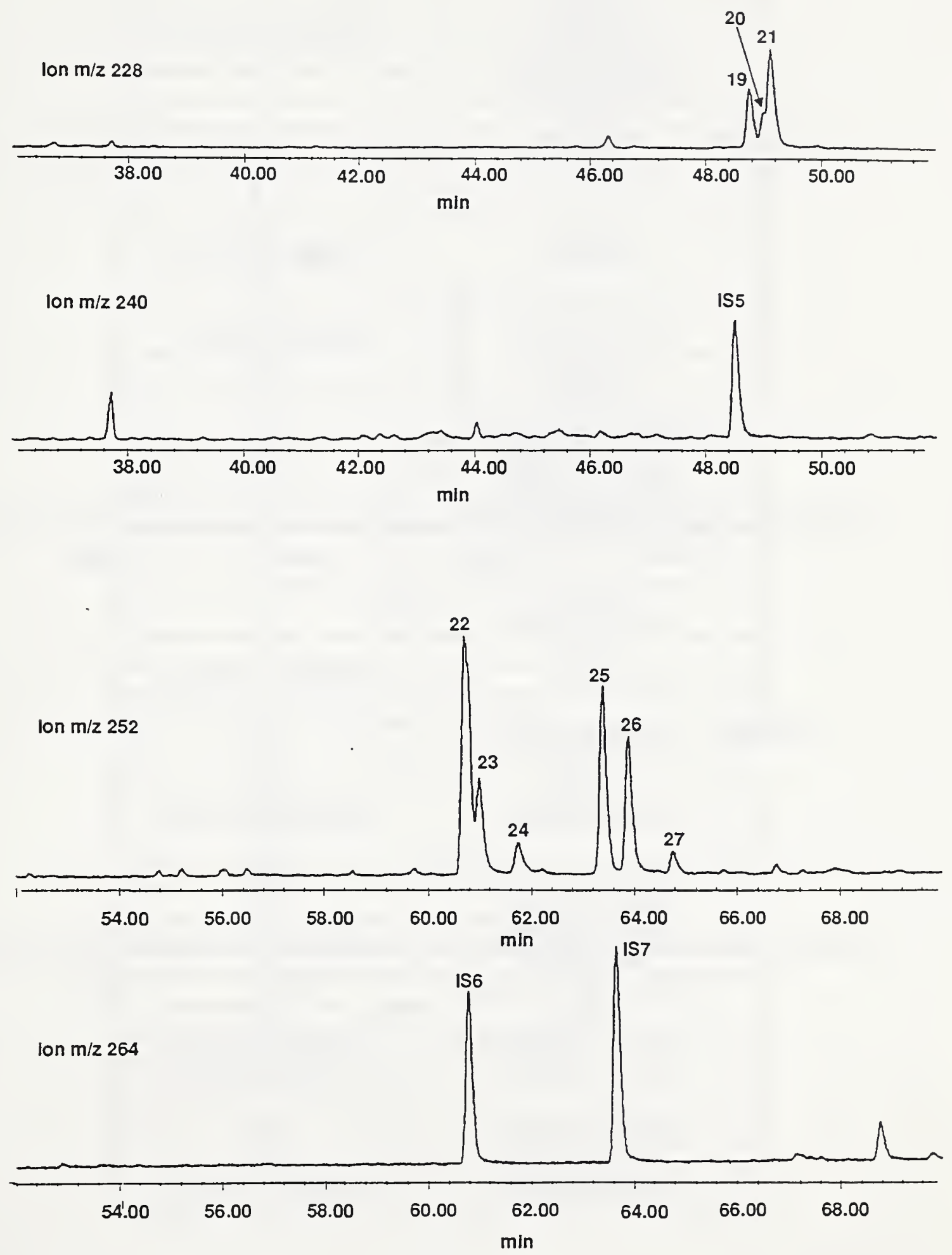
APPENDIX C. Reconstructed Selected-Ion Chromatograms of HiVol Filter Sample PM10-01 Collected at the King Fahad Military Medical Center

(See Table C-1 for peak identification)

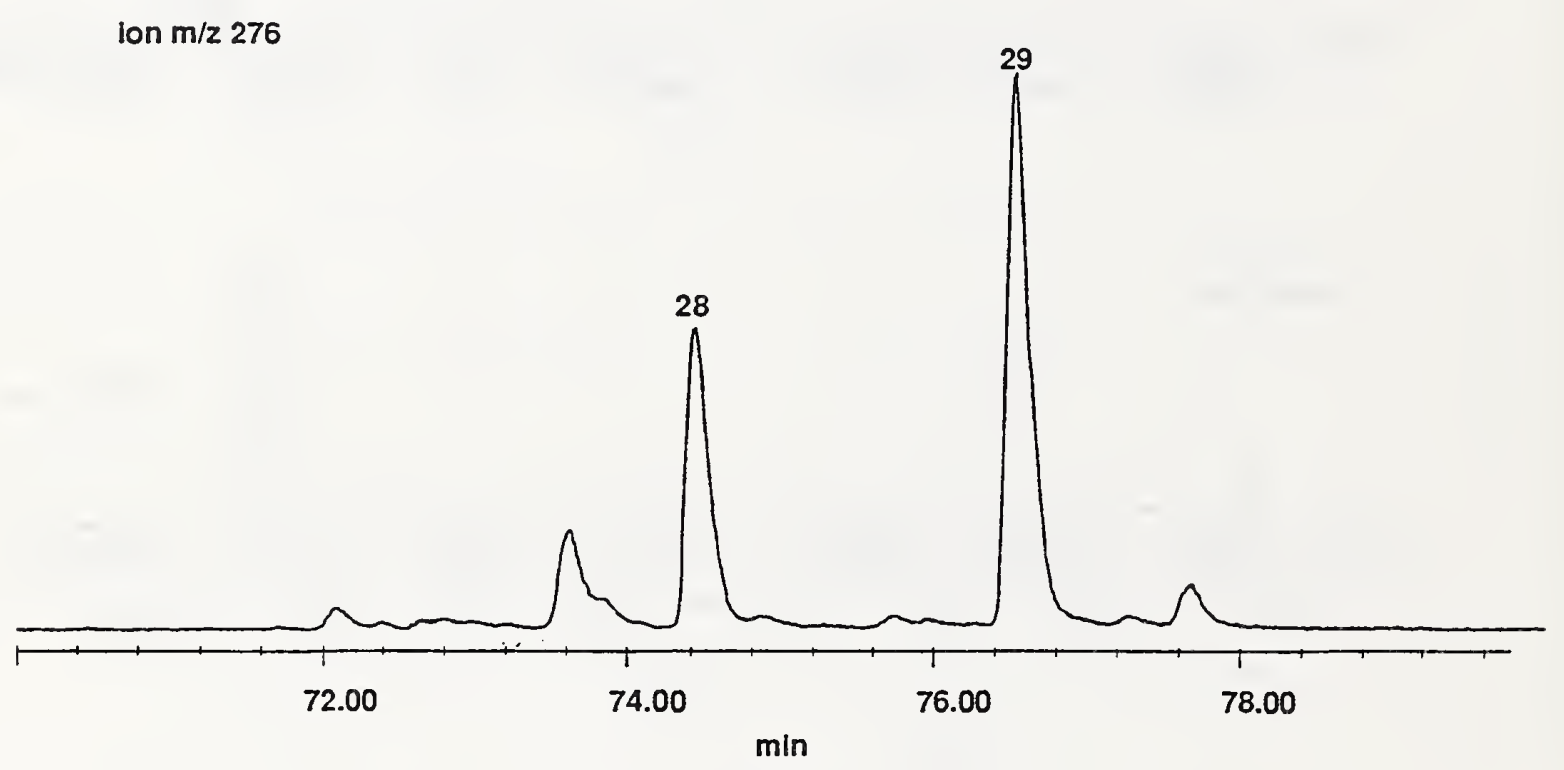

lon $\mathrm{m} / \mathrm{z} 288$

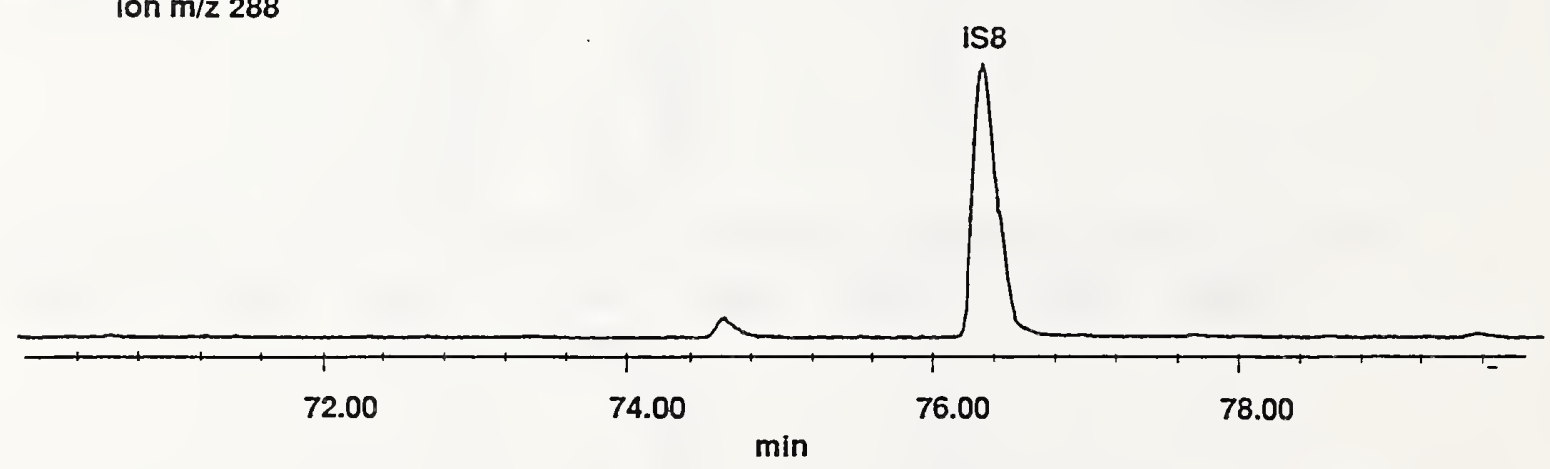


Table C-1. Peak Identifications for Reconstructed Selected-Ion Chromatograms of HiVol Filter PM-10-1.

\begin{tabular}{|c|c|}
\hline Peak Number & $\begin{array}{l}\text { Polycyclic Aromatic } \\
\text { Hydrocarbon (PAH) }\end{array}$ \\
\hline 4 & naphthalene \\
\hline IS1 (Internal Standard) & naphthalene- $d_{\delta}$ \\
\hline 2 & 2-methylnaphthalene \\
\hline 4 & 1-methylnaphthalene \\
\hline 4 & biphenyl \\
\hline 5 & acenaphthylene \\
\hline 9 & acenaphthene \\
\hline 7 & fluorene \\
\hline IS2 (Internal Standard) & fluorene- $d_{10}$ \\
\hline 8 & dibenzothiophene \\
\hline IS3 (Internal Standard) & phenanthrene-d ${ }_{10}$ \\
\hline 9 & phenanthrene \\
\hline 10 & anthracene \\
\hline 11 & 4,5-methylenephenanthrene \\
\hline 12 & 3-methylphenanthrene \\
\hline 13 & 2-methyiphenanthrene \\
\hline 14 & 4- and 9-methylphenanthrene \\
\hline$\overline{15}$ & 1-methylphenanthrene \\
\hline 16 & fluoranthene \\
\hline 17 & acephenanthrylene \\
\hline 16 & pyrene \\
\hline IS4 (Internal Standard) & pyrene- $d_{10}$ \\
\hline 16 & benz[a]anthracene \\
\hline 20 & triphenylene \\
\hline 21 & chrysene \\
\hline IS5 (Internal Standard) & benz[a]anthracene-d 12 \\
\hline 22 & benzo[b]- and benzo[j]fluoranthene \\
\hline 28 & benzo[k]fluoranthene \\
\hline 24 & benzo[a]fluoranthene \\
\hline 25 & benzo[e]pyrene \\
\hline 26 & benzo[a]pyrene \\
\hline 27 & perylene \\
\hline IS6 (Internal Standard) & benzo[k]fluoranthene- $d_{12}$ \\
\hline IS7 (Internal Standard) & benzo[e]pyrene- $d_{12}$ \\
\hline 28 & indeno[1,2,3-cd]pyrene \\
\hline 29 & benzo[ghi]perylene \\
\hline IS8 (Internal Standard) & benzo[ghi]perylene-d $d_{12}$ \\
\hline
\end{tabular}


APPENDIX D. Reconstructed Selected-Ion Chromatograms of Teflon Filter PAH-01 Collected at the Royal Saudi Naval Base

(See Table D-1 for peak identification)

Ion $\mathrm{m} / \mathrm{z} 128$

5.20
5.40

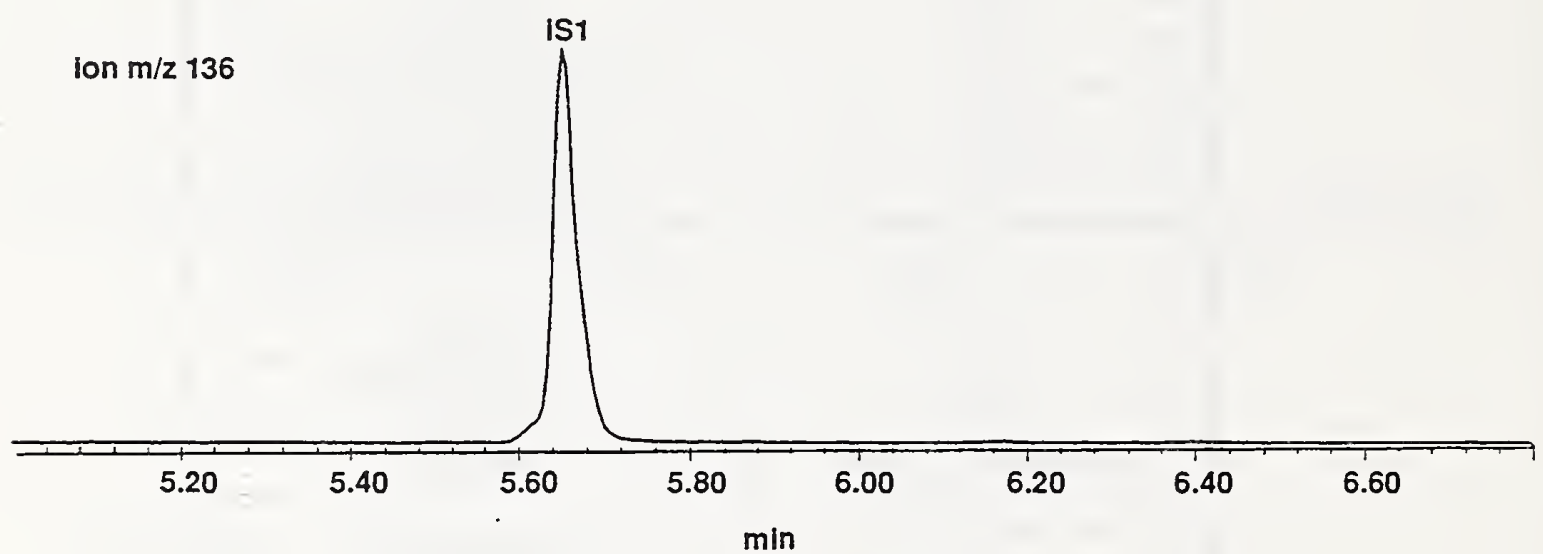

Ion $\mathrm{m} / \mathrm{z} 142$

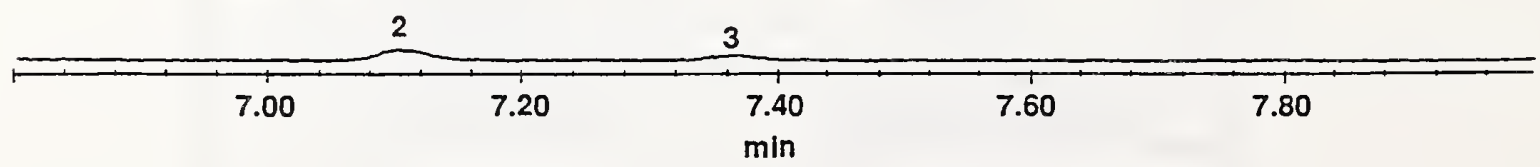


APPENDIX D. Reconstructed Selected-Ion Chromatograms of Teflon Filter PAH-01 Collected at the Royal Saudi Naval Base

(See Table D-1 for peak identification)

Ion $\mathrm{m} / \mathrm{z} 152$

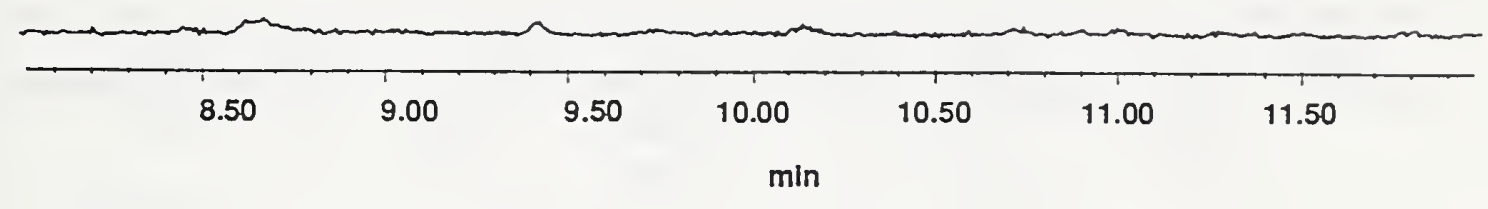

Ion $\mathrm{m} / \mathrm{z} 154$
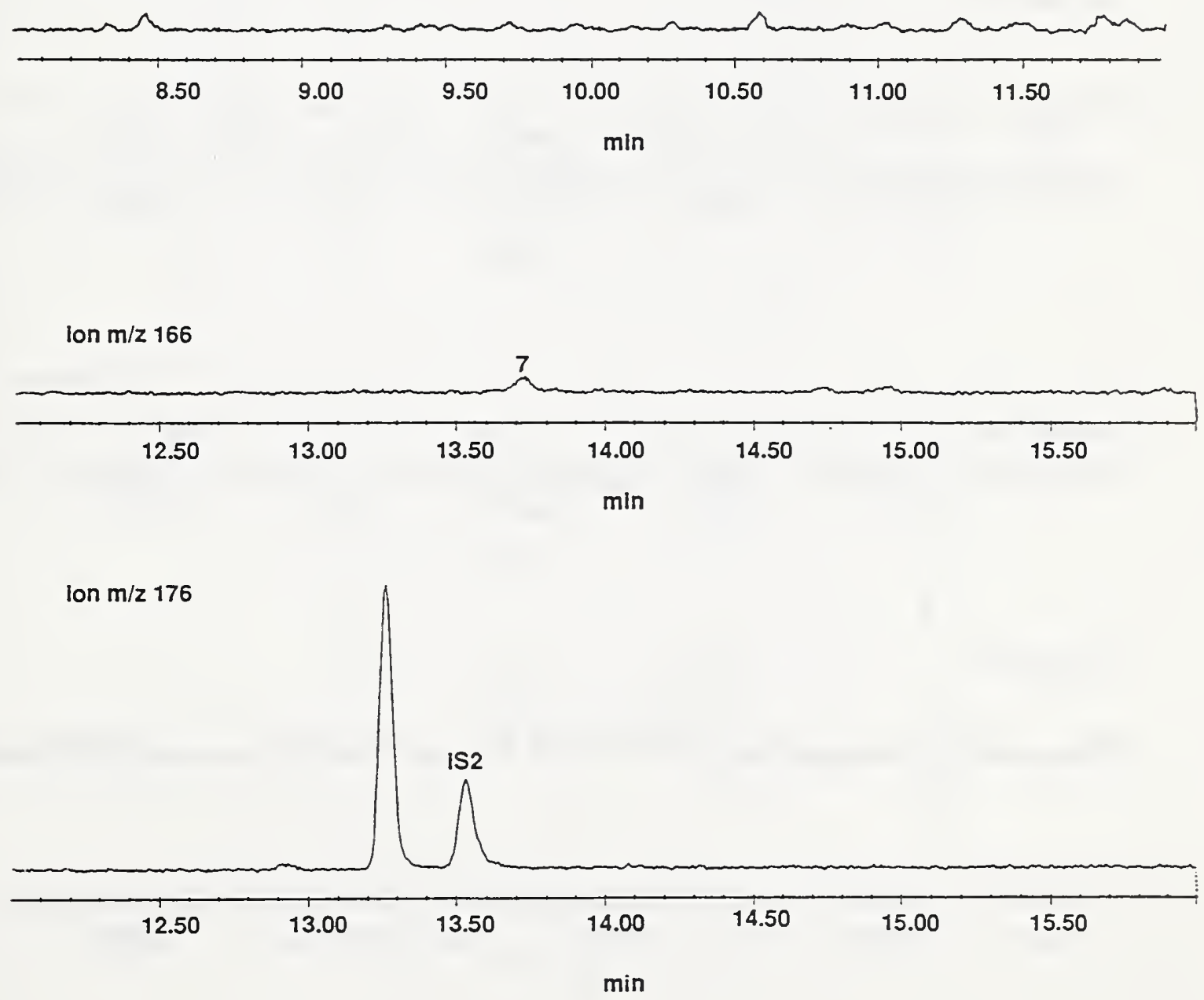
APPENDIX D. Reconstructed Selected-Ion Chromatograms of Teflon Filter PAH-01 Collected at the Royal Saudi Naval Base (See Table D-1 for peak identification)

Ion $\mathrm{m} / \mathrm{z} 184$
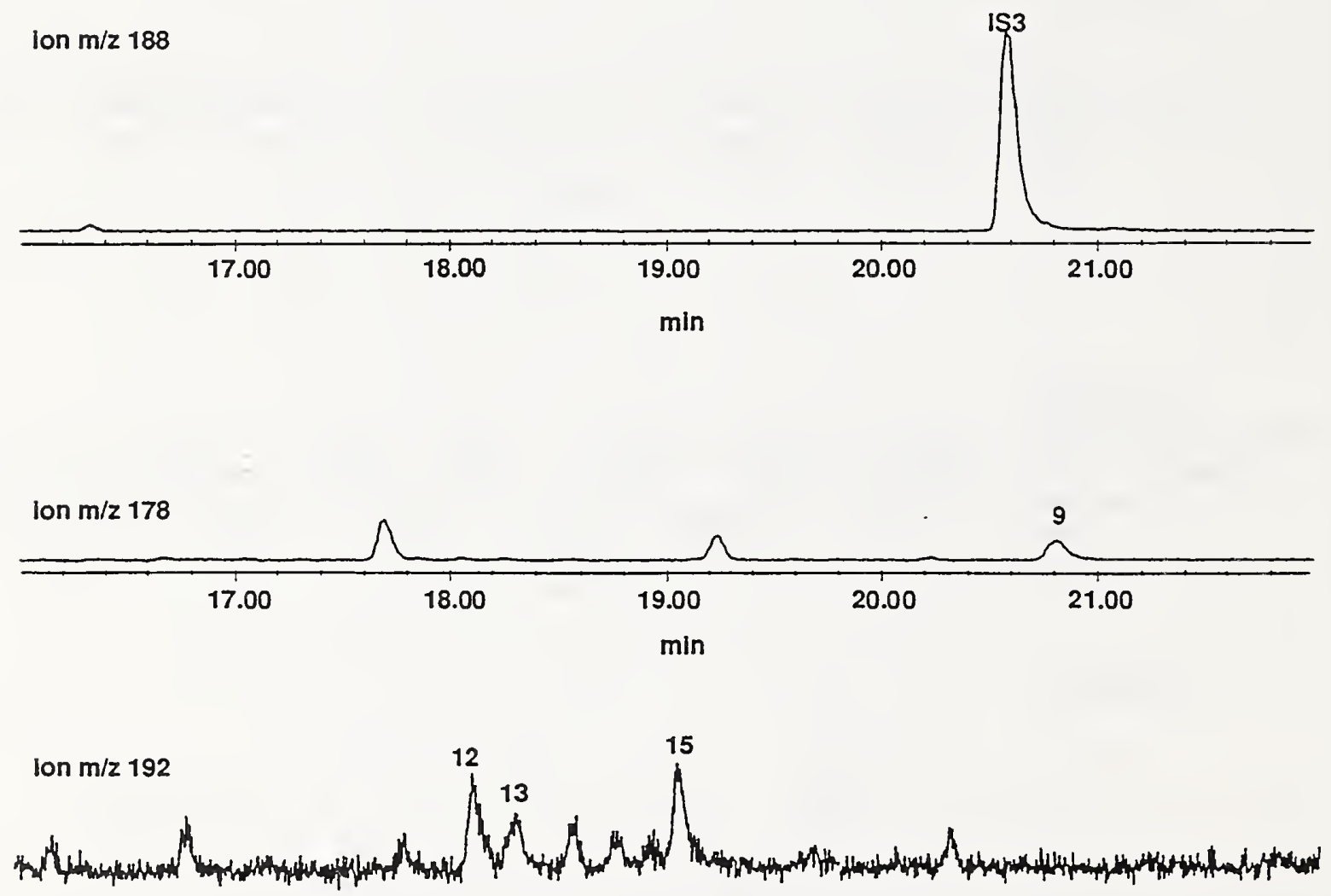

$24.00 \quad 26.00 \quad 28.00 \quad 30.00$


APPENDIX D. Reconstructed Selected-Ion Chromatograms of Teflon Filter PAH-01 Collected at the Royal Saudi Naval Base

(See Table D-1 for peak identification)

Ion $\mathrm{m} / \mathrm{z} 202$

$\begin{array}{llllllll}32.00 & 32.50 & 33.00 & 33.50 & \min ^{34.00} & 34.50 & 35.00 & 35.50\end{array}$

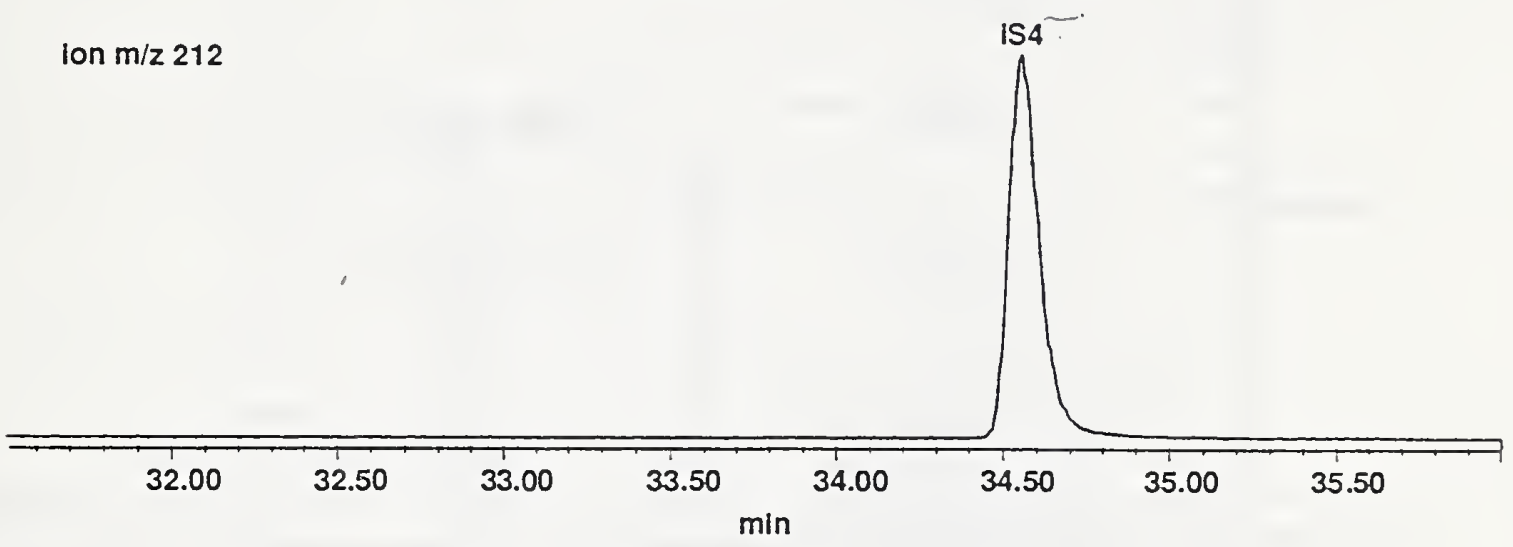

Ion $\mathrm{m} / \mathrm{z} 228$

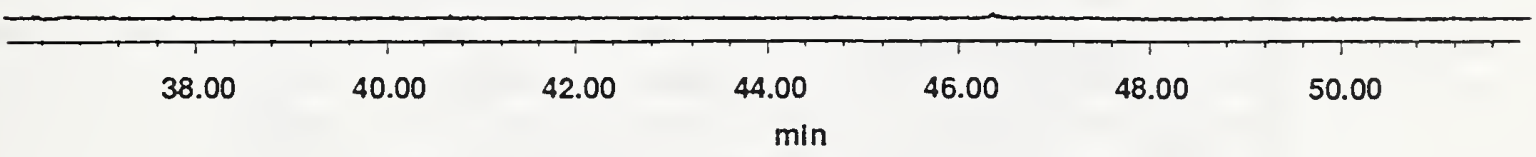

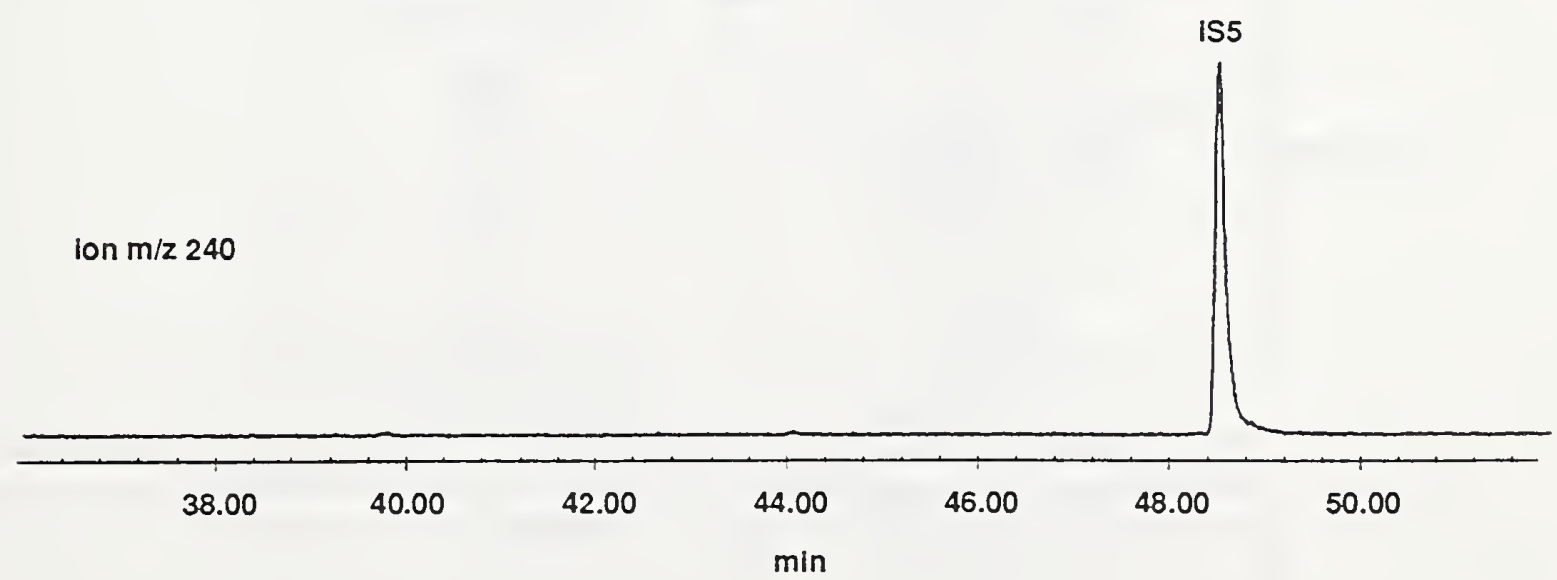


APPENDIX D. Reconstructed Selected-Ion Chromatograms of Teflon Filter PAH-01 Collected at the Royal Saudi Naval Base (See Table D-1 for peak identification)
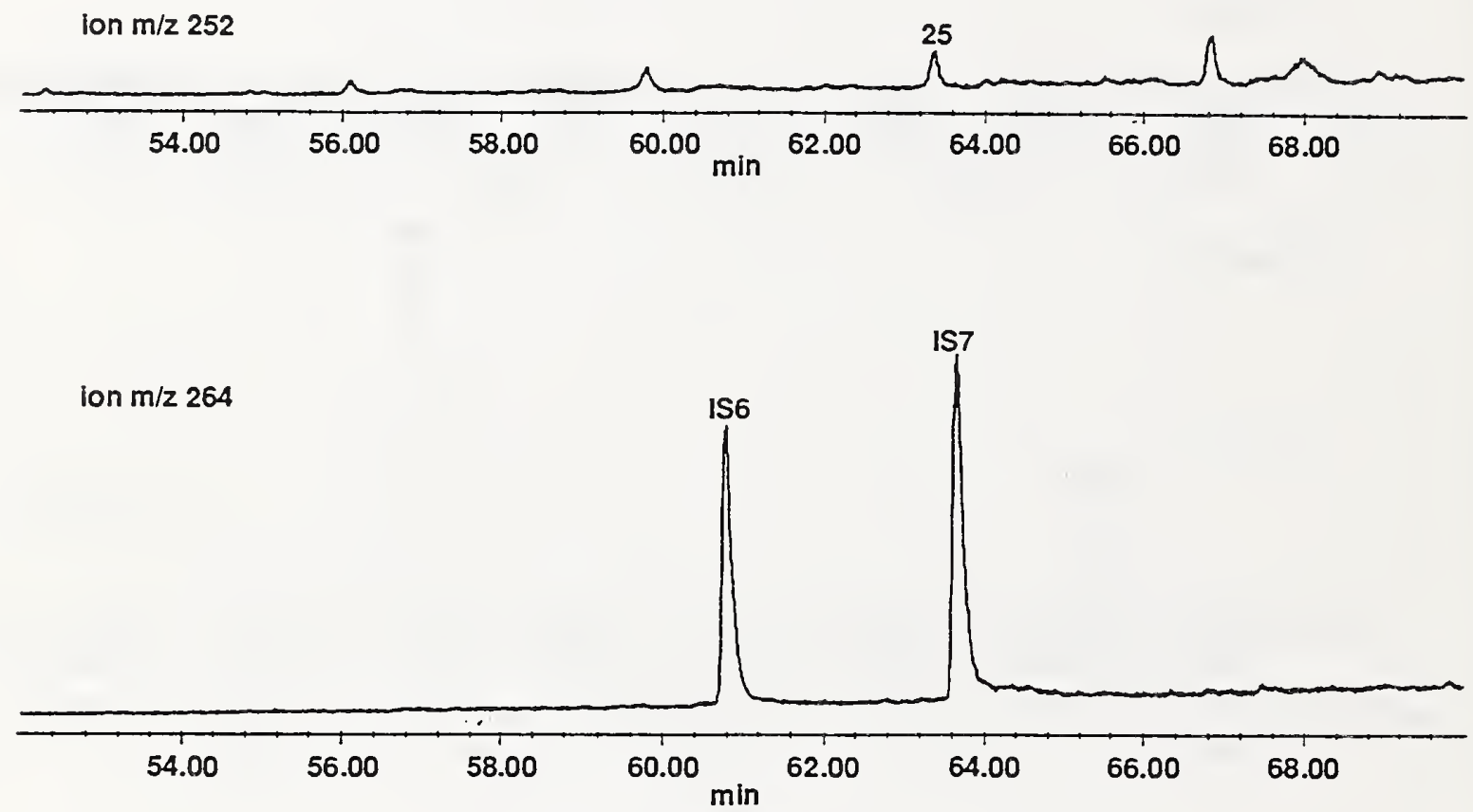

ion $\mathrm{m} / 2276$

ion $\mathrm{m} / \mathrm{z} 288$

72.00

74.00

$\min$

76.00

78.00

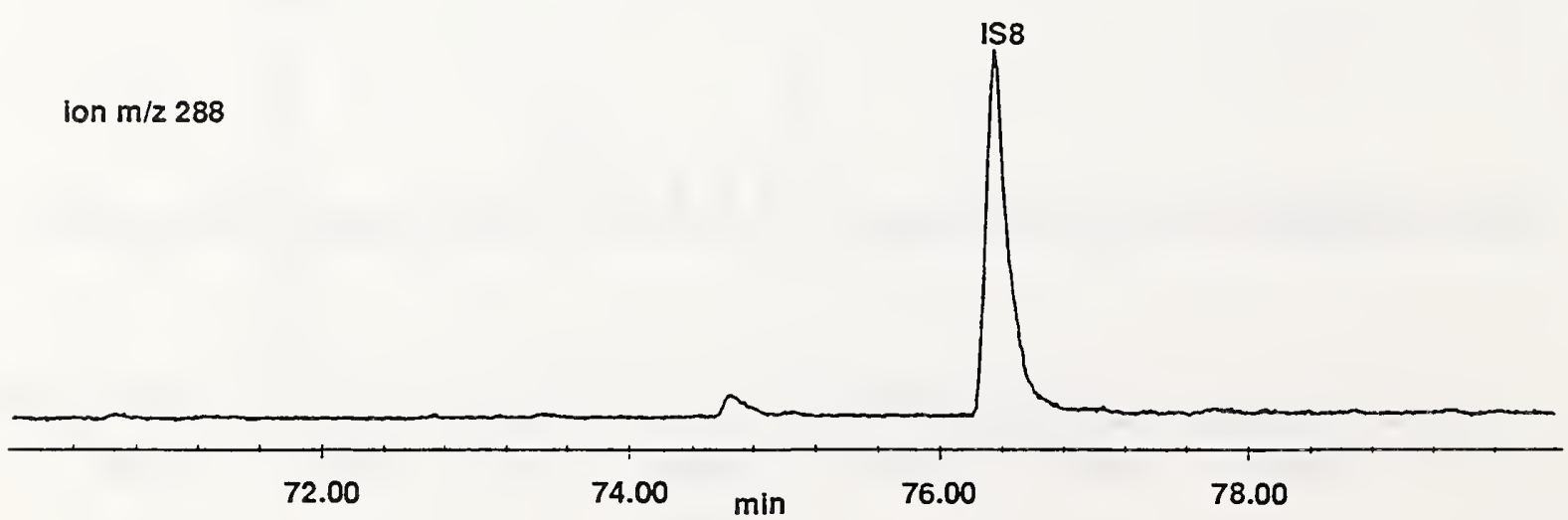


Table D-1. Peak Identifications for Reconstructed Selected-Ion Chromatograms of Teflon Filter PAH-01.

\begin{tabular}{|c|c|}
\hline Peak Number & $\begin{array}{l}\text { Polycyclic Aromatic } \\
\text { Hydrocarbon (PAH) }\end{array}$ \\
\hline 1 & naphthalene \\
\hline IS1 (Internal Standard) & naphthalene- $d_{8}$ \\
\hline 2 & 2-methyinaphthalene \\
\hline 3 & 1-methylnaphthalene \\
\hline 4 & biphenyl \\
\hline 5 & acenaphthylene \\
\hline 6 & acenaphthene \\
\hline 4 & fluorene \\
\hline IS2 (Internal Standard) & fluorene-d 10 \\
\hline 6 & dibenzothiophene \\
\hline IS3 (Internal Standard) & phenanthrene- $\mathrm{d}_{10}$ \\
\hline 9 & phenanthrene \\
\hline 10 & anthracene \\
\hline 11 & 4,5-methylenephenanthrene \\
\hline 10 & 3-methylphenanthrene \\
\hline 13 & 2-methylphenanthrene \\
\hline 14 & 4- and 9-methylphenanthrene \\
\hline 18 & 1-methylphenanthrene \\
\hline 16 & fluoranthene \\
\hline 17 & acephenanthrylene \\
\hline 18 & pyrene \\
\hline IS4 (Internal Standard) & pyrene-d 10 \\
\hline 19 & benz[a]anthracene \\
\hline 20 & triphenylene \\
\hline 21 & chrysene \\
\hline IS5 (Internal Standard) & benz[a]anthracene- $d_{12}$ \\
\hline 22 & benzo[b]- and benzo[j]fluoranthene \\
\hline 23 & benzo[k]fluoranthene \\
\hline 24 & benzo[a]fluoranthene \\
\hline 25 & benzo[e]pyrene \\
\hline 26 & benzo[a]pyrene \\
\hline 27 & perylene \\
\hline IS6 (Internal Standard) & benzo[k]fluoranthene- $\mathrm{d}_{12}$ \\
\hline IS7 (Internal Standard) & benzo[e]pyrene- $\mathrm{d}_{12}$ \\
\hline 26 & indeno[1,2,3-cd]pyrene \\
\hline 29 & benzo[ghi]perylene \\
\hline IS8 (Internal Standard) & benzo[ghi]perylene- $d_{12}$ \\
\hline
\end{tabular}



IST-114

(EV. 6-93)

DMAN 4.09
U.S. DEPARTMENT OF COMMERCE

NATIONAL INSTITUTE OF STANDARDS AND TECHNOLOGY

MANUSCRIPT REVIEW AND APPROVAL

\begin{tabular}{|l|l|}
\hline \multicolumn{2}{|c|}{ (ERB USE ONLY) } \\
\hline ERB CONTROL NUMBER & $\begin{array}{l}\text { DIVISION } \\
865\end{array}$ \\
\hline $\begin{array}{c}\text { PUBLICATION REPORT NUMBER } \\
\text { NISTIR 5306 }\end{array}$ & CA TEGORY CODE \\
\hline \begin{tabular}{|l|l|} 
PUBLICATION DATE \\
JanUATY 1994
\end{tabular} & $\begin{array}{l}\text { NUMBER PRINTED PAGES } \\
85\end{array}$ \\
\hline
\end{tabular}

HE SECRETARY, APPROPRIATE EDITORIAL REVIEW BOARD

TLE AND SUBTITLE (CITE IN FULL)

round-Based Smoke Sampling Techniques Training Course and Collaborative Local Smoke Sampling in Saudi Arabia

\begin{tabular}{|l|l|}
\hline ONTRACT OR GRANT NUMBER & TYPE OF REPORT AND/OR PERIOD COVERED \\
\hline
\end{tabular}

Final August 1992 - August 1993

UTHORIS) (LAST NAME, FIRST INITIAL, SECOND INITIAL)

PERFORMING ORGANIZATION (CHECK (X) ONE BOX)

ryner, N. P. and Benner, B. A., Jr.

NIST/GAITHERSBURG

NIST/BOULDER

JILA/BOULDER

ABORATORY AND DIVISION NAMES IFIRST NIST AUTHOR ONLY)

ire Science Division Building and Fire Research Laboratory

PONSORING ORGANIZATION NAME AND COMPLETE ADDRESS (STREET, CITY, STATE, ZIP)

1edical Services Department

1inistry of Defence and Aviation ROPOSED FOR NIST PUBLICATION

E JOURNAL OF RESEARCH (NIST JRES)

J. PHYS. \& CHEM. REF. DATA (JPCRD)

HANDBOOK (NIST HB)

SPECIAL PUBLICATION (NIST SP)

TECHNICAL NOTE (NIST TN)

ROPOSED FOR NON-NIST PUBLICATION (CITE FULLY)

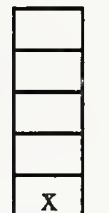

MONOGRAPH (NIST MN)

NATL. STD. REF. DATA SERIES (NIST NSRDS)

FEDERAL INF. PROCESS. STDS. (NIST FIPS)

LIST OF PUBLICATIONS (NIST LP)

NIST INTERAGENCY/INTERNAL REPORT (NISTIR)
LETTER CIRCULAR

BUILDING SCIENCE SERIES

PRODUCT STANDARDS

OTHER

\begin{tabular}{l|l|l|l|l}
\hline$x$ & U.S. & & FOREIGN & PUBLISHING MEDIUM
\end{tabular}

PAPER

DISKETTE (SPECIFY)

OTHER (SPECIFY)

UPPLEMENTARY NOTES

BSTRACT (A 2000-CHARACTER OR LESS FACTUAL SUMMARY OF MOST SIGNIFICANT INFORMATION. IF DOCUMENT INCLUDES A SIGNIFICANT BIBLIOGRAPHY OR ITERATURE SURVEY, CITE IT HERE. SPELL OUT ACRONYMS ON FIRST REFERENCE.) (CONTINUE ON SEPARATE PAGE, IF NECESSARY.)

imoke and gaseous emissions such as generated by oil-well fires impact the health of the local population. To assess the risk to public health, the hemical and physical properties of the smoke and gases must be quickly characterized. Local sampling via portable analyzers provides real-time haracterization of pollutant levels. The Ground-Based Smoke Sampling Techniques Training Course and Collaborative Local Smoke Sampling roject was initiated between the Ministry of Defence and Aviation (Kingdom of Saudi Arabia) and the National Institute of Standards and echnology (USA) to train Saudi medical personnel. A team of Saudi and NIST researchers collected samples in Saudi Arabia. Analysis included olycyclic aromatic hydrocarbons (PAHs), $\mathrm{CO}, \mathrm{CO}_{2}$ and total particulate concentrations. Split-sample analysis was conducted with some samples eing analyzed in Saudi Arabia and other samples being returned to NIST for more specialized analysis, including Micro-Raman, Laser Micro-Probe, nd Environmental Scanning Electron Microscopy. These analyses provide a snapshot of the physical and chemical properties of the aerosol sampled n Saudi Arabia, but the limited number of samples do not provide a reasonable basis for estimating the health risk due to exposure to smoke and rases. While these results suggest significant levels of PAH and dust, the data set is small and a program of collection and analysis of air samples in ir around Saudi Arabian urban areas would provide data for determining current airborne PAH concentrations as well as for devising future air ollution control strategies. PAH concentrations were about the same order of magnitude as samples in Roanoke, Virginia, but 3 to 10 times lower han samples from Boise, Idaho. The significant concentrations of PAHs in what was expected to provide background levels indicates that a comprelensive sampling program should be implemented to characterize the PAH concentrations throughout the Kingdom.

(EY WORDS (MAXIMUM OF 9; 2B CHARACTERS AND SPACES EACH; SEPARATE WITH SEMICOLONS; ALPHABETIC ORDER; CAPITALIZE ONLY PROPER NAMES) aerosols; environmental effects; fire research; oil spills; oil well fires; polycyclic aromatic hydrocarbons; smoke; smoke collection; smoke sampling

$\overline{A V A I L A B I L I T Y}$
FOR OFFICIAL DISTRIBUTION - DO NOT RELEASE TO NTIS ORDER FROM SUPERINTENDENT OF DOCUMENTS, U.S. GPO, WASHINGTON, DC 20402 ORDER FROM NTIS, SPRINGFIELD, VA 22161
NOTE TO AUTHOR(S): IF YOU DO NOT WISH THIS MANUSCRIPT ANNOUNCED BEFORE PUBLICATION, PLEASE CHECK HERE. 


